Aus der Universitätsklinik für Ohren-, Nasen- und Kehlkopfkrankheiten

Halle a. S. (Direktor: Geh. Med.-Rat Prof. Dr. Denker.)

\title{
Die systematische Sterilisierung der Antrotomiewunde mittels der Dakinlösung nach den Carrelschen Wund- verfahren.
}

Von Privatdozent Dr. med. Theodor Nühsmant, Oberarzt der Klinik.

Mit 4 Abbildungen.

Trotz der bereits recht zahlreichen Reformvorschläge für die Nachbehandlung nach Antrotomien, welche in der Hauptsache eine Abkürzung des Heilverlaufs und eine Verbesserung der kosmetischen Resultate bezwecken, und trotz der damit erzielten, zum Teil recht beachtenswerten Erfolge, bevorzugt die Mehrzahl der Ohrenärzte auch heute noch die von Schwartze eingeführte Form der offenen Wundbehandlung mittels dauernder Tamponade und nimmt die ihr anhaftenden Mängel - wenn auch resigniert - in Kauf. Die Gründe dafür lassen sich sehr leicht eruieren: einmal handelt es sich, wie durch klinische Untersuchungen immer wieder bestätigt wird, fast ausnahmslos um infizierte Wunden, welche nach den allgemeinen auch jetzt noch geltenden chirurgischen Anschauungen kaum eine andere Behandlung zulassen, solange ihre Infektion sich geltend machen kann, andererseits gestattet die offene Wundbehandlung jederzeit eine Kontrolle auch des verstecktesten Wundwinkels sowie des ganzen Wundverlaufs. Dieser letzte Grund fällt um so mehr in die Wagschale, als wir es bei der Antrotomiewunde mit besonders komplizierten Verhältnissen zu tun haben, ich weise nur hin auf die Kommunikation mit der ebenfalls infizierten Paukenhöhle und der Tube, auf die enge Nachbarschaft von Labyrinth, Dura, Sinus usw. Hierzu kommt, daß wir auch bei sorgfältigstem Operieren nie ganz sicher sein können, ob nicht eine versteckte kranke Zelle oder nekrotischer Knochen zurückgeblieben sind, von denen aus sich nachträglich der Krankheitsprozeß weiter ausbreiten kann. Endlich lehrt die Erfahrung, daB gar nicht selten in scheinbar unkomplizierten Fällen von Mastoiditis bei der einfachen Aufmeißelung schon schleichend eine intrakranielle Affektion besteht und bei späterem Manifestwerden weitere chirurgische Maßnahmen erfordert. Die neueren Methoden, insbesondere die des primären Verschlusses der Wunde unmittelbar nach dem Eingriff, verlangen einen 
Verzicht auf diese sehr bequeme und ein Gefühl der Sicherheit gebende Kontrolle des Wundverlaufs und dieser Punkt ist wohl in erster Linie dafür maßgebend gewesen, daß sich viele vorsichtig denkende Ohrenärzte zur Aufgabe der offenen Wundbehandlung selbst in günstig scheinenden Fällen bisher noch nicht entschließen konnten.

Wir müssen uns darüber klar sein, daß das Gefahrmoment auch nach dem Eingriff zunächst noch die Infektion ist und bleibt. Diese Tatsache ist besonders von Heine und Preysing in ihrer Stellungnahme gegen die Primärnaht scharf betont worden. Wie lange diese Gefahren praktisch noch bestehen bleiben, d. h. zur Auswirkung kommen können, ist eine Frage für sich. Es ist empirisch festgestellt worden, $\mathrm{da} B$ infizierte Wunden bei offener Behandlung auch ohne besondere Maßnahmen mit der Zeit ihre Infektion verlieren können, indem die meist mit einem mehr oder weniger kräftigen Antiseptikum imprägnierten Wundgazen und die bakterizide Kraft des Wundsekretes zusammenwirken und die Bakterien allmählich vernichten. Auf diese Tatsache gründen bekanntlich die Vertreter der sogenannten Sekundärnaht ihren Vorschlag (Mygind, Blegvad, Kubo, Held, Matsui u. a. m.). Sie glauben, daß nach etwa Io-20 Tagen die Antrotomiewunde klinisch aseptisch sei und nun ohne Gefahr geschlossen werden könne. Für die Indikationsstellung ist im allgemeinen der $\mathrm{Zu}$ stand der Wunde maßgebend, die überall gut aussehen und frisch granulieren muß. Beim Verschluß läßt man teilweise auch die Knochenhöhle sich aus den Hautgefäßen erst mit Blut füllen und vernäht über diesem sogenannten Blutschorf. Die Methode ist viel geübt worden, auch an unserer Klinik, und es läßt sich nicht leugnen, daß ihre Gefahren relativ gering sind, von unangenehmen Komplikationen dabei ist eigentlich nichts bekannt geworden. Sie hat nur den Nachteil, daß zu dem Zeitpunkt ihrer Anwendbarkeit oftmals schon eine erhebliche Retraktion der Weichteile vor allem bei größeren Knochenhöhlen eingetreten ist, und daß die Epidermis sich bereits in den äußeren Teil des Trichters vorgeschoben hat. Dadurch begegnet die Vereinigung der Wundränder vielfach größeren Schwierigkeiten oder gelingt nur teilweise, wenn nicht gar ein Entspannungsschnitt nötig ist; die definitiven Ergebnisse sind jedenfalls bei dieser Methode nicht immer befriedigend. So heilten z. B. von 64 Sekundärnähten Myginds nur 24 per primam. Bei einem größeren Teil der Fälle vereiterte außerdem das Blutkoagulum ganz oder teilweise, was als ein Beweis dafür angesehen werden muß, daß lediglich durch das Aussehen der Wunde ein sicheres Kriterium für ihre Keimfreiheit auch nur in praktischem Sinne noch nicht gegeben ist.

Von besonderem Interesse ist hier, wie sich diejenigen Autoren, welche die Primärnaht in. Vorschlag gebracht haben und immer wie- 
der warm befürworten, mit der Infektion abfinden: Zunächst läßt sich sagen, daß diese Frage, welche unter Berücksichtigung dessen, daß der primäre Verschluß einer infizierten Wunde immerhin ein mit einem fundamentalen chirurgischen Prinzip im Widerspruch stehendes Verfahren darstellt, eine gewisse Bedeutung beanspruchen kann, meistens nur sehr kurz berührt und ebenso kurz beantwortet wird. Piff1, welcher lange Zeit als Urheber der Primärnaht gegolten hat - tatsächlich haben Walb und Witzel sie zuerst empfohlen und bereits auf dem Otologentag zu Bonn I894 derart behandelte Fälle vorgestellt - , war ursprünglich von der Ansicht ausgegangen, daß durch die Operation die Infektion im Warzenfortsatz vollkommen beseitigt und deshalb ein sofortiger Verschluß ohne weiteres erlaubt sei. Diese Annahme mußte er jedoch bald als unhaltbar wieder fallen lassen. Es kam nämlich in einem relativ hohen Prozentsatz der so behandelten Fälle infolge einer auffallend starken Sekretbildung in der Operationshöhle zur Vorwölbung der Weichteile, z. T. auch zu einer Infiltration derselben, und schließlich zu einem Wiederaufbrechen der Wunde. Als Piffl auf Grund dieser Beobachtungen das Wundsekret bakteriologisch untersuchte, - es geschah dies in drei Fällen - mußte er feststellen, daß sowohl beim ersten wie auch beim zweiten Verbandwechsel eine große Anzahl der verschiedensten Wundinfektionserreger darin enthalten waren; daß also von einer Sterilität der Operationswunden keine Rede sein konnte. Piffl will jedoch den Eindruck gehabt haben, daß die Zahl der Bakterien beim zweiten Verbandwechsel im Vergleich zum ersten abgenommen habe und aus diesem Eindruck sowie der Tatsache, daß trotzdem die drei Fälle einen günstigen Verlauf nahmen und in 20-2I Tagen zur Heilung kamen, glaubt er folgern zu können, daß durch die bakterizide Kraft des Wundsekretes die Virulenz der Erreger herabgemindert und so die von ihnen drohende Gefahr bald beseitigt würde:

Den gleichen Standpunkt vertritt Reinking. Auch dieser Autor nimmt eine schnelle Virulenzverminderung der Infektionskeime an und glaubt außerdem, daß die Verhältnisse bei primärem Verschluß der Weichteile die gleichen seien, wie bei der akuten Otitis media, nämlich: ,Entzündung in der Pauke und in einem Hohlraum im Warzenfortsatz, ringsum aber restitutions- und resorptionsfähige Wände. Wie in einer großen Zahl von Fällen akuter Mittelohrentzündung heilt nun die Entzündung unter Resorption des Exsudates ab".

Endlich befaßt sich noch Imhofer mit dieser Frage und spricht die Uberzeugung aus, daß sich im Wundsekret von Antrotomiewunden keine virulenten Mikroorganismen mehr befinden, wenn der ganze Krankheitsherd des Warzenfortsatzes glatt und sauber ausgeräumt sei und keine Granulationen, Knochenherde usw. zurückgelassen seien.

Es ist klar ersichtlich, daß es sich bei diesen eben angefiihrten Be- 
gründungen, aus welchen die genannten Autoren die Berechtigung zur Primärnaht herleiten, um subjektive Erklärungsversuche handelt, die sich zwar mit unseren moderen Anschauungen größtenteils decken, aber noch keine für alle Fälle gültige Beweiskraft besitzen können. Bei kritischer Beurteilung lassen sich folgende Einwände nicht ohne weiteres von der. Hand weisen. Einmal genügen die drei bakteriologisch untersuchten Fälle Piffls wohl sicher nicht, um daraus allgemein gültige Schlüsse über das Verhalten der Bakterien, insbesondere ihrer Virulenz nach der Operation ziehen zu können. Um hierüber Aufschluß zu gewinnen, bedürften wir eingehender experimenteller und bakteriologischer Untersuchungen an einem großen Material, die unseres Wissens für diesen $Z$ weck noch nicht vorliegen. Denn auch Bondys Versuche, über welche er auf dem Otologentag I9II berichtete, und nach deren Ergebnissen er die Streptokokkenmastoitidis zur Primärnaht für geeignet, die durch andere Erreger hervorgerufene dagegen für ungeeignet hält, beschränken sich bezüglich dieser Schlußfolgerung auf rein klinische Beobachtungen. Es ist doch zum mindesten fraglich, ob nicht einmal ein hochvirulenter Streptococcus pyogenes gefährlichere Eigenschaften besitzen und zur Auswirkung bringen kann, als selbst der gefürchtete Streptococcus mucosus, wenn dessen Virulenz bereits mehr oder weniger herabgesetzt ist.

Auch Reinkings Vergleich zwischen primär geschlossener Antrotomiewunde und akuter Otitis media scheint etwas gewagt, wenn man die Tatsache berücksichtigt, daß durch die Operation eine große Anzahl von Lymph- und Gefäßbahnen eröffnet wird, auf welchen vor allem bei eintretender Sekretstauung eine weitere Propagation des Eiterungsprozesses möglich ist. Außerdem muß die Resorptionskraft einer selbst pathologisch veränderten Schleimhaut entschieden höher veranschlagt werden, als diejenige einer frischen, noch nicht granulierenden, dabei zum größten Teil knöchernen Wundhöhle.

Was endlich Imhofers Standpunkt anlangt, so wurde eingangs schon angedeutet, wie schwer, oft sogar unmöglich es ist, alles Krankhafte im Warzenfortsatz so restlos zu entfernen, wie er es als Vorbedingung für die Ausführung der Primärnaht verlangt. Besonders bei Frühfällen und sekundären Mastoiditiden ist eine Abgrenzung des Gesunden vom Kranken makroskopisch vielfach ausgeschlossen und somit diese Forderung fast unerfüllbar.

Es liegt mir fern und würde sich auch kaum rechtfertigen lassen, mit diesen eben angeführten Einwänden den Anschauungen Piffls, Reinkings und Imhofers jede Berechtigung absprechen zu wollen, das kann ich schon aus dem Grunde nicht, weil ich selbst davon überzeugt bin, daß sie für einen Teil der sofort nach dem Eingriff vernähten Fälle sicherlich zutreffen bzw. zugetroffen sind, zum mindesten für die- 
jenigen, welche primär und ohne Komplikation zur Heilung kamen. Im Grunde genommen basieren ja diese Anschauungen auf einem Faktor, dem auch wir eine hohe Bedeutung im Kampf gegen die Infektion zuzutrauen geneigt sind, nämlich den antibakteriellen Kräften des Organismus und seiner Regenerationskraft, die in der schließlichen Uberwindung der Infektion und einer besonders guten Heilungstendenz zum Ausdruck kommen. Leider sind wir nur nicht in der Lage, diesen Faktor von vornherein in seiner Größe bestimmen und einsetzen zu können, ebensowenig wie wir etwas über das Verhalten der Infektionserreger bezüglich ihrer Virulenz vorher aussagen können, und deshalb glaube ich, daß man den Stand punkt, daß das Gefahrmoment der Infektion nach gründlicher Ausräumung des. Krankheitsherdes im Warzenfortsatz keine erhebliche Bedeutung mehr habe, nicht verallgemeinern darf.

In diesem Sinne möchte ich den rein theoretischen Erörterungen noch einige praktische Beispiele an die Seite stellen. Es war schon erwähnt worden, daß Piffl relativ oft beim primären Verschluß Sekretstauungen beobachtet hatte, welche zum Wiederaufbrechen der Naht führten. Bei genauer Durchsicht der einschlägigen Arbeiten findet man diese Beobachtung auch seitens anderer Autoren gar nicht selten, und zwar besonders in der ersten Zeit nach dem Eingriff. In einigen wenigen Fällen bahnte sich das Sekret auch einen Weg durchs Trommelfell und es kam noch einige Zeit lang zu profuser Absonderung aus dem Gehörgang. Hielt die Naht bereits fest, so traten neben den reinen Stauungserscheinungen nicht selten auch Entzündungserscheinungen an den Weichteilen, wie Ödem und Infiltration, mitunter Fieber mittleren oder höheren Grades auf. Diese Erscheinungen veranlaBten fast sämtliche Autoren im Verlauf ihrer weiteren Versuche, von der vollkommenen Vernähung der retroaurikulären Wunde wieder Abstand zu nehmen und am unteren Winkel der Wunde, wo der Durchbruch am häufigsten stattfand und somit die Prädilektionsstelle lag, ein $\mathrm{I}-2 \mathrm{~cm}$ langes ",Sicherheitsventil" zu schaffen, welches durch ein Drain oder einen Tampon noch mehr oder weniger lange offen gehalten wurde. Durch diese Maßnahme war die Gefahr einer Retention des Wundsekrets zweifellos erheblich vermindert, sie genügte jedoch noch keinesfalls, um in allen Fällen Störungen des Wundverlaufs ganz auszuschalten, sei es, da $\beta$ es doch noch infolge vorzeitiger Verklebung zu Stauungserscheinungen kam, oder sei es, daß trotzdem Erscheinungen entzündlicher Natur sich entwickelten. Jedenfalls haben wir selbst trotz Drainage derartige Folgen mehrfach beobachtet. Solange sie durch geeignete Behandlung, wozu nicht selten Wiedereröffnung der Wunde gehörte, schnell zu beheben waren, mag man sich dem Urteil, daß sie relativ belanglos gewesen seien, anschließen, nicht aber kann man das meines Erachtens bei den Fällen, bei denen es zu schwereren Folgen und be- 
sonders zu einer Mitbeteiligung des Labyrinthes gekommen ist. Ich erinnere an den Fall von Bondy, welcher Preysing auf dem Otologentag I9II in der Diskussion Veranlassung gab, seine warnende Stimme gegen ein allzu experimentelles Vorgehen bei der Behandlung der Antrotomiewunden zu erheben. Hier war es zunächst nach dem primären Verschluß zu einer zweifellosen serösen Labyrinthitis gekommen, die in Schwindel, Kopfschmerz und Nystagmus ihren Ausdruck fand und die Wiedereröffnung der Wunde nötig machte. Nach Abklingen der Reizerscheinungen und Wiederverklebung der Weichteile trat nochmals eine Sekretverhaltung auf, welche diesmal zu Schwellung und Druckempfindlichkeit der Weichteile in der Umgebung der Wunde, Durchbruch des Trommelfells, Senkung der hinteren oberen Gehörgangswand und Temperatursteigerung über 39 Grad führte. Die Wunde mußte nochmals eröffnet und bis zur definitiven Heilung offen behandelt werden.

Diesem bis vor kurzem in der Literatur einzig und ausführlicher dargestellten Fall, in welchem es sich übrigens um Infektion mit Streptococcus mucosus handelte, sind aus neuerer Zeit zwei weitere Beobachtungen an die Seite zu stellen, welche Fleischmann bei seinen Versuchen mit der Primärnaht unter gleichzeitiger Verwendung der Morgenrothschen Chininderivate, auf welche ich noch ausführlicher zurïckkommen $m u B$, gemacht hat. Auch hier traten infolge Sekretverhaltung Labyrinthsymptome mit Nystagmus und Erbrechen auf. Ferner möchte ich hier noch einen Fall erwähnen, welchen Denker beobachtet und in seinem Lehrbuch mitgeteilt hat. Bei diesem kam es im Anschluß an die primäre Vernähung zum Fortschreiten des Prozesses in der Tiefe, zur Bildung eines tiefen Extraduralabszesses in der hinteren Schädelgrube und sogar zur Einschmelzung des hinteren Bogenganges.

In der Literatur ist kaum etwas darüber $z \mathfrak{u}$ finden, wie sich die Autoren das Zustandekommen der meist sehr starken Sekretbildung in der Operationshöhle während der ersten Zeit nach dem Eingriff, welche zumeist die unangenelımen Komplikationen bedingte, zu erklären suchen. Bei der offenen Wundbehandlung mit Jodoformgazetamponade ist doch trotz der sekretionsanregenden Wirkung derselben die Absonderung meist so gering, daß die Tampons beim ersten Verbandwechsel nach 6-7 Tagen noch relativ trocken sind. Wie erklärt sich der Unterschied im Verhalten der Operationswunde bei Nichttamponade? Ich glaube, daß sich die Antwort auf diese Frage unschwer finden läßt, wenn man sich die Vorgänge bei dem äußeren Verschluß der Höhle einmal genauer klar macht: Vermutlich schon während der Naht, sicher aber bald darauf wird sich der im Warzenfortsatz geschaffene HohIraum einschließlich Antrum und womöglich auch Pauke aus den eröffneten Gefäßen mit Blut füllen, und zwar solange, bis alle 
Nischen damit ausgefüllt sind und der Druck so stark ist, daß er dem in den Gefäßen herrschenden Gegendruck die Wage hält. Die Wunde hat sich also quasi selbst tamponiert. Bei der offenen Wundbehandlung ist diese Blutanfüllung der Knochenhöhle durch den Tampondruck verhindert. Hätten wir es nun mit einer aseptischen Wunde zu tun, so könnte man sich vorstellen, daß das Blut gerinnen und nun ein Resorptions- und Organisationsproze $B$ einsetzen würde mit schließlicher Umwandlung des Blutkoagulums in Bindegewebe, wie man es bei der sogenannten Heilung unter dem Blutschorf erstrebte. Leider gehört dieser Vorgang $\mathrm{zu}$ den Ausnahmen, in den meisten Fällen wird sich sehr bald der Einflub der bis auf vereinzelte Ausnahmen stets noch vorhandenen pathogenen Mikroorganismen geltend machen in der Form, daß der Bluterguß infiziert wird und vereitert. Diese Annahme findet in den Erfahrungen, welche man speziell bei den Versuchen mit der bereits erwähnten Heilung unter dem Blutschorf und auch sonst gemacht hat, eine wohl kaum angreifbare Stütze. Ehe es also zu einer Produktion von eigentlichem Wundsekret mit bakteriziden Eigenschaften gekommen ist, wozu immer eine gewisse Zeit gehört, hat in dem besten Nährboden, welchen man sich denken kann, bereits eine Vermehrung der Keime und vielleicht auch eine Zunahme ihrer Virulenz stattgefunden, das schließliche Resultat ist, daß der Warzenfortsatz anstatt mit Blut mit Eiter angefüllt ist. Setzt nun die eigentliche Wundsekretion ein, so wird sehr bald der Zeitpunkt kommen, wo die Flüssigkeit einen Druck auf die Umgebung ausübt und sich auf die eine oder andere Weise einen Ausweg suchen muB. Erst nach Entleerung des Eiters und Schaffung eines genügenden Abflusses gewinnt das Wundsekret die Uberhand, und erst dann kann es seine bakterizide Kraft zur Geltung bringen. In dem Maße, wie die Infektion nachläßt, wird auch die Wundsekretion geringer, bis sie nach völliger Beseitigung der ersteren ganz aufhört oder doch so minimal wird, daß man von einer physiologischen im Gegensatz zu der vorher entzündlichen Sekretion sprechen kann. Daß unleugbar ein Abhängigkeitsverhältnis zwischen Infektion und Sekretion besteht, wird meines Erachtens am treffendsten durch die Tatsache illustriert, daß die Sekundärinfektion einer Wunde stets auch mit einer beträchtlichen Zunahme der Absonderung einhergeht. Rückschließend darf man deshalb wohl behaupten, daß auch für die reichliche Sekretbildung in der Antrotomiewunde während der ersten Zeit bei Fehlen der Tamponade die noch restierende Infektion verantwortlich gemacht werden muß, und daß es sich bei der Sekretstauung nicht nur um rein mechanische Störungen des Wundverlaufs, sondern um entzündliche, durch Infektionserreger hervorgerufene und demgemä $\beta$ ein beträchtliches Gefahrmoment bergende Erscheinungen handelt. In diesem Sinne müssen auch die entzündlichen Er- 
scheinungen an den Weichteilen auf ein aktives Verhalten der Infektionserreger zurückgeführt werden.

Es ließe sich gewiß einwenden, daß die Zahl der Fälle mit wirklich ernsten Komplikationen bei der Primärnaht zu gering ist, um den Wert der letzteren beeinträchtigen zu können, wenn nicht die Annahme berechtigt wäre, daß derartige Komplikationen doch vielleicht häufiger vorgekommen sind, als man aus den diesbezüglichen Mitteilungen entnehmen kann, und daß sie sicherlich zahlreicher gewesen wären, wenn das Verfahren allgemeinere Anwendung gefunden hätte. ${ }^{1}$ ) Wenn man aber selbst hiervon absehen würde, so muß meines Erachtens die Befürchtung allein, daß in dem einen oder anderen Falle die Primärnaht eine ernste Gefährdung des Patienten im Gefolge haben kann, zur Vorsicht mahnen. Diejenigen Autoren, welche das Verfahren befürworten, empfinden dies selbst und haben das abgesehen von der Schaffung des bereits erwähnten Sicherheitsventils am unteren Wundwinkel auch dadurch zum Ausdruck gebracht, daß sie die Indikation für die Anwendung der primären Naht mit mehr oder weniger weitgehenden Einschränkungen bedacht haben, auf die einzugehen ich hier verzichten muß.

Es gehört wohl mit zu den bittersten Erfahrungen des Weltkrieges, daB wir auf Grund der langen Friedenszeit die Gefahren der Wundinfektion zu sehr unterschätzt haben. Beobachtungen traurigster Art in kaum übersehbarer Zahl haben uns erst die Augen darüber öffnen müssen, daß unsere schlimmsten Feinde die Wundinfektionserreger waren, und daß unsere Hauptaufgabe darin bestehen mußte, diese mit allen Mitteln zu bekämpfen. Schritt für Schritt wurden wir dazu gedrängt, unser passives Verhalten den infizierten Wunden gegenüber zugunsten eines mehr aktiven Vorgehens aufzugeben, und das Endresultat war, daß wir schließlich zu einer Methode zurückkamen, welche man fast für überwunden hielt, nämlich zur antiseptischen Wundbehandlung. Es kann nicht meine Aufgabe sein, eine auch nur kurze Ubersicht über alle die Mittel zu geben, welche man zum Kampf gegen die Wundinfektion mobil gemacht hat, ich muß mich hier auf diejenigen beschränken, welche sich am besten bewährt haben, so bewährt haben, da $B$ sie verdienen, auch in der jetzt wieder in den Vordergrund tretenden Friedenschirurgie verwertet $\mathrm{zu}$ werden. Das gilt in erster Linie von den Morgenrothschen Chininderivaten und der

1) Anmerkung bei der Korrektur: In einer soeben erschienenen Arbeit aus dem St. Georg-Krankenhaus zu Hamburg (Zeitschr. f. Ohrenheilkunde, Bd: 8o, H. 3-4) kommt Leichs en ring auf Grund einer ganzen Anzahl von zurzeit recht bedenklichen Komplikationen bei der primären Naht zu einer strikten Ablehnung der Methode.

In dem gleichen Heft spricht sich auch O. Beck dagegen aus. Letzterer hat außerdem den Nachweis erbracht, daß ein Zusammenhang zwischen den die Mastoiditis bedingenden Eitererregern und der Tendenz zur primären Wundheilung im Gegensatz zu Bondys Feststellungen (vgl. S. 176) nicht besteht. 
hauptsächlich bei unseren Gegnern zur Verwendung gekommenen Natriumhypochloridlösung, welche unter dem Namen Dakinlösung bekannt geworden ist. Die umfangreiche im Laufe des Krieges entstandene Literatur über die Chininderivate, vor allem das Vuzin, macht ein näheres Eingehen auf die Eigenschaften dieses Mittels überflüssig, es soll nur wiederholt werden, $\mathrm{daB}$ es seine hohe Bedeutung für die Bekämpfung der Wundinfektion hauptsächlich dem Umstande zu verdanken hat, daß es trotz einer außerordentlich großen bakteriziden Kraft gerade gegen die verbreitetsten Wundinfektionserreger keine oder nur unerhebliche Gewebsschädigungen herbeiführt, dabei eine relativ weitgehende Tiefenwirkung entfaltet und durch die Gewebsflüssigkeiten in seiner Wirkung nur wenig gehemmt wird. Durch diese Kombination günstiger Eigenschaften sind das Vuzin wie die Chininderivate überhaupt den sonst gebräuchlichen antiseptischen Mitteln überlegen, und weitgehendste klinische Prüfung der durch experimentelle Versuche gewonnenen Erfahrungen unter Führung Klapps und zahlreicher anderer namhafter Chirurgen haben diese Überlegenheit bei der Wundinfektionsbekämpfung besonders bei prophylaktischer Anwendung hinreichend kundgetan.

Fleischmann gebührt das Verdienst, als erster den Versuch unternommen $\mathrm{zu}$ haben, die günstigen Ergebnisse der Vuzinbehandlung auch für unser Fachgebiet nutzbar zu machen, und begreiflicherweise hat auch dieser Autor als Angriffspunkt die Antrotomiewunde gewählt. Es kam ihm speziell auf die Frage an, ob es bei geeigneter Verwendung des Vuzins möglich sei, die Gefahren des primären Verschlusses der Weichteile, welche auch Fleischmann voll und ganz würdigt, und die auch nach ihm lediglich durch die Infektion als solche bedingt sind, $z u$ beheben. Maßgebend gerade für die Verbindung mit der primären Naht war für ihn die Überlegung, daß besonders nach den Untersuchungen Langes der solideste Verschluß - vor allem auch durch Knochenneubildung - zu erwarten ist, wenn auch das äußere Periost zur Deckung des Knochendefektes mitbenutzt werden kann, eine Möglichkeit, die am besten naturgemäß nur bei frühster Vereinigung der Weichteile besteht. Die Versuche erstreckten sich auf 20 Antrotomiewunden. In den ersten drei Fällen bestand die Behandlung darin, daß nach gründlichster Operation die Wundhöhle mit einer einprozentigen wäßrigen Lösung von Eukupinum hydrochloricum ausgespült und dann nach Einlegen zweier mit der gleichen Lösung getränkten Gazestreifen, von denen der eine nach dem Antrum, der andere an der hinteren Sulcusumrandung entlang geleitet wurde, bis auf den unteren Wundwinkel vernäht wurde. Hier wurden die beiden Gazestreifen herausgeleitet und bei jedesmaligem Verbandwechsel - der erste nach $7-8$ Tagen verkürzt. Es stellte sich heraus, daB diese Form der Behandlung nicht genügte. In einem der drei Fälle kam es zu einem stärkeren entzünd- 
lichen Ödem in der Umgebung der, Wunde, welches höheres Fieber zur Folge hatte und zur Wiedereröffnung der Nähte zwang. Von der Annahme ausgehend, daß dieses Ödem möglicherweise auf eine Infektion der Weichteile bei Ausräumung des erkrankten Knochens zurückzuführen sei, hat Fleischmann dann bei den nächsten zwei Fällen analog dem prophylaktischen Vorgehen im Felde eine Umspritzung der Weichteile mit einer Vuzinlösung I : Ioooo vorgenommen und die Behandlung der Wunde selbst dahin modifiziert, daß er die mit dieser Lösung getränkten Tampons schon am Tage post operationem entfernte, dafür aber die Wunde noch täglich mit der gleichen Lösung durchspülte. Das Resultat war noch unbefriedigender, indem im ersten Falle ein Erysipel auftrat, im zweiten Falle wiederum eine Weichteilinfiltration mit Schüttelfrost und hoher Temperatur., Beide Wunden mußten wieder geöffnet werden. Hieraufhin wurde in den nächsten sechs Fällen auf die Umspritzung der Weichteile wieder verzichtet und der Schutz der Wundränder dadurch zu erhöhen gesucht, daß dieselben während der Operation sorgfältigst mit steriler Gaze abgedeckt wurden. Im übrigen war die Behandlung die gleiche. Auch jetzt trat noch in einem Falle ein Erysipel auf, bei weiteren vier Fällen beschränkten sich jedoch die Störungen des Wundverlaufs auf leichtes Fieber, Stichkanaleiterung und mäßige Weichteilinfiltration, welche durch geeignete Maßnahmen bald behoben werden konnten. Ein Fall heilte glatt und komplikationslos in 31 Tagen. Einmal brach die nach 23 Tagen vollkommen geschlossene Wunde wieder auf und sezernierte noch mehrere Wochen.

Der wenn auch noch nicht einwandfreie, so doch im Vergleich mit den ersten Versuchen wesentlich günstigere Verlauf der letzen sechs Fälle ermutigte Fleischmann, nunmehr auch den vollkommenen Verschluß der Wunde einschließlich des unteren Wundwinkels auszuführen. Da hierbei natürlich eine nachträgliche Durchspülung mit dem Desinfizienz nicht mehr möglich war, mußte ein Weg gesucht werden, auf welchem eine länger dauernde Einwirkung des Vuzins auch nach Wunsdchluß gewährleistet war. Das Ziel glaubt er durch Verwendung einer Vuzin-Gelatinelösung erreicht zu haben. Die Wundhöhle wurde nach ausgiebigster Resektion des kranken Knochens unter breiter Eroffnung des Antrums und nach sorgfältiger Glättung zunächst mit I\% iger Vuzinlösung ausgespült. Nach Entfernung der Weichteilabdeckungen und Unterbindung der Gefäße nochmalige Durchspülung unter besonderer Berücksichtigung der Taschen zwischen Weichteilen und Knochen und Vereinigung der Wundränder von unten nach oben mittels Michelscher Klammern. Vor Anlegung der obersten Klammer Auffüllung der Höhle mit $I \%$ iger (später $1 / 2-1 / 4 \%$ iger) Vuzin-Gelatinelösung. Schließlich noch Reinigung des Gehörganges, wenn nötig Parazentese, und Einführung eines mit Vuzin-Gelatinelösung getränkten. 
Streifens in den Gehörgang. Auf die Umgebung der Wunde wurden Vuzin-Salben-Kompressen gelegt und darüber locker verbunden. Verbandwechsel täglich oder jeden zweiten Tag, Entfernung der Klammern zwischen zweiten und fünften Tag. Die Resultate, welche Fleischmann mit dieser Form der Behandlung in neun Fällen (mit zwölf Antrotomien) erzielte, habe ich der Ubersichtlichkeit halber in folgendem kurz zusammengestellt:

$$
\text { Fall I. }
$$

Alter: I7 Jahre.

Verhalten der Temperatur: Abfall nach der Operation innerhalb weniger Tage.

Komplikationen: Leichte ödematöse Schwellung in der Wundumgebung mehrere Tage. Infolge Sekretverhaltung Auftreten von Übelkeit und Schwindel sowie von rotatorischem Spontannystagmus.

Verhalten der Wunde: Sekretverhaltung durch einfachen Druck auf die Narbe behoben. Aus dem unteren Wundwinkel längere Zeit Absonderung.

Erreger: Strept. long.

Heilungsdauer: 36 Tage, danach aber noch längere Zeit Absonderung durch das Trommelfell.

Alter: 9 Wochen.

\section{Fa112.}

Verhalten der Temperatur: Nach Operation (bds.) Anstieg auf 38,4 , danach Abfall in wenigen Tagen.

Komplikationen: Kein nennenswertes Ödem, aber infolge Sekretverhaltung $z$ weimaliges Erbrechen, das nach Parazentese sistierte.

Verhalten der Wunde: Links geringfügige Absonderung aus einem Stichkanal.

Erreger: Strept. long. bds.

Heilungsdauer: Rechts 8 Tage, links I4 Tage.

Alter: 3 Jahre.

Fall 3 .

Verhalten der Temperatur: Angabe fehlt. Operation bḍs.

Komplikationen: Nach beiden nacheinander vorgenommenen Operationen starke teigige Schwellung der Weichteile bis zum Hinterkopf und mit Lidödem.

Verhalten der Wunde: Rechts Stichkanaleiterung, Sekundärinfektion mit Prozyaneus, Lüftung des unteren Wundwinkels auf I cm Lä̀nge nötig.

Links Absonderung aus dem unteren Wundwinkel.

Erreger: Bds. Strept. long.

Heilungsdauer: Rechts 20 Tage, links 13 Tage.

Fall 4.

Alter: I6 Jahre Influenzaotitis.: Operation bds:

Verhalten der Temperatur: Abfall in einigen Tagen zur Norm.

Komplikationen: Sekretstauung nach Schluß der rechten Operationswunde, das Sekret wurde durch Punktion entfernt.

Verhalten der Wunde: Links Absonderung aus dem unteren Wundwinkel.

Erreger: Bds. Strept. long.

Heilungsdauer: Rechts 26 Tage, links 17 Tage. 
Fall 5.

Alter: Io Jahre. Antrotomie links.

Verhalten der Temperatur: Abfall in 2 Tagen.

Komplikationen: Nicht beobachtet.

Verhalten der. Wunde: Naht in der Mitte auseinandergewichen.

Erreger: Strept. long.

Heilungsdauer: 39 Tage.

Fall 6.

Alter: 5 Jahre. Antrotomie links.

Verhalten der Temperatur: Anfänglich Anstieg auf 38,5, dann in 2. Tagen Abfall zur Norm. Am 6. Tag postop. Anstieg auf 40,0, dann lytischer Abfall zur Norm.

Komplikationen: Sekundärinfektion der Operationshöhle mit Pyozyaneus und diphtheroiden Bazillen.

Verhalten der Wunde: Absonderung übelriechenden Eiters am unteren Wundwinkel, der auf $1 \mathrm{~cm}$ wieder eröffnet werden mußte. Baldige Besserung nach Vuzinspülungen und Borsäureeinblasungen.

Erreger: Zunächst nur Strept. long, dann Pyozyaneus und diphtheroide Stäbchen.

Heilungsdauer: 27 Tage.

Fall 7 .

Alter: 9 Jahre. Antrotomie rechts.

Verhalten der Temperatur: Längere Zeit nach Operation Fieber zwischen 37 und $3^{\circ}$. Am 6. Tag 39,8 (Fieber ist auf einen gleichzeitig bestehenden pulmonalen Proze $\beta$ zu beziehen).

Komplikationen: Nicht beobachtet.

Verhalten der Wunde: Mäßige Absonderung am unteren Wundwinkel. Erreger: Pneumokokken.

Heilungsdauer: 9 Tage.

Alter: 6 Jahre.

Fall 8.

Temperatur: Abfall in 2 Tagen.

Komplikationen: Nicht beobachtet.

Verhalten der Wunde: Absonderung am unteren Wundwinkel.

Erreger: Pneumokokken.

Heilungsdauer: 9 Tage.

Alter: 3 Jahre.

$$
\text { Fall } 9 .
$$

Temperatur: Noch mehrere Tage nash der Operation zwischen 37 und $38,0^{\circ}$.

Komplikationen: Leichte Schwellung in der Umgebung der Wunde.

Verhalten der. Wunde: Nach Heilung noch längere Zeit unter Narbe Flüssigkeitserguß palpierbar.

Erreger: Pneumokokken.

Heilungsverlauf: 8 Tage, hinterher noch längere Zeit Absonderung durch das Trommelfell.

Ich habe den Fleischmannschen Behandlungsergebnissen und der von ihm geübten Methode einen breiteren Raum einräumen müssen, 
weil sie den ersten klinischen Versuch darstellen, die Infektion der Antrotomiewunden systematisch aktiv zu bekämpfen. Ob die von ihm gewählte Kombination mit der primären Naht eine besonders glückliche gewesen ist, möchte ich - nach den bisherigen Ergebnissen wenigstens - noch dahingestellt sein lassen. Mir scheinen seine Resultate im Vergleich zu denen der Primärnaht ohne Benutzung antiseptischer Mittel nicht wesentlich nach der günstigen Stelle $\mathrm{zu}$ differieren, wenigstens nicht in dem Maße, um die Einwände, welche sich gegen die Primärnaht überhaupt erheben lassen und die ich bereits näher präzisiert habe, zu entkräften. Fleischmann gibt selbst zu, daB auch in den mit Vuzin-Gelatine behandelten Fällen eine Beseitigung der Infektion nicht erreicht werden konnte, seine dahingehenden, Untersuchungen ergaben vielmehr, daß verschiedentlich noch nach längerer Zeit die ursprünglichen Erreger in den Ausstrichen, allerdings vereinzelt, vorgefunden wurden. Diese Tatsache sowie besonders der Umstand, daß es mehrfach zu Erysipel, in einigen Fällen sogar zu einer Sekundärinfektion der Wunde kam, müssen als ein Beweis dafür angesehen werden, daß das Verfahren in der vorliegenden Form einen verläßlichen Schutz gegen die Weiterwirkung der Infektion noch nicht gewährt. Ich glaube und werde hierin durch den Ausfall meiner eigenen Versuche bestärkt, daß die zu kurze Einwirkungsdauer der Chininderivate bei der getroffenen Versuchsanordnung hieran die Schuld trägt, so da $\beta$ es, wie Fleischmann meint, nur zu einem „, Sturz" der Virulenz der Infektionserreger und damit zu einem milderen Ablauf der Infektion, nicht aber zu einer restlosen Beseitigung derselben kommen konnte.

Das zweite von mir genannte Antiseptikum, dessen günstige Eigenschaften auch auf deutscher Seite verschiedentlich bestätigt worden sind, hat dadurch eine beondere Bedeutung erlangt, als mit seiner Hilfe ein Problem gelöst sein soll, welches seit Lister das Ziel chirurgischen Strebens gewesen ist, nämlich die Sterilisation schwer infizierter Wunden. Das Verdienst, die als Desinfiziens bereits bekannte Natriumhypochloridlösung in für den Wundgebrauch geeigneter Weise modifiziert zu haben, gebührt dem Amerikaner Dakin, während sein Landsmann Carrel die Methode und Technik ihrer Verwendung in sinnreicher, aber doch einfacher Weise ausgebaut hat. Daß der von vornherein beabsichtigte Zweck, die Sterilisierung der Kriegswunden, in vielen Fällen tatsächlich erreicht wurde, daran läßt sich heute nach den Urteilen namhafter Forscher und Chirurgen sowie auf Grund der von ihnen erreichten Erfolge kaum mehr zweifeln.

Es, ist bezeichnend für den chirurgischen Standpunkt auch auf der Gegenseite zu Beginn des Krieges, daB die Carrelsche Wundbehandlung lange Zeit einem auBerordentlichen Widerstand begegnete, trotzdem sich 
die katastrophalen Wirkungen der Wundinfektion dort zum mindesten in gleicher Weise geltend machten wie bei uns. Die Uberzeugung, daB die Sterilisierung einmal infizierter Wunden durch chemische Mittel einfach ein Ding der Unmöglichkeit sei, war so fest verankert, daß man die Versuche Carrels trotz bereits erzielter Erfolge kaum für diskutabel hielt und sich nicht einmal die Mühe gab, sie objektiv nachzuprüfen. Als Beispiel dafür mag angeführt sein, daß im April 19I5, als Carrel schon im großen Lazarett zu Compiegne sein Verfahren klinisch handhabte, Sir Almroth Wright schrieb: ,Si jamais un antiseptique stérilisait une blessure profondement infectée, il faudrait l'annoncer dans tous les journaux du matin et du soir". Und noch am 5. Januar IgI6, als schon eine große Zahl Schwerverletzter dem neuen Wundverfahren lebens- und gebrauchsfähige Gliedmaßen verdankte, gebrauchte Brocat, der Präsident der Société de Chirurgie die Worte: „et nous apporter cela d'Amérique, laissez-moi rire". Es ist demnach nur um so höher zu veranschlagen und kennzeichnend für den Wert der Carrelschen Methode, wenn die Anhänger derselben sich schließlich doch damit durchsetzen und ihr die berechtigte Anerkennung verschaffen konnten.

Mit Rücksicht darauf, daß ich den Versuch unternommen habe, die Carrelsche Wundbehandlung systematisch bei Antrotomien zu erproben und vor allem die Frage zu prüfen; ob mit Hilfe dieses Verfahrens auch eine schnelle und sichere Sterilisation der Antrotomiewunden möglich sei, wodurch natürlich ein sekundärer Verschluß derselben auf eine präzise Indikation gestützt werden könnte, halte ich mich für berechtigt, noch etwas näher auf die Entwicklung der ganzen Methode und die Eigenschaften der Natriumhypochloridlösung, welche gerade zur Wahl dieses Mittels geführt haben, einzugehen.

Nach den Ausführungen der beiden genannten Autoren war die von Lister eingeführte und stets verteidigte antiseptische Wundbehandlung aus dem Grunde in Mißkredit geraten, weil die von ihm erzielten Erfolge bei allgemeiner Nachprüfung nicht bestätigt werden konnten. Es wurden im Gegenteil dabei häufig schwere Gewebsschädigungen beobachtet, welche neben fehlender Beeinflussung der Infektion als solcher natürlich eine ablehnende Kritik hervorrufen mußten. Bei genauer Prüfung ließ sich jedoch feststellen, daß bei der Nachprüfung ein grundlegender Fehler gemacht wurde und für Mißerfolge dieser Art fast allein verantwortlich gewesen ist, nämlich der, da $\beta$ man allzusehr schematisierte und glaubte, daß die Verwendung eines Antiseptikums allein bereits genügen müsse, um bei jeder Art von Wunde einen komplikationslosen günstigen Verlauf zu gewährleisten. Das führte dazu, daß oftmals die nötige Sorfgalt außer Acht gelassen wurde und die Beschaffenheit der Wunde, die Zahl und Art der die Infektion bedingenden Bakterien nur ungenügende Berücksichtigung fand. Jedes chemische 
Mittel, welches in vitro bakterizid wirkte, wurde wahllos zur Wundbehandlung benutzt, ohne Rücksicht darauf, ob es koagulierend auf Eiweiß wirkte oder sonst in einer Form die Gewebe schädigen konnte, oder ob es bei Gegenwart von Blutserum seine bakterizide Kraft mehr oder weniger verlor. Über die Konzentrationsgrenze des Mittels sowie über die Einwirkungsdauer, welche nötig war, um die erstrebte Wirkung zu erzielen, kurz über die präzise klinische Erforschung setzte man sich vielfach hinweg. Teilweise war auch die Technik der Wundbehandlung recht mangelhaft, jeder glaubte sie seinem Gutdünken entsprechend von vornherein nach dieser oder jener Richtung hin modifizieren zu können. Alle diese Faktoren müssen für die Mißerfolge verantwortlich gemacht werden und sind letzten Endes schuld, daB die von Lister tatsächlich erzielten günstigen Ergebnisse bald wieder in Vergessenheit gerieten.

Als sich auch bei unseren Feinden herausstellte, daß die Bekämpfung der Wundinfektion in möglichst frühem Stadium die Aufgabe des Feldarztes war, griffen Dakin und Carrel auf die antiseptischen Wundbehandlungsmethoden zurück und suchten zunächst systematisch. zu prüfen, welches Mittel für eine Applikation auf Wunden überhaupt in Frage kommen konnte. Daß diese Prüfung natürlich auf Grund der weit fortgeschrittenen wissenschaftlichen Kenntnisse auf einer ganz anderen Basis geschehen konnte, als zur Zeit Listers, wo die biologische und biochemische Forschung noch in den Kinderschuhen steckte, ist ohne weiteres klar. Die Ergebnisse haben Carrel und Dehelly in einer ziemlich umfangreichen Monographie niedergelegt. Als Beweis für die enorme Arbeit, welche zunächst zu bewältigen war, mag gelten, daß sich die Prüfung auf über 20.0 chemische Mittel erstreckte, ehe es gelang, ein geeignetes und aussichtsreiches Antiseptikum zu finden, und zwar wurde jedes einzelne Mittel auf folgende Punkte hin untersucht:

I. Bakterizide Wirkung.

2. Bakterizide Wirkung bei Gegenwart von Blutserum.

3. Wirkung auf die Bakterientoxine.

4. Toxische Wirkung des Mittels selbst auf den ganzen tierischen Organismus.

5. Wirkung auf die tierischen bzw. menschlichen Gewebe,

a) auch solche, welche vom Blut versorgt sind;

b) auch solche, die vom Blutkreislauf ausgeschaltet sind;

c) auf jsolierte anatomische Elemente (Blutzellen).

Es kann gleich vorweg genommen werden, daß die meisten der geprüften Antiseptika, darunter die bekanntesten, den unbedingt not-wendigen Anforderungen nicht genügten, weil sie entweder in einer Konzentration, welche zur Erzielung einer kräftigen bakteriziden Wirkung erforderlich war, die Gewebe allzusehr schädigten, oder aber 
ihre bakterizide Kraft bei Gegenwart von Gewebsflüssigkeiten zu stark einbüßten.

Hierfür mag die nachstehende kleine Tabelle, welche ich dem Originalwerke Carrels und Dehellys entnommen habe, als Beispiel dienen.

Zum Verständnis sei bemerkt, daß die als Grundlage dienenden Versuche in folgender Weise ausgeführt wurden (Daufresne):

Eine Serie von Röhrchen wurde mit je $5 \mathrm{ccm}$ der zu prüfenden antiseptischen Lösung in zunehmender Verdünnung gefüllt und jedem Röhrchen ein oder zwei Tropfen einer 24 stündigen Bouillonkultur einer bestimmten Bakterienart zugefügt. Kontrollröhrchen mit Aqu. dest. wurden in gleicher Weise behandelt. Alle halbe Stunden wurden die bei $18-20^{\circ}$ Temperatur gehaltenen Röhrchen gut durchgeschüttelt und nach Ablauf von zwei Stunden aus jedem von ihnen auf Bouillon übergeimpft. Diese Bouillonröhrchen kamen 24 Stunden in den Brutschrank bei $37^{\circ}$. Nach dieser Zeit ließ sich schon durch ein. fache Besichtigung leicht feststellen, welche Konzentration des Mittels noch $z u$ einem völligen Absterben der Keime geführt hatte.

Um die Wirkung bei Gegenwart von Blutserum zu prüfen, wurden den ersten Röhrchen, welche das antiseptische Agens enthielten, je $5 \mathrm{ccm}$ Pferdeserum hinzugefügt. Die sonstige Versuchsanordnung blieb dieselbe. In der nun folgenden Tabelle gibt das Zeichen pos. Bakterienwachstum in der Bouillon nach Einwirkung des Mittels an, das Zeichen neg. bedeutet, daß dieselbe steril geblieben war. Der in vorliegendem Versuch gewählte Erreger war der Staphylokokkus pyogen aur.

Tabelle I.

\begin{tabular}{|c|c|c|}
\hline Antisepticum & Ohne Blutserum & Mit Blutserum \\
\hline Carbolsäurelösung & $\begin{array}{l}I: 250- \\
I: 500+\end{array}$ & $\begin{array}{l}\text { I: } 50- \\
\text { I: } 100+\end{array}$ \\
\hline Salizylsäurelösung & $\begin{array}{l}1: 2500- \\
1: 5000+\end{array}$ & $\begin{array}{l}I: 100- \\
1: 250+\end{array}$ \\
\hline Wasserstoffsuperoxydlösung & $\begin{array}{l}\text { I: } 3500- \\
\text { I: } 8000+\end{array}$ & $\begin{array}{l}\text { I: } 1700- \\
1: 2000+\end{array}$ \\
\hline Jodlösung & $\begin{array}{l}\text { I: } 100000- \\
\text { I: } 1000000+\end{array}$ & $\begin{array}{l}\text { I: } 1000- \\
\text { I: } 2500+\end{array}$ \\
\hline Sublimatlösung & $\begin{array}{l}I: 5000000- \\
I: 10000000+\end{array}$ & $\begin{array}{l}\text { I: } 25000- \\
\text { I: } 50000+\end{array}$ \\
\hline Argentumlösung & $\begin{array}{l}\text { I: } 1000000- \\
\text { I. } 10000000+\end{array}$ & $\begin{array}{l}\text { I: } 10000- \\
\text { I: } 25000+ \\
\end{array}$ \\
\hline Natriumhy pochloridlösung & $\begin{array}{l}\text { I: } 500000- \\
\text { I: } 1000000+\end{array}$ & $\begin{array}{l}I: 1500- \\
\text { I: } 2000+\end{array}$ \\
\hline
\end{tabular}

Nachdem auf diese Weise der Grad der Wirksamkeit jedes einzelnen Antiseptikums auf die verschiedenen Wundinfektionserreger ermittelt war, folgte mittels Tierversuchs die Prüfung der Giftigkeit sowie die Feststellung, ob und in welcher Form die toten und lebenden Gewebe 
durch eine länger währende Applikation des Mittels beeinflußt wurden. Die Beantwortung der letzten Frage war insofern von entscheidender Bedeutung, als selbstverständlich nur eine fortdauernde Einwirkung des Desinfiziens auf infizierte Wunden einen Erfolg im Sinne einer Sterilisation bringen konnte. Hierbei ergab sich nun ein Versagen fast der meisten zur Untersuchung gekommenen Mittel. Vor allem diejenigen, welche noch bei Gegenwart von Blutserum eine relativ hohe antibakterielle Kraft besaßen (aus obiger Tabelle z. B. die Argentumund Sublimatlösung), verursachten selbst in eben noch wirksamer Konzentration frühzeitig schwere und nachhaltige Gewebsschädigungen, besaßen außerdem vielfach toxische Eigenschaften, so daß sie aus diesen Gründen ausschalten mußten. Das gleiche ergab sich, um bei den in der Tabelle aufgeführten Mitteln zu bleiben, für die Jodlösung, sie wirkte koagulierend auf Eiwei $\beta$ und bei längerem Gebrauch auch stark reizend. Das Wasserstoffsuperoxyd gab seine wirksame Komponente schon im Augenblick der Applikation fast restlos ab und verlor damit die bakterizide Wirksamkeit. Von allen geprüften Mitteln stellten sich die Aussichten der Natriumhypochloridlösung, deren bakterizide Kraft bei Gegenwart von Serum derjenigen des Jods und Wasserstoffsuperoxyds annähernd gleichkam, weitaus am günstigsten. Selbst bei ziemlich hoher Konzentration und dauernder Einwirkung war die schädigende Wirkung dieser Lösung auf die Gewebe geringfügig und anscheinend nur dadurch bedingt, da $B$ sie bei der üblichen Form der Herstellung stets freies Alkali enthielt. Werin es demnach gelang, diesen Alkaligehalt durch ein neutralisierendes Mittel zu beseitigen, ohne der antibakteriellen Kraft Abbruch zu tun, konnte man mit einer völligen Unschädlichkeit für die Wundgewebe rechnen.

Es erscheint mir mit Rücksicht auf meine eigenen Erfahrungen wichtig, darauf hinzuweisen, daß die Neutralisierung der Natriumhypochloridlösung noch großen Schwierigkeiten begegnete. Der Versuch, den Gehalt an freiem Alkali durch Auswahl bester Chemikalien sowie durch peinlichste Sorgfalt bei der Herstellung der Lösung zu beseitigen, war ohne Erfolg, selbst bei einer Verdünnung, in welcher die bakterizide Kraft bereits auf ein Minimum reduziert war, fand sich immer noch deutlich alkalische Reaktion. Duyk stellte sogar fest, daß sich der Alkaligehalt der Lösung bei längerem Stehen durch hydrolytische Wirkung noch erhöhte. Es bedurfte erst noch zahlreicher fruchtloser Versuche der verschiedensten Art, bis es Dakin gelang, in der Borsäure ein Mittel zu finden, welches die alkalische Reaktion zum Schwinden brachte und damit auch die gewebsreizende Wirkung soweit verminderte, daß sie praktisch nicht mehr von Bedeutung. war.

Die Vorschrift für die Herstellung der Lösung war nach Dakin nunmehr folgende: I40 g Natriumkarbonat (Solvay-Soda) werden in 
Io Liter Wasser gelöst und dieser Lösung 200 g guten Chlorkalks hinzugefügt. Das Ganze wird gut vermischt, $1 / 2$ Stunde stehen gelassen und danach die klare Flüssigkeit vom Bodensatz abgehebert und filtriert. Dem Filtrat werden $40 \mathrm{~g}$ Borsäure zugesetzt, nach deren völliger Auflösung die Flüssigkeit gebrauchsfertig ist.

Mit dieser Original-Dakinlösung, deren neutrale Reaktion vor jedesmaligem Gebrauch mit Hilfe der Phenol-Phthallein-Probe kontrolliert wurde, wurden die ersten praktischen Versuche am Lebenden angestellt und auch die ersten äußerst vielversprechenden Erfolge erzielt. Es gelang in der Tat unter Anwendung der später noch zu beschreibenden Technik eine große Zahl schwer infizierter Kriegswunden selbst von kompliziertester Beschaffenheit in verhältnismäßig kurzer Zeit damit keimfrei zu machen, so daß sie wie aseptische Wunden behandelt und sekundär vernäht werden konnten. Allerdings stand den Erfolgen noch eine Reihe von Mißerfolgen gegenüber, besonders bei der Nachprüfung des Verfahrens durch andere Autoren, welche man sich zunächst nicht erklären konnte, da sowohl die Herstellung der Lösung als auch die Methodik der Behandlung in korrektester Weise den gegebenen Vorschriften entsprachen. Daufresne gelang es, die Fehlerquelle aufzudecken. Als er nämlich die an verschiedenen Orten benutzte Dakinlösung einer genauen Analyse unterzog, zeigte es sich, daß sie sowohl bezüglich ihres Prozentgehaltes an Hypochlorid häufig differierte, als auch trotz Zusatzes von Borsäure nicht selten noch alkalisch reagierte, und dies beruhte wiederum darauf, daß der im Handel befindliche und zur Bereitung der Lösung verwendete Chlorkalk in seinem Gehalt an freiem Chlor erhebliche Schwankungen aufwies., Die Unterschiede betrugen an verschiedenen Stellen zwischen 20,5 und 35,9\%, waren also recht bedeutend. Hieraus ergab sich die Notwendigkeit, den Chlorkalk vorher auf seinen Chlorgehalt $\mathrm{zu}$ untersuchen und danach die Mengen der übrigen Chemikalien zu modifizieren.

Für die Titrierung des Chlorkalks gibt Daufresne folgendes Verfahren an: 20 Gramm des zu prüfenden Chlorkalks werden in I Liter Wasser so vollständig âls möglich gelöst und die Lösung einige Stunden in Ruhe gelassen. Sodann werden to $\mathrm{ccm}$ der Flüssigkeit abgehebert und mit $20 \mathrm{ccm}$ einer 10\% igen Jodkaliumlösung sowie mit $2 \mathrm{ccm}$ Acidum hydrochloricum oder aceticum vermischt. Diesem sich braunfärbenden Gemisch wird tropfenweise $1 / 10$ Normal-Natriumthiosulfatlösung $(2,48$ : 1oo,o) zugesetzt, bis Entfärbung eintritt. Die Zahl der bis zu diesem Moment gebrauchten Kubikzentimeter der Natriumthiosulfatlösung mit I,775 multipliziert gibt ohne weiteres den Prozentgehalt des Chlorkalks an freiem Chlor an.

Erwähnt sei hier gleich, daß zur Feststellung des Hypochloridgehaltes der fertiggestellten Lösung das gleiche Verfahren dient, nur 
wird hierbei an Stelle der Chlorkalklösung die Dakinlösung eingesetzt (Io $\mathrm{ccm}$ ) und die Zahl der zur Entfärbung nötigen Kubikzentimeter der Natriumthiosulfatlösung mit 0,03725 (anstatt mit 1,775) multipliziert. Das Resultat gibt den Hypochloridgehalt der Lösung in Prozenten an.

Des weiteren ist es Daufresne gelungen, die zur Neutralisierung dienende Borsäure, die in manchen Fällen für die mangelhafte Stabilität der Lösung verantwortlich gemacht werden mußte, wieder auszuschalten und zwar dadurch, da $B$ er einen Teil der zur Verwendung gelangenden Soda durch Natrium bicarbonicum ersetzte. Nach seinen Untersuchungen erhält man stets automatisch eine neutrale, $0,475 \%$ ige Lösung, wenn man - nach Feststellung des Chlorgehaltes im Chlorkalk (Kolumne I der nachfolgenden Tabelle) - die folgenden Mengen der einzelnen Reagentien verwendet.

\section{Tabelle II.}

\begin{tabular}{|c|c|c|c|}
\hline \multirow{3}{*}{$\begin{array}{c}\text { Titer des } \\
\text { Chlorkalks } \\
\mathrm{Cl} \%\end{array}$} & \multicolumn{3}{|c|}{ Gewichtsmengen, die nötig sind, um Io Liter Hypo- } \\
\hline & chloridlösung & $\begin{array}{l}0,475 \% \text { Hypo } \\
\text { zustellen. }\end{array}$ & loridgehalt her. \\
\hline & Chlorkalk & Soda (Solvay) & Natr. bicarbon. \\
\hline 20 & $230 \mathrm{~g}$ & II5 g & $96 \mathrm{~g}$ \\
\hline $2 \mathrm{I}$ & 220 & IIo & 92 \\
\hline 22 & 210 & 105 & 88 \\
\hline 23 & 200 & 100 & 84. \\
\hline 24 & 192 & 96 & 80 \\
\hline 25 & I 84 & 92 & 76 \\
\hline 26 & 177 & 89 & 72 \\
\hline 27 & 170 & 85 & 70 \\
\hline 28 & I64 & 82 & 68 \\
\hline 29 & .159 & 80 & 66 \\
\hline 30 & I54 & 77 & 64 \\
\hline $3 \mathrm{I}$ & I 48 & 74 & 62 \\
\hline 32 & 144 & 72 & 60 \\
\hline 33 & I 40 & 70 & 59 \\
\hline 34 & 135 & 68 & 57 \\
\hline 35 & 132 & 66 & 55 \\
\hline 36 & 128 & 64 & 53 \\
\hline 37 & 124 & 62 & 52 \\
\hline
\end{tabular}

Um endlich noch eine besonders innige Verbindung der einzelnen chemischen Stoffe miteinander zu erzielen, hält Daufresne es für zweckmäßig, die Lösung in folgender, etwas modifizierter Weise zuzubereiten.

1. Die nach obiger Tabelle zu bestimmenden Mengen der einzelnen Chemikalien werden genau abgewogen.

2. In einer ca. zwölf Liter fassenden Flasche wird der Chlorkalk mit fünf Liter gewöhnlichen Wassers vermischt, mehrmals tüchtig geschüttelt und umgerührt und eine Nacht stehen gelassen.

3. In einem zweiten Gefäß werden Natrium carbonicum und Natrium bicarbonicum zusammen in fünf Liter Wassers gelöst. 
4. Die beiden Lösungen werden auf einmal zusammengegossen, eine Minute lang tüchtig gerührt und dann eine halbe Stunde in Ruhe gelassen, damit die ungelösten Teile sich setzen können.

5. Nach Ablauf der halben Stunde wird die helle Flüssigkeit vom Bodensatz abgehebert und durch doppeltes Papier filtriert.

Die auf diese Weise hergestellte modifizierte Dakinlösung enthält bei einem Prozentsatz von $0,475 \%$ Hypochlorid das Optimum der Konzentration und ist, wenn sie kühl und an einem vor Licht geschützten Ort aufbewahrt wird, etwa I Monat lang haltbar. Licht und Wärme schaden der Lösung, sie kann dabei im Laufe eines Monates $24 \%$ ihres Hypochloridgehaltes verlieren. Bei richtiger Aufbewahrung soll der Verlust höchstens $\mathrm{I}-\mathrm{I} 1 / 2 \%$ betragen und für die Wirksamkeit ohne Belang sein. Als ein gutes Mittel, die Haltbarkeit der Lösung in unschädlicher Weise zu erhöhen und zugleich eine Verwechselung mit anderen Flüssigkeiten $z u$ vermeiden, wird noch der Zusatz von $5 \mathrm{mg}$ Kalium permanganat pro Liter der filtrierten Lösung empfohlen, wodurch dieselbe eine rosa Farbe erhält.

Nachdem es somit gelungen war, eine einwandfreie, stets neutral reagierende und optimal konzentrierte Natriumhypochloridlösung herzustellen, blieben die eingangs erwähnten Mißerfolge, soweit sie der Lösung als solcher zur Last fallen mußten, aus oder wurden wenigstens nur vereinzelt beobachtet. Kamen Versager noch in größerer Anzahl vor, so waren andere Gründe dafür maßgebend, vor allem trug vielfach die Unkenntnis der durch langwierige weitere Versuche erst vollerkannten Eigenschaften der Dakinlösung bzw. eine fehlerhafte Wundbehandlungstechnik daran die Schuld. Es ist deshalb notwendig, hierauf noch etwas näher einzugehen.

Bei der Besprechung der bakteriziden Eigenschaften der verschiedenen Antiseptika war schon erwähnt und nummerisch dargestellt worden (vgl. Tabelle I), in welch hohem Maße sich die antibakterielle Wirkung auch der Natriumhypochloridlösung bei Gegenwart von Blutserum vermindert. Dem ist noch hinzuzufügen, daß die bakterizide Wirkung bei einmaliger Applikation außerordentlich schnell weiter nachläßt, schließlich sogar ganz verloren geht, und zwar deshalb, weil ihr Hypochloridgehalt durch die Gegenwirkung der Wundsekrete zum Schwinden gebracht wird. Nach Carrel ergaben Versuche im vitro, daß das Hypochlorid der Dakinlösung, wenn man letztere mit gleichen Teilen Eiter vermischte, nach zwei Stunden zumeist nicht mehr nachgewiesen werden konnte. In Wunden ging dieser Prozeß noch schneller vor sich. Schon sechs Minuten nach einmaliger Applikation der Lösung war der Prozentgehalt von 0,5 auf 0,16 gesunkenBei mehrmaligè Applikation in kurzen Intervallen trat dieser ZersetzungsprozeB langsamer ein, aber erst bei dauernder ununterbrochener 
Zuführung der Lösung blieb der Hypochloridgehalt annähernd auf der gleichen Höhe. Die Lösung wird also in Wunden außerordentlich schnell zersetzt. Diese Tatsache ist für den ganzen Ausbau der Carrelschen Wundbehandlung von entscheidender Bedeutung gewesen, und es ist in hohem Maße wahrscheinlich, daß die ungenügende Berücksichtigung und vielleicht auch Unkenntnis dieser Eigenschaft verhältnismäßig oft die Ursache von Mißerfolgen gewesen ist und dann mit Unrecht zu einer falschen Beurteilung des ganzen Verfahrens geführt hat.

Daß die Dakinlösung nicht auf alle Bakterien in gleich starker und schneller Weise einwirkt, hat sie mit allen anderen Antiseptizis gemein. Hierüber hat Richter in neuerer Zeit Versuche angestellt und gefunden, daß

Staphylokokken in 7 Minuten,

Streptokokken in Io Minuten,

Bac. pyocyaneus in I5 Minuten,

Kapselbakterien in 7 Minuten

abgetötet wurden. Die praktische Bedeutung dieser Befunde, welche im allgemeinen den Ergebnissen Carrels und Dehellys entsprechen, nur daß letztere eine intensivere Wirkung auf die Streptokokken annehmen, tritt bei richtiger Anwendung des Verfahrens in den Hintergrund. Weit wichtiger ist, daß die Hypochloridlösung auch die Bakterientoxine vernichtet, was neben anderem daraus hervorgeht, daß Tetanusbazillen enthaltender Eiter, welcher eine halbe Stunde mit Dakinlösung behandelt war, Versuchstieren ohne Schaden injiziert werden konnte. Vergiftungserscheinungen wurden bei oberflächlicher, subkutaner und selbst intraperitonealer Applikation der Lösung niemals beobachtet, was auch von Richter in vollem Maße bestätigt werden konnte. Im Gegensatz hierzu ist ihre intravenöse Anwendung gefährlich und kontraindiziert, da sie hochgradige hämolytische Eigenschaften besitzt.

Uber die Wirkung der Hypochloridlösung auf die tierischen und menschlichen Gewebe ist zunächst ganz allgemein zu sagen, daß eine Wunde, mochte sie noch so groß sein, die Applikation der Lösung - stets ihre richtige Zusammensetzung vorausgesetzt - Tage und Wochen lang vertrug, ohne klinisch die geringsten Reizerscheinungen zu zeigen. Hieraus geht schon hervor, daß eine Schädigung der Gewebe im praktischen Sinne dadurch nicht entsteht. Andererseits muß es als sicher gelten, daß die den Chininderivaten nachgerühmte Tiefenwirkung der Dakinlösung fehlt. Das machte sich besonders bemerkbar, wenn nekrotische Partien in einer Wunde vorhanden waren. Diese von der Blutzirkulation abgeschlossenen $\mathrm{Ge}$ websteile grenzten sich zwar durch die Einwirkung des Mittels schneller 
ab, konnten aber nicht keimfrei gemacht werden, sie bildeten im Gegenteil unterhalb der Einwirkungsgrenze desselben einen besonders guten Nährboden für die Wundinfektionserreger und waren nicht selten die Ursache für ein MiBlingen des Sterilisationsversuchs, Daher ist diese Tatsache von wichtiger praktischer Bedeutung. Mehr theoretisch interessiert die Beeinflussung isolierter anatomischer Elemente, insbesondere der Blutzellen. Auf diese wirkte die Dakinlösung destruktiv, wenn auch mit einem gewissen Unterschied ein. Während die roten Blutkörperchen außerordentlich schnell aufgelöst wurden, ging der Vernichtungsprozeß bei den weißen, vor allem den polymorphkernigen Leukozyten langsamer vonstatten. Jedenfalls fand man im Sekret der behandelten Wunden noch relativ häufig viele gut erhaltene Leukozyten, darunter oft solche, welche Bakterien enthielten. Vereinzelt ließ sich allerdings auch eine restlose Vernichtung der Phagozyten feststellen. Diese an sich etwas bedenkliche Eigenschaft der Dakinlösung wird aber nach Carrel durch ihre fehlende Tiefenwirkung paralysiert, und zwar insofern, als die Phagozytose, welche sich unterhalb der Einwirkungsgrenze des Mittels vollzieht, und die als ein wichtiges Glied des ganzen Sterilisationsprozesses angesehen werden muß, unbeeinflußt bleibt. Sind die Phagozyten an die Oberfläche vorgedrungen, so schadet ihre Vernichtung nichts, weil ja die Bakterien mitvernichtet werden.

Entsprechend den geschilderten Eigenschaften der Dakinlösung ergab sich für die eigentliche Wundbehandlung als erste Forderung eine sorgfältige Vorbereitung der Wunde. Vor allem war es notwendig, bereits deutlich kenntliche Nekrosen und solche Partien, deren Nekrose gefürchtet werden mußte, restlos zu entfernen. Daß diese Wundvorbereitung bei den Kriegsverletzungen entsprechend ihrer Mannigfaltigkeit, ihres Zustandes und der bereits eingetretenen Komplikationen eine ganz andere Rolle spielte, als bei Operationswunden; bedarf kaum eines Hinweises. Für jede Gattung derartiger Wunden hat Carrel besondere Vorschriften gegeben, die hier übergangen werden können. Besonderer Wert wurde auch gelegt auf eine tadellose Blutstillung, da geronnenes Blut das Herandringen der Lösung in die Gewebe verzögern oder gar verhindern konnte. Am wichtigsten war die richtige Einleitung und Durchführung der weiteren Behandlung. Zwei Hauptaufgaben waren dabei zu lösen, erstens eine Verbandtechnik zu finden, welche ein Hingelangen der Flüssigkeit in sämtliche Nischen und Buchten der Wunde und an die gesamte Oberfläche gewährleistete, und zweitens Vorkehrungen zu treffen, welche eine möglichst fortdauernde Einwirkung der Lösung in wirksamer Konzentration garantierten.

Was den ersten dieser beiden Punkte anlangt, so haben sich für die Zuleitung der Lösung in sämtliche Teile der Wunde am vorteilhaftesten Gummischläuche erwiesen, welche so eingerichtet sein 
mußten, daß eine gleichmäßige Verteilung der Flüssigkeit gewährleistet war. $\mathrm{Zu}$ diesem $\mathrm{Zweck}$ waren die Gummischläuche an einem Ende zugebunden oder besser zugeschmolzen und seitlich in ganz kurzen Intervallen mit einer großen Anzahl feinster Löcher versehen, und zwar so weit, als der Schlauch sich innerhalb der Wunde befand. Je nach Größe, Ausdehnung und Beschaffenheit der Wunde (Buchten) wurden so viele Schläuche eingefiihrt, daß man bei Eingießen der Lồsung von außen her auf eine gleichmäßige Verteilung derselben rechnen konnte. Hierauf wurden die Zwischentäume und Buchten der Wunde mit steriler in Dakinlösung getränkter Gaze bis zum Hautniveau angefüllt. Darüber kam eine nach der Wunde zu hydrophile, nach außen zu weniger aufsaugende, aber nicht undurchlässige Verbandstoffschicht, durch welche die Gummischläuche hindurchgeleitet wurden. Der Verband wurde mit Binden oder - an Extremitäten - nach einmaliger Herumführung um das Glied mit Sicherheitsnadeln befestigt. Die aus dem Verband herausragenden Gummiröhren wurden nun noch durch besondere Glasansätze mit doppelter oder mehrfacher Gliederung miteinander verbunden, so daß man sie sämtlich von einer Stelle aus füllen konnte, oder aber die Flüssigkeit mußte in jedes einzelne Röhrchen eingegossen werden.

Bezüglich der Instillation selbst haben sich zwei verschiedene Methoden als praktisch erwiesen, die kontinuierliche und die intermittierende. Bei der ersteren wurde $1 / 2^{-I} \mathrm{~m}$ oberhalb der zu behandelnden Wunde am Bett des Kranken ein Glasgefäß (Irrigator oder Ampulle) angebracht, welches etwa ein Liter Dakinsche Flüssigkeit enthielt und durch einen Schlauch mit dem Wundröhrchen verbunden war. Dazwischen eingeschaltet war ein Tropfenzähler, oberhalb desselben befand sich eine Schraubklemme, durch deren Einstellung man - wie beim Tröpfcheneinlauf - die Zuführung der Lösung regulieren konnte. Die Zahl der in der Minute $z$ instillierenden Tropfen richtete sich natürlich nach der Größe der Wunde und der Anzahl der zu speisenden Wundröhrchen und mußte in jedem Fall erprobt werden. Der Zweck war erfüllt, wenn die Wundkompressen stets vollständig durchfeuchtet waren, ohne daß sich jedoch Flüssigkeit auf der Unterlage ansammelte.

Die intermittierende Methode verzichtete auf den Tropfenzähler, im übrigen war die Apparatur dieselbe. Die Durchfeuchtung der Kompressen erfolgte in der Form, daß mittelst einfacher Mohrscher Klammer alle $\mathrm{x}-2$ Stunden, eventuell auch früher, so viel Flüssigkeit als notwendig in die Wunde irrigiert wurde. Bei Wunden, welche nur schwer in dauernder Verbindung mit dem Irrigator zu halten waren, besonders bei solchen am Kopf, wurde auch ganz auf den Apparat verzichtet und die Instillation in gleichen Intervallen mit einer Pipette oder Spritze vorgenommen. 
Nach der Vorschrift der französichen Autoren wurde diese Berieselung ununterbrochen Tag und Nacht durchgeführt, bis zu dem Augenblick, wo die Wunde als steril gelten konnte. $\mathrm{Zu}$ diesem Zweck war eine ständige Kontrolle des Wundsekrets mittels des Mikroskops notwendig, die stets bei dem etwa täglich bis zweitäglich vorgenommenen Verbandwechsel erfolgte. Die Untersuchung war sehr einfach. Mittels einer vor jeder Entnahme gut ausgeglühten Platinöse wurde Sekret besonders aus den Teilen der Wunde, deren Zustand am wenigsten frisch erschien, entnommen und auf einem gut gereinigten und vorher bezeichneten Objektträger verrieben. Die Entnahme an Stellen, welche bluteten, mußte vermieden werden, da sich herausgestellt hatte, daß dadurch eventuell verhängnisvolle Irrtümer entstehen konnten. Nach Fixierung in der Flamme wurde mit Thionin oder Methylenblau gefärbt und untersucht. Carrel ging im allgemeinen so vor, daß er die Anzahl der in einem Gesichtsfeld durchschnittlich vorhandenen Bakterien (ohne Rücksicht auf ihre Art) zählte (Ölimmersion, Okular 3) und diese Zahl in eine Tabelle eintrug. Durch Verbindung der in gleichen Intervallen erhobenen Befunde erhielt er eine Kurve, aus welcher er den Verlauf der Sterilisation genau verfolgen konnte. Der normale Ablauf derselben wurde dadurch erkannt, daß diese Kurve eine ständig absteigende Tendenz zeigte. Kamen Schwankungen vor, so deuteten diese fast ausnahmslos auf Fehler in der Behandlungstechnik hin. Als praktisch steril und für die Sekundärnaht reif war eine Wunde, in deren Sekret sich nicht mehr als durchschnittlich ein Keim in zehn Gesichtsfeldern fand. In diesem Stadium wurde der Wundverschluß nach den allgemeinen chirurgischen Regeln vorgenommen.

Auf die Erscheinungen, welche die mit Dakinlösung behandelten Wunden zugleich unter dem Einflu $B$ der fortschreitenden Sterilisierung in klinischer Beziehung boten, komme ich an Hand meiner eigenen Versuche noch zurück. Hier ist nur noch ein Hinweis nötig auf verschiedenen Fehlerquellen, welche das Gelingen der Wundsterilisation relativ häufig in Frage gestellt bzw. vereitelt haben.

Die meisten Mißerfolge waren abgesehen von einer zu schwachen oder zu starken bzw. nicht neutral reagierenden Lösung darauf zurückzuführen, daß die Flüssigkeitszufuhr nicht genügte. Oft lag dies daran, da $\beta$ die Drainageröhrchen ungenügend perforiert oder verstopft waren - das letztere geschah besonders leicht bei mangelhafter Blutstillung oder daß sie in der Wunde falsch plaziert waren. Ein zweiter Grund, wenigstens bei Verwendung eines Instillationsapparates für kontinuierliche Berieselung war der, daB eine falsche Einstellung der Stellschraube erfolgt war. Endlich, und das geschah weitaus am häufigsten, wurde vom Personal bei der intermittierenden Instillierung einfach nicht 
genügend Flüssigkeit instilliert. Nach Carrel sollen zwei Symptome für die Erkennung dieses wichtigsten Fehlers charakteristisch sein, einmal das Auftreten von Fötor im Wundsekret und zweitens eine wesentliche Veränderung in der Konsistenz des Wundeiters. Der letztere soll zähflüssig und transparent sein, außerdem nur in geringer Menge produziert werden. Zeigt er diesen Zustand nicht oder tritt gar Fötor auf, so soll man mit fast absoluter Sicherheit auf eine ungenügende Durchspülung der Wunde schließen können.

Eine zweite Fehlerquelle, welche zwar auf die Wundsterilisation an sich keinen Einfluß ausübte, aber anderweitig den Wundverlauf störte, war eine zu reichliche Flüssigkeitszufuhr. Sie führte dazu, daß die Patienten häufig völlig durchnäßt waren, sich erkälteten, zum mindesten in ihrem Befinden litten, mitunter auch Ekzeme bekamen. Die letzteren ließen sich jedoch durch Einfetten der Wundumgebung mit Vaseline sicher vermeiden. Endlich wurde noch eine Schädigung dadurch beobachtet, daß die Wundöffnung, durch welche die Flüssigkeit speziell bei tieferen Wunden zugeführt wurde, zu klein war. Es kam dann leicht infolge Druckwirkung bei der Instillation zu Schmerzen, welche die Wundbehandlung niemals ber eiten soll.

Bekanntlich hat die Dakinlösung schon während des Krieges ihren Weg auch zu uns und unseren Verbündeten gefunden und ist in der Human- und Veterinärmedizin vielfach zur Anwendung gekommen. Hierüber hat Richter in einer Dissertation ausführlich berichtet. Die überwiegende Mehrzahl der Autoren, von denen ich nur Dobbertin, Läwen, Stephan, Rychlik, Freusberg, Bumiller, Hauser, Otto, Hirschberg, Troell und Winkelmann nennen will, hat, nachdem von Bruns auf das Mittel aufmerksam gemacht und zu seiner Verwendung die Anregung gegeben hat, nur recht gute Resultate gemeldet und übereinstimmend vor allem die reinigende und granulationsanregende Wirkung des Antiseptikums gerühmt. Skeptischer haben sich Chiari, Hufschmid und PreuBe, z. T. auch Busch über ihre Beobachtungen geäußert. Man hat jedoch mit ganz wenigen Ausnahmen die Dakinlösung lediglich als Wundantiseptikum gebraucht, die eigentliche Carrelsche Methode und ihre Durchführung bis zur vollständigen Sterilisation der Wunde mit nachfolgender Sekundärnaht hat bisher bei uns nur vereinzelt Nachahmung gefunden. Seit Kriegsende ist es überhaupt wieder recht still davon geworden. Nur Rit ter und K ey Ber haben sich noch experimentell und klinisch mit der Wirkung der Dakinlösung beschäftigt, ohne jedoch die günstigen Ergebnisse Carrels damit erzielt zu haben. Möglicherweise ist dies darauf zurückzuführen, da $B$ das Prinzip und die Einzelheiten des Verfahrens bei uns in Deutschland noch nicht hinreichend bekannt geworden sind und das ist für. mich auch der Grund gewesen, warum ich ausführlicher darauf ein- 
gegangen bin, als es vielleicht sonst nötig gewesen wäre. Meines Erachtens sind die Erfolge der Carrelschen Wundbehandlung, von denen ich mich durch das Studium des mehrfach zitierten Werkes überzeugen konnte, so außerordentlich bedeutungsvoll, daß ich mich einer systematischen Nachprüfung derselben, einer Anregung meines Chefs, Herrn Geheimrats Denker folgend gern unterzog, zumal ich sehr bald den Eindruck gewonnen hatte, daß die Aussichten dafür bei der Antrotomiewunde durchaus günstige waren. Die Reformbedürftigkeit der Nachbehandlung nach dieser Operation ist unbestitten, gelang die Sterilisierung der Wunde, so war damit die Möglichkeit gegeben, die Behandlung durch frühzeitigen sekundären Verschluß im Sinne Carrels erheblich abzukürzen, und zugleich ein Weg gefunden, welcher auch denjenigen, welche die von seiten einer infizierten Wunde immer drohenden Gefahren nicht in Kauf zu nehmen gewillt sind, gangbar. erscheinen mußte.

Es darf nicht unerwähnt bleiben, daß die Carrelsche Behandlung der Antrotomiewunde kein Novum darstellt, sondern bereits versucht worden ist. Der erste, welcher die Dakinlösung dabei verwandt hat, war der französische Arzt Mahu (zit. b. Carrel). Ich konnte jedoch nichts weiter darüber finden, als daß es diesem Autor gelungen sei, die Behandlungszeit auf ein Drittel der vorher üblichen zu reduzieren. Ferner hat Berggren in sechs Fällen das. Verfahren geübt und Sterilisation der Wunden im Sinne Carrels in $3-$ II Tagen erzielt. Anstatt Gummirohr und Irrigator benutzte Berggren nur durchnäßte Gazetampons, welche dreistündlich gewechselt wurden. Genaueres kann ich auch hierüber nicht angeben, weil mir die Arbeit nur im Referat zugänglich war. Die Sekundärnaht heilte in den sechs Fällen fünfmal per primam.

Schließlich bedarf an dieser Stelle noch ein Punkt der Erwähnung, über welchen die Ansichten der Autoren auch heute noch auseinandergehen und welcher die Frage betrifft, worauf speziell die bakterizide Wirkung der Dakinlösung zurückzuführen sei.

Dakin selbst vertritt den Standpunkt, daß die Fähigkeit des Hypochlorids, mit den Proteinen und Aminosäuren feste Verbindungen einzugehen, in der Form, daß seine Chloratome die Atome $\mathrm{H}$ einzelner NH-Gruppen unter Bildung von Chloraminen ersetzen, die bakterizide Wirkung bedingt. Seine Annahme, daß demnach das Chlor der wirksame Faktor sei, wird von Bier und Dunker geteilt.

Die größere Mehrzahl der Autoren nimmt jedoch an; daß der chemische Zersetzungsprozeß der Lösung in der Wunde genau so vor sich geht wie in der Technik. Hier wird die Natriumhypochloridlösung in Form der Labarraqueschen Lauge zum Bleichen von Farbstoffen benutzt, ein Vorgang, welcher auf Oxydation durch 
freiwerdenden Sauerstoff beruht und sich ganz einfach nach der Formel vollzieht:

$$
\mathrm{NaClO}=\mathrm{NaCl}+\mathrm{O} .
$$

Demnach wäre Sauerstoff in statu nascendi, dessen außerordentlich große bakterizide Kraft unbestritten ist, der wirksame Faktor. (Dobbertin nimmt einen gewissermaßen vermittelnden Standpunkt ein, indem er meint, daß die Toxine durch Chlorierung der Eiweißkörper, die Bakterien durch die Einwirkung naszierenden Sauerstoffs vernichtet werden.)

Die Ansicht der letztgenannten Autoren, welche auch von den meisten Chemikern geteilt wird (Erdmann) hat die größere Wahrscheinlichkeit für sich, würde auch am zwanglosesten erklären, daß trotz der ununterbrochenen Einwirkung der Lösung keine Gewebsschädigungen eintreten. Nach Abspaltung des Sauerstoffs bleibt nur eine schwache, den Körperflüssigkeiten fast isotonische, höchstens ganz leicht hypertonische Kochsalzlösung zurück, welche unter Umständen noch durch Unterhaltung einer zur Wundoberfläche gerichteten Lymphströmung die Reinigung der Gewebe von Bakterien und deren Giften beschleunigen kann.

\section{Eigene Versuche.}

Ehe ich meine Versuche in Angriff nahm, überlegte ich mir, inwieweit es möglich sei, bei der Behandlung der Antrotomiewunden den. Forderungen Carrels zu entsprechen. Es schien mir unbedingt notwendig zu sein, mich peinlichst genau an die gegebenen Vorschriften zu halten und jede Modifikation - zunächst wenigstens - auszuschalten, weil sich nur so ein Urteil über den. Wert der Methode gewinnen und gleichzeitig, bei eventuellem Mißlingen, der Vorwurf einer fehlerhaften Technik zurückweisen ließ. Dementsprechend war auch eine Kombination mit der primären Naht, wie sie Fleischmann beim Vuzinverfahren gewählt hatte, von vornherein ausgeschlossen, da hierbei eine der grundlegenden Bedingungen, die dauernde Berieselung der Wunde mit der Lösung, nicht erfüllt werden konnte.

Anfangs stand mir das Carrel-Dehellysche Werk, in welchem ich später die Herstellung der Dakinschen Lösung nach Daufresne mit allen ihren Einzelheiten fand, noch nicht zur Verfügung, deshalb bereitete ich mir die Lösung zunächst nach dem von Dobbertin angegebenen Verfahren, welches im großen und ganzen mit der von Dakin selbst gegebenen Vorschrift übereinstimmt. Die so hergestellte Lösung reagierte im allgemeinen neutral, wovon ich mich mit Hilfe der Phenolphthalleinprobe überzeugen konnte. Sie wurde an dunklem kühlen Ort aufbewahrt und bei Bedarf, nach erneuter Kontrolle, in kleinen Mengen an den Operationssaal und die Station abgegeben, um eine Zersetzung der Lösung bei Licht zu vermeiden. Die Schwestern, 
welche mit der Instillation des Mittels betraut wurden, waren angewiesen, für rechtzeitigen Ersatz zu sorgen.

Die zweite Forderung, eine sorgfältige Vorbereitung der Wunde, war leicht zu erfüllen, sie deckte sich mit dem an unserer Klinik ohnehin geübten Vorgehen, bei jeder Aufmeißelung alles makroskopisch Kranke restlos zu entfernen und dabei auch das Antrum breit zu eröfnen. Wir haben, da wir operativ nur bei absolut strikter Indikation vorzugehen pflegen, gar nicht selten die Erfahrung gemacht, daß sich Einschmelzungsprozesse und erkrankte Zellen auch an der medialen und hinteren Antrumwand fanden, deren Zurücklassen bzw. Nichteröffnen $\mathrm{zu}$ weiteren unangenehmen Komplikationen hätte führen können, und waren vereinzelt bei primär nicht genügender Freilegung des Antrums durch den Wundverlauf gezwungen, das nachträglich noch zu tun. Wir führen deshalb den Eingriff stets radikal aus, ohne Rücksicht darauf, daß durch Schaffung großer Knochenwunden eventuell eine Verzögerung der Heilung bedingt sein könnte. Zur Vermeidung vielleicht entstehender und den Sterilisationsverlauf störender Nekrosen habe ich besonderen Wert darauf gelegt, die für die Freilegung des Knochens zurückgeschobenen Sehnenansätze des Musculus sterno-cleidomastoideus nach Beendigung des Eingriffs möglichst sorgfältig mit der Cooperschere zu entfernen, was manchmal, vor allem bei weitgehender Spitzenresektion nicht ganz einfach war. In einer Anzahl von Fällen habe ich überhaupt auf ein Abschieben der Sehnenstränge verzichtet und sie nur glatt mit dem Meißel soweit durchtrennt, als sie in den Operationsbereich fielen. Das Periost wurde mit einem einzügigen glatten Schnitt durchtrennt und dann sehr vorsichtig zurückgeschoben, eventuell nach vorheriger Ablösung mittels eines Elevatoriums. Subperiostale Abszesse wurden zunächst durch Stichinzision vollständig entleert, damit ihr Inhalt die später durchtrennten Weichteile nicht mehr überfluten konnte, sodann wurden ihre Wandungen mit dem scharfen Löffel und der Schere sorgfältig gesäubert und darauf geachtet, daß keine zur Nekrose neigenden Gewebsfetzen zurückblieben. Später habe ich noch, analog dem Vorgehen Fleischmanns, vor dem Anlegen der Wundhaken die Wundränder mit einer Lage sterilen Mulls abgedeckt und mich davon überzeugen können, daß dadurch eine wesentliche Schonung derselben beim Auseinanderziehen der Wunde mit den Haken erreicht wird.

Sobald bei der nun folgenden Knochenoperation Eiter erschien, wurde von demselben ein Abstrich genommen und dem hygienischen Institut zur bakteriologischen Untersuchung eingeschickt, um auch die Art der infizierenden Bakterien festzustellen, weil dadurch eventuell die Möglichkeit gegeben war, ein differentes Verhalten der verschiedenen Infektionserreger gegenüber der Dakinlösung festzustellen. Über den 
Zeitpunkt, in welchem ich mit der Carrelschen Behandlung beginnen sollte, war ich anfangs im Zweifel. Aus einer gewissen Vorsicht heraus, und weil ich mir sagte, $\operatorname{da} ß$ trotz einwandfreier Blutstillung, soweit die Weichteile in Frage kommen, die Knochengefäße weiterbluten und die Wirkung der Dakinlösung hemmend beeinflussen könnten, habe ich zunächst noch einige Zeit mit Jodoformgaze tamponiert, um auch im Knochenbereich die Hämostase abzuwarten. Genauere Angaben darüber finden sich in den Krankengeschichten der einzelnen Fälle. Außerdem hatte ich mich trotz der vielfachen Hinweise, daB bereits Peritoneal- und Hirnwunden ohne Schädigung mit der Hypochloridlösung behandelt worden waren, dazu entschlossen, zu meinen ersten Versuchen nur solche Antrotomiewunden zu verwenden, bei welchen Dura und Sinus nicht erkrankt bzw. freigelegt waren. Der Zufall war mir dabei günstig, indem die ersten nacheinander zur Operation kommenden Fälle keinerlei weitere Komplikationen darboten und eine Freilegung der Dura vermieden werden konnte. Ich ging nun so vor, daß ich ein der Größe der Knochenhöhle entsprechendes ca. Io cm langes Drain, welches im Bereich der Wunde mit mehreren seitlichen Öffnungen versehen war, ins Antrum einführte und um dasselbe herum sterile Gazestreifen bis zur völligen Ausfüllung der Wunde locker tamponierte. Durch Eingießen der auf $37^{\circ}$ erwärmten Lösung in das Drain mittels einer Spritze wurden die Tampons ausgiebig durchtränkt. Sodann wurde eine in der Mitte für das Drain durchlochte, ebenfalls stark angefeuchtete und die Haut in größerem Umkreise deckende Mullkompresse darüber gelegt und diese noch mit einer Lage trockener Verbandwatte versehen. Der ganze Verband wurde mittels Binde fixiert und dabei darauf geachtet, daß das herausragende Drain nicht abgeknickt wurde. Hierauf wurde der Kranke ins Bett gebracht und bekam nun zweistündlich - zunächst auch in der Nacht - mittels Spritze die stets angewärmte Lösung durch das Drain instilliert. Die erforderliche Menge ergab sich am besten aus der Beobachtung, ob die Flüssigkeit bei genau seitlich und horizontal gelagertem Kopf allseitig unter dem Verband hervorsickerte. Im allgemeinen genügten $15 \mathrm{ccm}$ bei der jedesmaligen Einspritzung. Die eventuell überschießende Flüssigkeit wurde mittels eines sterilen Tuches oder steriler Mullabfälle aufgesogen, um ein unnötiges Durchfeuchten des Kopfkissens zu vermeiden. Da dies nicht immer gelang, wurden späterhin schon in Hinsicht auf die große Wäschenot mit einem Tuch bedeckte wasserdichte Unterlagen benutzt, die sich als sehr zweckmäßig erwiesen haben. Alle $\mathrm{x}-2$ Tage wurde der stets gleichbleibende Verbandwechsel vorgenommen und bei dieser Gelegenheit von verschiedenen Stellen der Wunde, darunter stets aus dem Antrum und dem unteren Wundwinkel, bei subperiostalem AbszeB auch aus dessen tiefst gelegenster Nische Sekret 
entnommen und auf einen oder mehrere Objektträger verrieben zwecks mikroskopischer. Untersuchung. Die letztere erfolgte in der bereits vorher skizzierten Weise, über jeden Befund wurden Notizen geführt. Sobald der Bakterienbefund 2-3 mal hintereinander negativ war, erfolgte der sekundäre Schluß der retroaurikulären Wunde einschließlich des unteren Wundwinkels.

Bezüglich der Methode, welche ich bei diesem sekundären Verschluß befolgte, ist noch folgendes zu sagen. Die großen Vorteile, welche. einer möglichst ausgiebigen Bedeckung des Hohlraumes im Warzenfortsatz mit äußerem Periost zugeschrieben werden müssen (Lange 1. c.) ließen es ratsam erscheinen, eine möglichst weitgehende Annäherung der bei der Operation durchtrennten tieferen Schichten wenigstens zu versuchen. $Z$ u diesem $Z$ weck habe ich, nachdem als erstes eine nicht sehr weitgehende Mobilisierung des äußeren Schnittrandes durch Präparation mit dem Messer, welche ein gutes Evertieren der Epidermis möglich machen sollte, vorausgegangen war, hauptsächlich eine subperiostale Ablösung der Weichteile weit nach oben, hinten und unten, aber auch nach vorn zum proc. zygomaticus zu vorgenommen und dann zunächst diese tieferen Schichten durch zwei bis vier kräftige Katgutnähte miteinander zu vereinigen gesucht. Bei Wunden, welche zur Zeit der Naht noch nicht zu alt waren, gelang dies ohne Schwierigkeiten, bei älteren blieb in der Mitte ein schmaler Spalt bestehen, doch hatte die Annäherung schon so erhebliche Vorteile, daß ich niemals später mehr darauf verzichtet habe. Die äußere Naht erfolgt dann mit Zelluloidzwirn resp. Michelschen Klammern. Nach Verschluß der Wunde wurde noch täglich einmal mit feuchter Dakinkompresse, deren Zweck später noch zu erörtern sein wird, verbunden bis zur definitiven Heilung. Die Entfernung der äußeren Nähte erfolgte durchschnittlich am vierten Tage.

Ich lasse nun zunächst die in obiger Weise behandelten Fälle folgen. Den Zeitumständen Rechnung tragend, habe ich nur das Notwendigste dabei aufgeführt.

\section{Fall I.}

D., Anna, $50 \mathrm{~J}$., Arbeitersfrau. Aufgenommen 23. V. I9I9.

Rechtsseitige Ohreiterung seit zwei Monaten. Mastoiditis mit teigiger Infiltration der Weichteile über dem Warzenfortsatze. Außerdem hochgradige Otitis diffusa externa mit völliger Verengung des Gehörgangs. Antrotomie am 30. V. I919. Durchbruch der Corticalis an der hinteren Grenze der Fossa mast. Sämtliche Zellen und Antrum mit graurötlichen schlaffen Granulationen und serös eitrigem Sekret angefüllt. Ausgiebigste Resektion alles Krankhaften, so daß eine sehr große Operationshöhle entsteht. Keine Freilegung vón Dura und Sinus. Jodoformgazetamponade, Okklusivverband.

Bis zum 13. VI. ständig. Jodoformgazetamponade. Dabei Wundreaktion außerordenttich gering, kaum Granulationsbildung. Otitis externa unverändert. Einleitung der Carrelbehandlung.

26. VI. Unter dem Einfluß der Dakinlösung hat sich die ganze Wunde mit 
schönen, frischen Granulationen bedeckt. Das Wundsekret, welches bei Einleitung der Carrelbehandlung noch sehr reichlich war und zahlreiche Bakterien der verschiedensten Art enthielt, ist immer spärlicher geworden, die Bakterienzahl hat ständig abgenommen, seit drei Tagen sind im mikroskopischen Präparat keine Bakterien mehr nachweisbar. Deshalb heute Sekundärverschluß einschließlich des unteren Wundwinkels.

30. VI. Entfernung der Nähte. Wunde bis auf den unteren Wundwinkel primär verheilt, völlig trocken. Der letztere klafft I cm weit, doch besteht keinerlei Absonderung. Patientin ist beschwerdefrei, Wundverlauf völlig fieberlos.

3. VII. Retroaurikuläre Wunde vollkommen verheilt, tadellose glatte, nur ganz leicht eingezogene Narbe.

Dauer 34 Tage, seit Beginn der Carrelbehandlung 20 Tage.

Epikrise: Dieser Fall schien mir anfangs wegen der bestehenden recht unangenehmen Gehörgangskomplikation, welche infolge versehentlichen Eingießens einer Io\%igen Argentumlösung in denselben sich entwickelt hatte, für den ersten Versuch nicht geeignet, ich entschloß mich aber schließlich doch dazu, weil die Wunde noch nach I tägiger Jodoformgazetamponade ein schlechtes Aussehen zeigte und nur sehr mangelhaft granulierte, und weil der Dakinlösung neben ihrer antibakteriellen auch gerade eine lebhafte Granulation anregende Wirkung zugeschrieben wurde. Da sich zudem mikroskopisch auch noch zahlreiche Bakterien fanden, ließ sich eventuell der Einfluß nach beiden Richtungen erproben. Das Ergebnis war in der Tat ein überraschendes. Fast von einem Tag zum andern änderte sich das Bild der Wunde, überall schossen frische, blutstrotzende Granulationen auf, nach wenigen Tagen schon war die ganze Wundfläche davon bedeckt und nirgends mehr bloßliegender Knochen sichtbar. Die Bakterienzahl nahm zuerst rapide, dann etwas langsamer $a b$, elf Tage nach Beginn der Behandlung waren mikroskopisch keine Keime mehr nachzuweisen. Zur Sicherheit wartete ich noch drei Tage ab, und als danach der Bakterienbefund negativ geblieben war, schloß ich die Wunde. Vier Tage später war sie bis auf etwa I cm des unteren Wundwinkels primär verheilt, der letztere schloß sich in weiteren drei Tagen.

Demnach betrug die Gesamtdauer von der Operation bis zur Heilung 34 Tage. Rechnet man die ersten I4 Tage nicht mit, wozu insofern eine gewisse Berechtigung besteht, als die Wunde nach dieser Zeit sich kaum verkleinert hatte und noch reichlich infiziert war, so würde die Heilungsdauer der sehr großen Antrotomiewunde sich auf 20 Tage belaufen. Nach dem Verlauf kann kein Zweifel darüber bestehen, daß das erstrebte Ziel, die Sterilisation der Wunde, wirklich erreicht wurde. Auch der günstige Einfluß der Dakinlösung auf die Granulationsbildung war unverkennbar.

Der weitere Aufenthalt der Patientin in der Klinik war bedingt durch die diffuse Otitis externa, die jedoch auch schlieBlich unter 
Behandlung mit Salbenbougies ohne Stenosenbildung zur Ausheilung kam.

\section{Fall 2.}

Sch., Marta, Rechnungsratsfrau, 52 J. Aufgenommen 30. VI. I9I9.

Rechtsseitige akute Mittelohrentzündung seit drei Wochen. Trotz Parazentese des Trommelfells und regelmäßiger konservativer Behandlung Auftreten mastoidaler Erscheinungen und Senkung der hinteren oberen Gehörgangsauskleidung, Temperaturerhöhung bis 37,5, deshalb am 8. VII. Antrotomie: Corticalis $1 / 2 \mathrm{~cm}$ dick, sklerotisch. Zellen mit serös eitrigem Sekret angefüllt, Schleimhaut verdickt. In der Nähe des Sulcus transversus finden sich mehrere größere Zellen mit rahmigem Eiter, doch ist der Sinus nirgends erreicht und wird ebenso wie Dura nicht freigelegt. Nach Resektion alles Krankhaften Jodoformgazetamponade, Okklusivverband.

II. VII. Im Wundsekret reichlich Streptokokken, sowohl mikroskopisch wie kulturell. Einleitung der Carrelbehandlung.

I4. VII. Tamponwechsel. Gehörgang trocken. Wunde sieht sehr frisch aus. Im Wundsekret heute keine Bakterien mehr nachweisbar. Fieberloser Verlauf.

17. VII. Wundsekret auch gestern bakterienfrei, deshalb heute Sekundärverschluß.

22. VII. Entfernung der Nähte. Wunde primär verheilt, trocken, keine Sekretretention.

26. VII. Geheilt mit reizlosem Trommelfell und glatter Narbe entlassen. Flüstersprache $5 \mathrm{~m}$

Heilungsdauer 14 Tage (davon drei Tage Jodoformgazetamponade.

Epikrise: Der Erfolg in diesem Falle war noch augenscheinlicher. Trotzdem mit Rücksicht darauf, daß die Kranke als Privatpatientin in der Klinik lag, die Instillation der Dakinlösung nachts nur einmal vorgenommen war, fanden sich schon beim ersten Tamponwechsel keine Bakterien mehr im Wundsekret. An den folgenden Tagen ergab sich der gleiche negative Befund, weshalb ich schon am sechsten Tage nach Einleitung der Behandlung die Wunde schließen konnte Auch hier primäre Heilung ohne Sekretretention in der Wundhöhle, so daß die Patientin am I8. Tag p. o. nach Hause entlassen werden konnte. In kosmetischer Beziehung war das Resultat geradezu ideal.

Da die beiden ersten Fälle so vielversprechend verlaufen waren und insbesondere die Patienten die Behandlung ohne die geringsten Beschwerden und Reizerscheinungen vertragen hatten, entschlo $B$ ich mich nunmehr zu dem Versuche, mit derselben sofort nach der Operation $\mathrm{zu}$ beginnen, in der Hoffnung, daß dadurch die Sterilisation noch schneller gelingen würde.

$$
\text { Fall } 3 \text {. }
$$

J., Rosa, Arbeitersfrau, 4I J. Aufgenommen am I8. IX. I9I9.

Rechtsseitige Ohreiterung seit fünf Wochen. Profuser rahmig-eitriger Ausfluß. Senkung der hinteren:oberen Gehörgangswand. Starke Druckempfindlichkeit der Warzenfortsatzspitze. Schlechtes Allgemeinbefinden, reduzierter Ernährungszustand, aber kein Fieber. Da auf konservative Behandlung 
die mastoidalen Erscheinungen noch zunahmen, insbesondere die Weichteile hinter dem Ohr beginnende Infiltration zeigten, am 25. IX. Antrotomie.

Knochen an der Spitze grauverfärbt. In der Fossa mast. erbsengroßer Durchbruch, aus welcher unter Druck dickrahmiger Eiter herauspulsiert. Nach dem Gehörgang zu zweiter, etwas größerer Durchbruch. Zellen zum größten Teil eingeschmolzen, Sinus an kleiner Stelle erreicht, so daß er in $11 / 2 \mathrm{~cm}$ Länge freigelegt werden muß. Warzenfortsatzspitze wird zum größten Teil reseziert. Entfernung alles Krankhaften, sofortige Einleitung der Carrelbehandlung.

26. IX. Der Versuch, die Dakinlösung zweistündlich ungewärmt mittels Irigators zuzuführen, mißlingt. Patientin bekommt sofort Schwindel und starken Nystagmus. Die Behandlung wird deshalb in der früheren Weise mittels Eingießens erwärmter Lösung durchgeführt.

29. IX. Behandlung wird jetzt gut vertragen. Beschwerden haben völlig nachgelassen, Allgemeinbefinden und Aussehen der Patientin wesentlich gebessert. Kein Fieber. Wunde sieht gut aus, zeigt bereits an vielen Stellen Granulationen. Einige nekrotische Sehnenfetzen am unteren Wundwinkel werden mit der Schere entfernt. Im Wundsekret noch ziemlich reichlich Streptokokken.

2. X. In jedem Gesichtsfeld noch vereinzelte Bakterien.

5. X. Einzelne Bakterien nur noch in jedem fünften Gesichtsfeld.

9. X. Gestern und heute keine Bakterien mehr nachweisbar. Da der Verlauf völlig fieberfrei war, der Gehörgang trocken ist und die Wunde außerordentlich frisch und schön aussieht, heute Sekundärverschlu $B$.

I4. X. Entfernung der Nähte, Wunde völlig trocken, ist primär verheilt. Keinerlei Beschwerden, nicht die greingste Sekretverhaltung. Trommelfell blaß. Flüstersprache bds. $6 \mathrm{~m}$.

Heilungsdauer 19 Tage.

Epikrise: Im vorliegenden Fall hatte ich versucht, die von Carrel für die intermittierende Behandlung angegebene Apparatur anzuwenden, indem ich dazu den beim Tropfcheneinlauf üblichen Flüssigkeitsbehälter benutzte. Der letztere war mit Dakinlösung gefüllt (ca. I Liter), der Gummischlauch mit Mohrscher Klemme abgeklemmt und am Ende mit einem weiten Paukenröhrchen versehen, welches in das Wundröhrchen gut hineinpaßte. Natürlich hatte die Lösung nur Zimmertemperatur, ein Erwärmen vor der jedesmaligen Einspritzung war technisch nicht gut möglich. Meine wenn auch geringe Hoffnung, daß die Patientin die nur kleine Flüssigkeitsmenge unter Körpertemperatur vielleicht vertragen würde, ohne Schwindelerscheinungen oder $\mathrm{Ny}$ stagmus zu bekommen, wodurch die ganze Applikation wesentlich vereinfacht worden wäre, erwies sich als trügerisch. Im Gegenteil traten diese Erscheinungen außerordentlich schnell auf und waren recht erheblich, weil ja der unter relativ hohen Druck selbst bei $1 / 2 \mathrm{~m}$ Fallhöhe einschießende Flüssigkeitsstrahl direkt auf den freiliegenden horizontalen Bogengang traf. Ich habe deshalb diese Anordnung sofort wieder aufgegeben und bin zu der Eingießung mittels Spritze nach vorheriger Anwärmung der Lösung auf $37^{\circ}$ zurückgekehrt.

$\mathrm{DaB}$ hier vier Tage nach Beginn der Behandlung noch reichlich 
Streptokokken vorhanden waren, möchte ich auf das Zurückbleiben der Sehnenansätze zurückführen, zumal sich auch die Bakterien besonders in dem dieser Stelle entnommenen Ausstrich fanden. Nach Entfernung der nekrotischen Fetzen nahm der Bakterienbefund progressiv ab bis zum Verschwinden. Auch in diesem Falle erfolgte glatte ungestörte Heilung in I9 Tagen mit vorzüglichem kosmetischem Resultat.

Patientin stellte sich I4 Tage und vier Wochen nach der Entlassung nochmals vor. Nie sind auch in der Folge die geringsten Störungen aufgetreten.

\section{Fall 4 .}

R., Otto, II J. Aufgenommen 4. XI. 1919.

Wird mit rechtsseitiger akuter Mittelohreiterung und Infiltration der Weichteile über dem rechten Warzenfortsatz eingeliefert. Auf dem Trommelfell Blutblasen. Einige Tage konservative Behandlung, dann am Io. XI. wegen Zunahme der Erscheinungen seitens des Warzenfortsatzes Antrotomie:

Durchbruch an der Warzenfortsatzspitze. Muskulatur und Weichteile in der Umgebung mißfarben und infiltriert. Sinus vorgelagert, wird in $1 \mathrm{~cm}$ Länge freigelegt, Wand gesund. Sämtliche Zellen mit zähem Schleimeiter angefüllt, große Terminalzelle. Gründliche Ausräumung mit brẹter Eröffnung des Antrums, in welchem sich Granulationen befinden. Sofortige Einleitung der Carrelbehandlung.

I3. XI. Verbandwechsel: Ziemlich starke Absonderung dünnflüssigen, fadenziehenden Sekretes. Abstrich zeigt in jedem Gesichtsfeld mehrere Diplokokken.

20. XI. Sekretion sehr gering. Wundhöhle überall gleichmäßig mit frischroten Granutationen angefüllt. Im Sekretausstrich in jedem zweiten bis dritten Gesichtsfeld vereinzelte Diplokokken (Pneumokokken). Gehörgang trocken, im Trommelfell hirsekorngroße trockene Perforation.

25. XI. Gestern und heute negativer Bakterienbefund, deshalb heute Sekundärnaht (vollständig).

29. XI. Entfernung der Nähte, Wunde völlig trocken und reizlos. Wegen geringer Sekretverhaltung Eröffnung des unteren Wundwinkels mit der Pinzette und Einlegen eines kurzen dünnen Drains.

2. XII. Sekretion hat aufgehört, Drain fortgelassen.

5. XII. Wunde reaktionslos verheilt, Ohr trocken, Verband fällt fort. (Vgl. Abb. r.)

10. XII. Im Anschluß an einen akuten Schnupfen ist erneute schleimige Absonderung aus dem Gehörgang aufgetreten. Spülung, Politzer, Borsäurebehandlung.

I3. XII. Der unterste Teil der bereits geschlossenen Operationsnarbe hinter dem Ohr ist in I cm Länge wieder aufgebrochen und sondert ab. Sekretion aus der Pauke hat dagegen nachgelassen. Jodoformgazetamponade.

20. XII. Kaum noch Absonderung. Wunde hinter dem Ohr verkleinert sich allmählich.

I. I. 1920. R. Ohr trocken. Perforation im Trommelfell stecknadelkopfgroß. Die kleine Wunde hinter dem Ohr annähernd geschlossen.

5. I. I920. Wunde verheilt. Ohr trocken. Flüstersprache rechts $3 \mathrm{~m}$, links $6 \mathrm{~m}$ und $\mathrm{mehr}$.

6. I. I920. Geheilt entlassen. Heilungsdauer 25 Tage. 
Epikrise: Der Fall verlief zunächst völlig wunschgemäB, die Wunde war nach I3 Tagen bakterienfrei geworden, wurde geschlossen und heilte auch anstandslos, denn die geringfügige Sekretverhaltung am unteren Wundwinkel war ohne Bedeutung. Leider kam es dann im Anschluß an einen frisch acquirierten Schnupfen auf tubarem Wege $z u$ einer Neuinfektion nicht nur der Pauke sondern auch der Wundhöhle. Die Folge war, daß Sekretion auftrat, die Narbe am unteren Winkel wieder aufbrach und hier noch eine Zeitlang Absonderung bestehen blieb. Ich glaube, daB man hier ohne weiteres von einer Neuerkrankung sprechen kann, welche mit der ersten, zur. Heilung gekommenen Affektion nicht mehr in ursächlichem Zusammenhang steht und deshalb auch für die Beurteilung des auch in diesem Falle erzielten Erfolges irrelevant ist. Aus der Anamnese ergab sich, daB der Patient sehr häufig an Mittelohreiterung gelitten hat, die wohl durch einen besonders günstigen tubaren Infektionsweg bedingt waren. Wenn man die geschilderten Verhältnisse berücksichtigt, kann man die tatsächliche Heilungsdauer auf 25 Tage beziffern.

\section{Fall 5.}

H., Willi, $46 \mathrm{~J}$. Aufgenommen 20. XI. I919.

Anamnese: 1917 im Felde durch Minenexplosion Ruptur beider Trommelfelle. Keine Ohreiterung. Seitdem viel Kopfschmerzen. Seit 14 Tagen ohne besondere Ursache linksseitiges Ohrlaufen. Aufnahmebefund: Großer mäßig genährter Mann von leicht ikterischem Aussehen. Temp. 39. Schmerzen an der linken Halsseite. Bei Kopfbewegungen auch Schmerzen im Hinterkopf. Innere Organe o. B., ebenfalls Urin.

Nervenstatus: Kein pathologischer Befund, insbesondere kein Kernig und keine Nackensteifigkeit.

Puls 76. Schläge p. M.

Rechtes Ohr: Große zentrale Perforation, trocken.

Linkes Ohr: Reichlich rahmiger Eiter. Große nierenförmige Perforation, nicht randständig. Warzenfortsatz druckempfindlich.

24. XI. Dauernd starke halbseitige Kopfschmerzen, deshalb nachts kaum Schlaf. Nervenstatus o. B. Temperatur auf die Norm heruntergegangen, Puls um 60 herum. Mit Rücksicht auf die dauernden Beschwerden Operation.

Antrotomie links.

Der größte Teil des Warzenfortsatzes enthält nur ödematöse Schleimhaut, ein Einschmelzungsproze 3 findet sich nur an der Spitze mit kleinem Durchbruch in die Fossa digastrica, hier auch freier Eiter. Im Antrum Granulationen. Nach sorgfältiger Ausräumung alles Kranken Tamponade zur Carrelbehandlung. kokken.

26. XI. Im Warzenfortsatzeiter mikroskopisch und kulturell Strepto-

28. XI. Wunde sieht sehr gut aus, an keiner Stelle Eiter.

I. XII. Bei Untersuchung zahlreicher Gesichtsfelder mikroskopisch nur an einer Stelle Streptokokken nachweisbar.

4. XII. Wegen der dauernden Kopfschmerzen, die seit der Operation noch in keiner Weise nachgelassen haben, Lumbalpunktion. Ergebnis: DruckI40-I50 mm, Reaktionen absolut normal. Leukozytenzählung (Blut): 8300. 
8. XII. Trotzdem schon seit mehreren Tagen Bakterien im Wundsekret nicht mehr nachgewiesen werden konnten, wurde mit Rücksicht auf die ständig in der linken Scheitelgegend lokalisierten heftigen Schmerzen, welche eine intrakranielle Komplikation vermuten ließen, von dem Sekundärverschluß der Wunde Abstand genommen.

I2. XII. Nachoperation. Freilegung der mittleren und hinteren Schädelgrube in großer Ausdehnung. Dura der ersteren wölbt sich stark vor und pulsiert nicht. Mehrere Punktionen des Schläfenlappens negativ, Aspiration normal aussehender Hirnzylinder.

15. XII. Es ist eine allmählich zunehmende Trübung des Sensoriums eingetreten. Lumbalpunktion ergibt heute trüben Liquor mit zahlreichen weißen Blutzellen. Bei der erneut vorgenommenen Hirnpunktion findet sich ein Schläfenlappenabszeß von etwa Pflaumengröße.

I8. XII. Unter den Zeichen fortschreitender Meningitis Exitus letalis.

Epikrise: Der erstrebte Erfolg, die Sterilisation der Antrotomiewunde wurde auch hier erreicht, doch konnte dieselbe wegen der stets. vermuteten und schlieBlich auch" aufgefundenen intrakraniellen Komplikation nicht ausgenutzt werden.

\section{Fall 6.}

J., Kurt, 23 J., Landwirt. Aufgenommen I6. XII. I9I9.

Seit Mitte November rechtsseitige Ohrenschmerzen, seit Ende November akute Mittelohreiterung.

Auf konservative Maßnahmen zunächst Nachlassen der Eiterung, dann seit IO. XII. wieder Zunahme. Temperatur bis $38^{\circ}$. Warzenfortsatzspitze leicht druckempfindlich. Bei Aufnahme in klinische Behandlung I6. XII. besteht auf dem rechten Ohr profuse Eiterung. Trommelfell stark verdickt und vorgewölbt, im hinteren Teil stecknadelknopfgroße Perforation. Warzenfortsatzspitze stark druckschmerzhaft. Weichteile hinter dem Ohr o. B. Zunächst noch Behandlung mit Eis und den üblichen Mitteln. Als daraufhin keine Änderung eintrat, am

23. XII. Antrotomie.

Knochen äußerlich o. B. Warzenfortsatz in großer Ausdehnung eitrig eingeschmolzen, große mit Eiter gefüllte Spitzenzelle. Resektion der ganzen Spitze und Ausräumung aller erkrankten Zellen. Antrum mit Granulationen ausgefüllt. Sinus und Dura werden nicht freigelegt. Nach Beendigung des. Eingriffs sofort Tamponade zur Carrelbehandlung.

26. XII. Tamponwechsel. Wunde sieht frisch aus. Keine Temperatur, keine Beschwerden. Im Abstrich des Wundsekrets finden sich mäßig reichlich Bakterien.

2. I. I920. Völliges Wohlbefinden, normale Temperatur. Im Wundsekret heute keine Bakterien mehr nachweisbar. Mittelohr trocken.

5. I. I920. SekundärverschluB.

7. I. I920. Keine Temperatur, keine Beschwerden. Nahtlinie reaktionslos, Gehörgang trocken.

9. I. I920. Naht und angrenzende Weichteile vorgewölbt, doch fehlt jede entzündliche Infiltration. Aus den Stichkanälen entleert sich bei Druck dünnflüssiges, gelbliches, ganz klar aussehendes Selkret in ziemlicher Menge, das aber mikroskopisch keine Bakterien enthält. Es wird durch leisen Druck völlig durch die Stichkanäle entleert. Irgendwelche Störung im Befinden besteht nicht, auch keine Temperatur. 
I I. I. I920. Sekretansammlung unter der Nahtlinie nicht mehr aufgetreten, es entleert sich auch bei Druck keine Flüssigkeit mehr. Nahtlinie reaktionslos verheilt. Entfernung der Nähte.

I5. I. I920. Bis heute keine Veränderung mehr. Es besteht eine tadellose glatte Narbe ohne jede Einziehung. Trommelfell blaß, Perforation geschlossen. Flüstersprache $6 \mathrm{~m}$. Entlassen.

29. I. I920. Kontrolle. Keine Störung aufgetreten. Patient fühlt sich vollkommen gesund, geht seit I4. Tagen ohne Beschwerden seinem Berufe nach.

Dauer i9 Tage.

Epikrise: In diesem Falle wurde nach sonst einwandfreiem und wunschgemäßem Verlauf zum ersten Male bei vollständigem Verschluß der retroaurikulären Wunde eine Sekretstauung in der Operationshöhle beobachtet, welche eine Vorwölbung der Weichteile im Gefolge hatte. Von Bedeutung scheint mir jedoch zu sein, daß das Sekret, wie es hier gebildet war, sich von Eiter sehr wesentlich unterschied. Es war ganz dünnflüssig, bernsteingelb, sah vollständig klar aus und enthielt bei mikroskopischer Untersuchung keine Bakterien. Diesem Befund entsprach auch, daß jedes Symptom einer entzündlichen Reizung, wie Fieber, Weichteilinfiltration, Störung des Allgemeinbefindens oder gar Labyrintherscheinungen, völlig fehlte. Ein sanfter Druck auf die vorgewölbten Weichteile genügte, um die angesammelte Flüssigkeit durch die Stichkanäle zu entleeren, so daß die Wiedereröffnung der fest verklebten Wunde unnötig war. Auffallenderweise war der weitere Verlauf ganz ungestört, mit der einmaligen Entleerung kam die Absonderung zum Stillstand und der Fall in I9 Tagen zur vollständigen, idealen Heilung.

Die Möglichkeit, daß es sich bei der Sekretstauung in diesem Falle um die Auswirkung einer etwa noch bestehenden Infektion gehandelt hat, kann meines Erachtens mit ziemlicher Sicherheit ausgeschlossen werden. Die Beschaffenheit der abgesonderten Flüssigkeit, ihre Keimfreiheit und das Fehlen jeglicher Entzündungserscheinungen sprechen absolut dagegen. Aus dem gleichen Grunde kommt auch eine Sekundärinfektion durch vielleicht nicht einwandfreies Nahtmaterial nicht in Frage. Ein Reizmoment muß aber doch vorhanden gewesen sein, welches als Ursache für die Sekretbildung verantwortlich zu machen ist, und als solches möchte ich die Alteration der Wunde ansehen, wie sie sich bei der Vornahme des Sekundärverschlusses nun einmal nicht vermeiden läßt, zumal nicht bei einer so weitgehenden subperiostalen Ablösung der Weichteile, die ich aus bereits erwähnten Gründen für zweckmäßig halte. Die Tatsache, daß die ersten vier Fälle Symptome einer solchen Sekretbildung vermissen ließen, spricht nicht dagegen, denn abgesehen davon, daß die einzelnen Individuen sehr verschieden auf einen derartigen Eingriff reagieren können, kann ja auch bei ihnen ein derartiger seröser ,Erguß“, wie ich ihn nennen möchte, vorhanden ge- 
wesen sein, ist aber vielleicht nur gering gewesen und bald wieder resorbiert worden. Immerhin hat mich diese Beobachtung zur Vorsicht gemahnt, und deshalb habe ich, trotzdem ich in dem gelegentlichen Auftreten einer geringfügigen Stauung, sofern das Sekret steril ist, keine wesentliche Gefahr sehe, in den späteren Fällen am unteren Wundwinkel ein feines Gummidrain eingeschoben von einer solchen Länge, daß es bis in die Knochenhöhle hineinreichte. Durch diese sehr einfache Maßnahme, welche ich jederzeit unterbrechen konnte, wenn sich herausstellte, daß die Sekretion aufhörte oder überhaupt fehlte, war ich vor Stauungserscheinungen gesichert und'konnte sehr bald feststellen, daß die Drainage auf das definitive kosmetische Resultat nicht den geringsten Einfluß hatte. Ich empfand es sogar als sehr angenehm, daß der feine Drainkanal die Durchspülung der Wunde mittels Paukenröhrchens bei jedem Verbandwechsel ganz wesentlich erleichterte.

Fall 7.

B., Martha, 2 I J., Stütze. Aufgenommen 22. II. 1920.

Seit acht Tagen Ohrschmerzen und akute Eiterung links im Anschluß an Grippe.

Bis 24. III. nach Parazentese konservative Behandlung, durch welche jedoch die Eiterung nicht beeinflußt wurde. Seit heute Infiltration der Weichteile über dem Warzenfortsatz und starke Druckempfindlichkeit, deshalb

24. III. Antrotomie. Warzenfortsatz äußerlich o. B. Zellen sämtlich mit Eiter angefüllt, große Spitzenzelle, deshalb Resektion dèr Spitze. Sulcuswand in geringer Ausdehnung ( $\mathrm{Icm}$ ) eingeschmolzen, Sinus hier mit Granulationen bedeckt. Freilegung bis ins Gesunde. Im Antrum Granulationen. Breite Eröffnung. Nach gründlicher Ausräumung alles Krankhaften und Säuberung übliche Versorgung der Wunde zur Carrelbehandlung. Im Warzenfortsatzeiter Streptokokken (Hyg. Institut).

3I. III. Nach zunächst zweitägigem, später täglichem Verbandwechsel zeigt die Wunde bereits überall frische Granulationen von gutem Aussehen. Im Abstrich noch Bakterien.

I3. IV. In den letzten beiden Abstrichen keine Bakterien mehr nachweisbar. Wundverlauf völlig afebril. Heute Sekundärnaht.

15. IV. Naht sieht gut aus, doch entleert sich aus dem unteren Wundwinkel etwas schleimiger Eiter (mikroskopisch ohne Bakterien).

I8. IV. Absonderung aus dem unteren Wundwinkel hat aufgehört. Naht reizlos. Entfernung der Fäden. Gehörgang trocken.

26. IV. Trommelfell blaß, Wunde hinter dem Ohr glatt verheilt. Keine Sekretretention nachweisbar.

Patientin wurde noch bis 3. V. unter Beobachtung gehalten, es traten jedoch keinerlei Störungen auf. Entlassung mit normaler Hörfähigkeit auf beiden Ohren.

Dauer 33 Tage.

Epikrise: Trotzdem hier die Behandlung mit der Dakinlösung unmittelbar post operationem einsetzte, hat es 18 Tage gedauert, bis die Bakterien aus dem Wundsekret verschwunden waren. Ich habe die Behandlung dieser Patientin während der ersten Zeit nicht selber 
leiten können, da ich beurlaubt war, finde aber in meinen Aufzeichnungen unter dem 6. 4., daß bei Verbandwechsel die Tampons vollkommen trocken waren. Daraus war zu entnehmen, daB die Behandlung nicht richtig durchgeführt sein konnte, und in der Tat ergaben die Nachforschungen die Richtigkeit dieser Annahme. Es stellte sich heraus, daB seit dem I. IV. neue Hilfsschwestern auf der Station tätig waren, welche in Unkenntnis der Methode die Instillationen in völlig ungenügender Weise vorgenommen hatten. Ich sehe sowohl nach den voraufgegangenen wie späteren Erfahrungen hierin den Grund, warum die Sterilisierùng sich in diesem Falle so auffallend in die Länge gezogen hat.

Fall 8.

Sch., Ilse, I9 J. Aufgenommen 7. IV. 1920.

Anamnese: Seit vier Wochen nach Grippe rechtsseitige Ohreiterung. Seit der gleichen Zeit heftige, über den ganzen Kopf ausstrahlende Schmerzen.

Befund: Rechtes Ohr: Rahmige Eiterung. Weichteile hinter dem Ohr stark infiltriert, anscheinend kleiner subperiostaler Abszeß. Starke Druckempfindlichkeit des Warzenfortsatzes.

7. IV. Antrotomie. Nach Abschieben der Weichteile zeigt sich der hintere Teil der Spitze eingeschmolzen. Der ganze Knochen ist mit eiterhaltigen Zellen durchsetzt, die sich besonders weit nach dem Bulbus zu erstrecken, so daß Resektion der ganzen Spitze notwendig ist. Sinus in Pfennigstückgröße mit schwartig verdickter Wand freiliegend, wird bis ins Gesunde aufgedeckt. Im Antrum derbe, leicht blutende Granulationen. Breite Eröffnung. Nach Säuberung und Revision Jodoformgazetamponade.

13. IV. Seit Operation Wohlbefinden und normale Temperatur. Wunde zeigt gutes Aussehen und beginnende Granulation. Aus der Bulbusgegend etwas reichlichere Sekretion.

16. IV. In den drei letzten Tagen infolge Angina erhöhte Temperatur, die aber heute zur Norm abgefallen ist. Wunde sieht gut aus. Im Wundsekret vereinzelte Bakterien nachweisbar. Übergang zur Behandlung mit Dakinlösung.

20. IV. Wunde zeigt tadellose Verhältnisse. Bakterien in Sekret heute nicht mehr nachweisbar.

22. IV. Wie 20. IV., deshalb heute Sekundärverschluß, kleines Drain im unteren Wundwinkel.

27. IV. Nach fieber- und beschwerdelosem Verlauf Entfernung der Nähte. Wunde bis auf eine ca. I cm lange Stelle im Bereich des oberen Drittels und bis auf die Drainöffnung primär verheilt. Aus der Wundhöhle Spur seröseitrige Absonderung.

28. IV. Absonderung so minimal, daß das Drain fortgelassen werden kann.

30. IV. Wunde in ganzer Ausdehnung verheilt, keine Sekretretention.

4. V. Auch bis jetzt keine Sekretverhaltung beobachtet. Sehr schöne Narbe, Trommelfell blaß. Beschwerdefrei nach Hause entlassen.

Dauer 23 Tage.

Fall 9.

B., Hilde, 5 J. Aufgenommen 28. VI. 1920.

Seit drei Tagen linksseitige Ohrenschmerzen, seit zwei Tagen allmählich zunehmende Anschwellung hinter dem linken Ohr. 
Befund: Teigige Infiltration über dem Warzenfortsatz. Senkung der hinteren oberen Gehörgangswand.

5. VII. Da sich hinter dem Ohr ein deutlicher subperiostaler Abszeß ausgebildet hat, die übrigen Erscheinungen keine Veränderungen aufweisen und leichtes Fieber besteht, heute Antrotomie.

Entleerung des subperiostalen Abszesses durch Stichinzision. Corticalis an kleiner Stelle fistulös durchbrochen. Knochen des Warzenfortsatzes zum größten Teil eingeschmolzen, die Höhle mit Granulationen und Eiter gefüllt. Antrum wird breit aufgedeckt, Zellen in Gegend des Ursprungs des Processus zygomaticus und der Warzenfortsatzspitze erkrankt. Fortnahme alles Kranken, Entfernung der nekrotischen Partien der Abszeßhöhle, bis eine glatte, einwandfreie Wunde vorliegt. Übliche Wundversorgung zur Carrelbehandlung.

7. VII. Erster Verbandwechsel, da das Kind sich das Drain herausgezogen hatte. Wunde sieht überall gut aus, teilweise sind schon frische Granulationen erkennbar. Übliche Wundversorgung nach Entnahme eines Abstriches. Wohlbefinden, keine Temperatur. Im Abstrich vereinzelt Streptokokken.

Io. VII. Wunde sah beim heutigen Verbandwechsel weiter sehr gut aus. Mikroskopische Untersuchung des Wundsekrets ergibt keine Bakterien, Kultur steril.

13. VII. Der aus äußeren Gründen verschobene Verschlui\} wird, nachdem auch der gestrige Abstrich keinerlei Bakterien enthält, heute vorgenommen.

I6. VII. Verbandwechsel, Wunde sieht gut aus, ganz geringe Sekretion aus dem unteren Wundwinkel. Entfernung der Nähte. Wohlbefinden, keine Temperatur.

I7. VII. Drain fortgelassen.

I9. VII. Wunde hinter dem Ohr verheilt, völlig trocken. Trommelfell blaß. Wohlbefinden, keinerlei Temperatur.

22. VII. Temperaturanstieg auf 39, deshalb Entlassung heute nicht möglich. Verband seit zwei Tagen nicht mehr nötig. Typische Angina lacunaris.

27. VII. Vollkommenes Wohlbefinden. Angina abgeheilt.

30. 7. Patientin wird heute entlassen. Dauer I4 Tage.

Epikrise zu Fall 8 und 9: Úber den Verlauf dieser beiden Fälle ist nicht viel zu sagen, die Sterilisation der Wunden erfolgte außerordentlich schnell, nachdem die Carrelsche Behandlung eingesetzt hatte. Im Fall 8 tamponierte ich zunächst noch acht Tage lang mit Jodoformgaze, weil ich die Befürchtung hatte, daß von seiten des Sinus bzw. Bulbus noch Komplikationen eintreten könnten oder bereits vorhanden waren. Erst nachdem dies durch den Verlauf ausgeschlossen werden konnte, ging ich zur Behandlung mit der Dakinlösung über.

Im Fall 9 habe ich neben der mikroskopischen jedesmal eine kulturelle Untersuchung des. Wundsekretes vornehmen lassen, um festzustellen, ob bei Fehlen der Bakterien in Präparat auch kulturell kein Wachstum mehr zu finden sei. Es ergab sich hierbei eine völlige Übereinstimmung.

Die beiden Fälle kamen in 23 bzw. I4 Tagen zur Heilung.

Fall Io.

B., Hertha, io J. Aufgenommen 6. VII. I920.

Mit typischer Mastoiditis nach akuter Mittelohreiterung eingeliefert. 
Schwerkrankes Aussehen. Temp. 38,5. Intern kein Krankheitsbefund. Schiefhaltung des Kopfes nach links. Fluktuierender Abszeß und starke Weichteil. infiltration hinter dem Ohr. Infiltration des Sternokleidoansatzes. Ödem reicht bis zum Processus zygomaticus. Im Gehörgang massenhaft rahmiger Eiter. Trommelfell gerötet, infiltriert und hinten oben vorgewölbt.

Parazentese.

8. VII, Profuse Sekretion. Schwellung hinter dem ohr hat noch zugenommen. Antrotomie.

Außerordentlich großer subperiostaler Abszeß. Sämtliche Zellen mit leicht blutenden Granulationen und serös-blutigem Exsudat angefüllt. Sinus liegt in Bohnengröße frei, bei der Erweiterung der Lücke zeigt sich seine Wand vom oberen Knie bis in die Nähe des. Bulbus und die angrenzende Dura zum teil mit Granulationen, zum teil mit speckig aussehenden Belägen bedeckt. Großer Sekundärschnitt nach hinten. Nach dem Bulbus zu war es nicht möglich, auf ganz einwandfrei aussehende Sinuswand zu kommen. Punktion ergab flüssiges Blut. Sofortige Einleitung der Carrelbehandlung.

10. VII. Verbandwechsel. Wunde sieht frisch und gut aus. Nirgends Eiter. Temperatur bis heute auf die Norm abgefallen. Das bei der Operation entnommene Sekret enthielt Streptokokken.

I2. VII. Verbandwechsel. Das beim ersten Verbandwechsel entnommene Wundsekret erwies sich bereits kulturell als steril, ebenso das Sinusblut. Im heutigen Abstrich mikroskopisch keine Bakterien mehr. Im Bereich der erkrankten Sinuswand und der Dura schöne frische Granulationen. Temperatur dauernd normal, Wohlbefinden.

I5. VII. Wundsekret ständig bakterienfrei, deshalb heute Sekundär : verschluß. An der Abgangsstelle des Sekundärschnittes bleibt eine kleine Öffnung bestehen.

19. VII. Nähte haben gehalten. Nur in der Mitte besteht eine etwa I cm lange und $1 / 2 \mathrm{~cm}$ breite Lücke. Fieberfrei, Wohlbefinden.

23. VII. Wunde bis auf den kleinen Trichter verheilt, aus dem letzeren keine Sekretion.

30. VII. Der kleine Wundtrichter hat sich mit Granulationen gefullt. Bei Druck auf die Umgebung kommt jedoch ein Eitertröpfchen aus der Tiefe. Einschieben eines feinen Streifchens. Kein Fieber, keine Beschwerden.

3. VIII. Beffund seit drei Tagen unverändert. Bei der heutigen Revision der Wunde kommt man mit der Sonde auf ein kleines rauhes Knochenstückchen, welches sich mit der Pinzette leicht extrahieren läßt und sich als ein kleiner zurückgebliebener Meißelsplitter erweist.

5. VIII. Nach Entfernung des Knochensplitters hat die Wunde sich ge. schlossen, granuliert etwa noch bohnengroß.

7. VIII. Wunde verheilt. Kind wird beschwerdefrei, mit blaßem Trommelfell und normaler Hörfähigkeit nach Hause entlassen.

Heilungsdauer 30 Tage.

Epikrise: Dieser Fall ist von besonderem Interesse dadurch, daß hier die Carrelsche Behandlung zum ersten Male bei ausgedehnten pathologischen Veränderungen der Sinuswand und der Dura zur Anwendung kam. Irgendwelche Erscheinungen, die eine Kontraindikation dagegen hätten abgeben können, wurden nicht beobachtet, ich gewann im Gegenteil den Eindruck, daß sich die erkrankten Durapartien ganz besonders schnell mit frischen, gut aus- 
sehenden Granulationen bedeckten. Die Sterilisierung erfolgte auch hier außergewöhnlich schnell, wiederum entsprach das Ergebnis der bakteriologischen Untersuchung dem der mikroskopischen. Die definitive Heilung wäre noch eher erzielt worden, wenn nicht durch das Zurückbleiben des Meißelsplitters ein in diesem Falle aseptischer Entzündungsprozeß unterhalten wäre, welcher den Wundschluß um mindestens acht Tage verzögerte. Immerhin darf man wohl mit Rücksicht auf die Größe der Wunde, den nötig gewesenen Sekundärschnitt und die bestehende extradurale Komplikation die zur Heilung erforderlich gewesene Zeit von 30 Tagen als sehr kurz bezeichnen.

$$
\text { Fall II. }
$$

H., Karl, 23 J. Aufgenommen 5. VIII. I920.

Anamnese: Patient kam Ende Juli mit akuter linksseitiger Mittelohreiterung in poliklinische Behandlung. Im Verlaufe derselben kam es bei nur geringfügigen Paukenerscheinungen (Flüstersprache $6 \mathrm{~m}$ ) zur Senkung der hinteren oberen Gehörgangswand und Bildung eines subperiostalen Abszesses hinter dem Ohr, deshalb am 5. VIII. Aufnahme zur Operation. Temperatur bis $38^{0}$.

7. VIII. Antrotomie. Subperiostaler AbszeB. Durchbruch am hinteren Rande der Fossa mast. Warzenfortsatz größtenteils kleinzellig pneumatisiert. Zellen angefült mit Eiter und Granulationsgewebe. Antrum klein und makroskopisch frei von pathologischem Inhalt. Nach der hinteren Pyramidenkante zu kommit man auf freiliegenden Sinus, dessen Wand sich in ganzer Ausdehnung zwischen oberen und unteren Knie speckig belegt erweist. Nach gründlicher Resektion alles Krankhaften sofortige Einleitung der Carrelbehandlung.

9. VIII. Temperatur auf die Norm abgefallen. Allgemeinbefinden vorzüglich. Im Eiter des Warzenfortsatzes mikroskopisch vereinzelte Kokken. Kulturell kein Wachstum.

IO. VIII. Erster Verbandwechsel. Wunde sieht sehr gut aus. Abstrich enthält noch einzelne Kokken.

I2. VIII. Zweiter Verbandwechsel. Abstrich kulturell steril, auch mikroskopisch keine Bakterien mehr nachzuweisen. Da die Wunde auch im Bereich des Sinus sehr gut aussieht, am

13. VIII. Sekundärverschluß in üblicher Weise.

I6. VIII. Fieberfreier Verlauf. Wunde primär verheilt, Entfernung der Nähte. Aus den unteren. Wundwinkel entleeren sich nur bei Druck auf die Nahtlinie wenige Tropfen einer klaren, gelblichen Flüssigkeit. Drain fortgelassen.

18. VIII. Naht völlig verheilt. Keine Sekretretention, Verband fällt fort. Trommelfell blaß und reizlos. Flüstersprache $6 \mathrm{~m}$. Wunde ist als geheilt anzusehen (vgl. $\mathrm{Abb} .2$ ).

24. VIII. Patient wird mit glatter, kaum erkennbarer Narbe entlassen. Heilungsdauer II Tage.

Epikrise: Die hier in überraschend kurzer Zeit erfolgte Sterilisierung der Wunde gestattete einen frühzeitigen Verschluß, dementsprechend nahm die ganze Behandlung nur elf Tage in Anspruch. Auch in diesem Falle lagen schwere Veränderungen der Sinuswand vor, wiederum war es auffallend, wie schnell sich auf der letzteren gesund 
aussehende Granulationen entwickelten. Ich behielt den Patienten nach erfolgter Heilung noch längere Zeit in zunächst klinischer, dann ambulanter Beobachtung, um bei eventuellen nachträglichen Störungen sofort eingreifen zu können, doch trat nichts derartiges in Erscheinung.

\section{Fall 12 .}

L., Gustav, 45 J. Aufgenommen 7. VIII. 1920.

Anamnese: Februar 1920 Grippe. Seit April Ohrensausen und Schmerzen rechts.

Bei der Aufnahme: Senkung der hinteren oberen Gehörgangswand rechts. Warzenfortsatz druckschmerzhaft. Bei Kopfbeugen Schmerzen im Nacken. Temperatur $38^{\circ}$. Heftige Kopfschmerzen. Neurologische Untersuchung ergibt normalen Befund. Wassermann: - .

9. VIII. Antrotomie. Kleiner subperiostaler AbszeB in Gegend des Emissariums. Die im hinteren Teil des Prozessus liegenden Zellen enthalten Eiter, nach der Spitze zu und im Artrum nur Granulationen. Sulcuswand fistulös durchbrocken, die Fistel führt in einen ausgedehnten perisinuösen Absze B. Auch in der mittleren Schädelgrube großer Extraduralabsze $\beta$. Dura und Sinuswand in großer Ausdehnung pachymeningitisch verändert. Zur gründlichen Freilegung wird Resektion der hinteren oberen Pyramidenkante bis ans Labyrinth notwendig. Der Sinus ist thrombosiert und wird vom oberen bis unteren Knie geschlitzt. Da der Thrombus nicht infiziert erscheint, wird er an Ort und Stelle belassen. Mehrere Punktionen des Groß- und Kleinhirns ergebnislos. Jodoformgazetamponade. Dreimal täglich I g Urotropin.

I2. VIII. Allgemeinbefinden gebessert, Kopfschmerzen erheblich geringer. Temperatur nach dem Eingriff auf die Norm gesunken. Verbandwechsel und Übergang zur Carrelbehandlung (zwei Drains). Im Abstrich fanden sich kulturell und mikroskopisch in jedem Gesichtsfeld reichlich Staphylokokken und Streptococcus mucosus.

I4. VIII. Verbandwechsel. Bis auf eine kleine Stelle in Gegend des oberen Sinusknies zeigt die Wundhöhle gutes Aussehen. Kulturelles Wachstum von Staphylokokken und Streptococcus mucosus, mikroskopisch gleicher Befund, jedoch hat die Bakterienzahl erheblich abgenommen (nur in jedem zweiten bis dritten Gesichtsfeld).

20. VIII. Bei fieberlosem, völlig ungestörtem Wundverlauf ergaben die kulturellen Untersuchungen des Wundsekrets am I4., I6. und I7. stets noch gleichbleibenden positiven Ausfall. Wunde selbst zeigt jetzt auch einschließlich der gesamten Sinusgegend schönes frisches Aussehen. Mikroskopisch nur in zwei Gesichtsfeldern insgesamt Bakterien auffindbar. Keinerlei Beschwerden, Kopfschmerzen völlig geschwunden, Urotropin fortgelassen.

23. VIII. Gestern und heute mikroskopisch kein Bakkterienbefund mehr, deshalb SekundärverschluB. Mobilisierung der Weichteile war nicht ganz leicht, da sie sich schon ziemlich stark retrahiert hatten entsprechend der großen Ausdehnung der Wunde.

25. VIII. Nahtlinie trocken. Weichteile nach hinten zu etwas gespannt, aber vollständig reaktionslos. Kaum Absonderung aus dem Drain. Gehörgang trocken. Keine Beschwerden, fieberfrei, Drainwechsel.

Das am Tage des Sekundärverschlusses entnommene mikroskopisch freie Wundsekret ergab kulturell noch Wachstum von Streptokokken.

27. VIII. Naht fest verklebt, keine Absonderung aus dem unteren Wund- 
winkel, keine Retention. Entfernung der Klammern. Bei Durchspülung der Höhle entleeren sich keinerlei Beimengungen.

29. VIII. Wunde einschließlich des unteren Wundwinkels verheilt.

30. VIII. Abends Fieber $39^{\circ}$. Wunde o. B. Angina.

I. IX. Angina abgeheilt, Temperatur wieder normal. Keinerlei Beschwerden. Trommelfell blaß, etwas verdickt.

4. IX. Patient wird mit schöner, fester und linearer Narbe und $2 \mathrm{~m}$ Flüstersprache auf dem kranken Ohr bei völligem Wohlbefinden geheilt entlassen. Heilungsdauer 20 Tage.

Epikrise: Nachdem es in diesem Falle, der unter den bisherigen die weitaus hochgradigsten Veränderungen an Dura und Sinus zeigte, gelungen war, die Bakterien mikroskopisch zum Schwinden zu bringen, hielt ich mich nach den voraufgegangenen Beobachtungen für berechtigt, die Sekundärnaht in üblicher Weise auszuführen, nahm aber wie letzthin stets beim Eingriff nochmals Wundsekret zur kulturellen Untersuchung. Der zwei Tage später eintreffende Bescheid des hygienischen Institutes, nach welchem noch Streptokokken gewachsen waren, war mir aus dem Grunde besonders unangenehm, weil es sich um eine Mukosusinfektion gehandelt hatte, und ich war im $Z$ weifel, ob ich es bei dem Wundverschluiß belassen sollte. Ich entschloß mich schließlich dazu, den weiteren Verlauf abzuwarten, der dann auch durchaus günstig war. Ich möchte daraus entnehmen, daß virulente Keime sicherlich nicht mehr in der Wunde vorhanden waren, zumal jede Sekretion fehlte. Für diese Annahme scheint mir auch noch Folgendes zu sprechen: Der Patient kam etwa vier Wochen nach der Entlassung nochmals zu mir, weil sich am unteren Winkel der Narbe eine ca. bohnengroße weiche Anschwellung gebildet hatte. Schmerzen oder sonstige Entzündungserscheinungen fehlten. Ich öffnete diese anscheinend Flüssigkeit enthaltende Schwellung und es entleerte sich auch eine kleine Menge klaren, gelblichen, fadenziehenden Sekrets. Bei genauerem Forschen entdeckte ich jedoch noch ein feines $2 \mathrm{~cm}$ langes, $2 \mathrm{~mm}$ dickes Drain, welches nach dem Sekundärverschluß in die Wunde hinein gerutscht sein mußte und seitdem in ihr verblieben war, Zwei Tage nach Entfernung des Drains war die kleine Öffnung wieder verheilt.

Fall I3.

N., Hermann, 24 J. Aufgenommen 3I. VII. I920:

Anamnese: Seit sieben Wochen Ohreiterung linkes Ohr nach Schnupfen. Sechs Wochen poliklinische Behandlung, dann wegen Senkung der hinteren oberen Gehörgangswand am 3I. VII. Aufnahme.

20. VIII. Wegen des bei konservativer Behandlung dauernd gleichbleibenden Befundes und insbesondere wegen heftiger Kopfschmerzen und Druckemp findlichkeit des Warzenfortsatzes einfache Aufmeißelung.

Kortikalis etwas sklerosiert. In Richtung auf das Antrum derbe Granulationen und grüngelblicher nicht fötider Eiter. Sinus vorgelagert, seine Wand ist an kleiner Stelle mit Granulationen besetzt. Freilegung bis ins Gesunde. Nach Entfernung alles makroskopisch Krankhaften übliche Wundversorgung 
zur Carrelbehandlung. Eiterprobe kulturell steril. In mikroskopischen Präparat reichlich Bakterien, darunter Streptokokken.

23. VIII. Erster Verbandwechsel. Wunde sieht frisch aus. Antrum trocken, im Gehörgang noch etwas Absonderung. Im Wundselkret noch ziem. lich reichlich Bakterien. Kein Fieber, Kopfschmerzen geschwunden.

25. VIII. Wie 23. VIII. Das am 23. VIII. eingeschickte Wundselkret war wiederum kulturell steril. Im heutigen Präparat Bakterien nùr vereinzelt.

29. VIII. Wundsekret vom 25. enthielt kulturell Staphylokokken, das vom 27. Streptokokken.

30. VIII Mikroskopisch gestern und heute keine Bakterien mehr zu finden. Wunde sieht vorzüglich aus. Sekundärnaht.

I. IX. Wohlbefinden, kein Fieber. Naht sieht sehr gut aus, kaum Absonderung. Durchspülung. Drain fortgelassen. Aus dem Gehörgang noch eine Spur Sekretion.

Im Asbtrich vom 30. VIII. (Tag des Verschlusses) kulturell Streptokokken

3. IX. Gehörgang trocken. Wunde völlig verklebt. Keine Sekretretention. Verband fortgelassen.

6. IX. Narbe reizlos. Gehörgang trocken geblieben.

I3. IX. Bei völligem Wohlbefinden mit linearer, glatter Narbe entlassen. Heilungsdauer I3 Tage.

Epikrise: Hier sind vor allem die verschiedenartigen Ergebnisse bei mikroskopischer und kultureller Untersuchung des Wundsekrets bemerkenswert. Es muB auffallend erscheinen, daB die Kultur bei mikroskopisch stark positivem Befund zunächst steril blieb; später dagegen als mikroskopisch keine Bakterien mehr nachzuweisen waren, das eine Mal (25. VIII.) Staphylokokken und die beiden folgenden Male Streptokokkenwachstum ergab. Auch im vorigen Falle hatte sich in dieser Beziehung bereits eine Differenz feststellen lassen. Ich möchte mir eine Erörterung dieses Punktes noch für später vorbehalten und an dieser Stelle nur konstatieren, daß das positive kulturelle Ergebnis auf den klinischen Verlauf des Falles nicht den geringsten Einfluß ausgeübt hat. Er kam ohne die geringste Komplikation in der auffallend kurzen Zeit von I3 Tagen zur Heilung.

\section{Fall I4.}

Sch., Therese, 65 J. Aufgenommen 13. VIII. 1920.

Anamnese: März 1920 rechtsseitige Antrotomie wegen Mastoiditis. Jetzt subakute Mittelohreiterung links.

Stark gealterte, schwächliche Frau in reduziertem Ernährungszustand (Siechenheim). Erhebliche Arteriosklerose. Senile Demenz. Rechts: Tief eingesunkene Antrotomienarbe mit breiter eiternder Fistel. In der Tiefe rauher Knochen, Links: Im Gehörgang dünnflüssiger Eiter. Profuse Absonderung. Warzenfortsatz stark druckempfindlich.

2I. VIII. Einfache Aufmeißelung rechts. Knochen erweicht und brüchig. Alle Zellen voller Granulationen und serösen Sekrets, nach dem Antrum zu Eiter, Die kranken Zellen reichen sehr weit nach hinten oben und nach vorn bis in den Processus zygomaticus. Spitze vollkommen eingeschmolzen, Sinuswand an kleiner Stelle bloßliegend, aber gesund aussehend. Nach gründlicher Resektion sofort Carrelbehandlung 
22. VIII. Im Sekretabstrich der Operationswunde mikroskopisch und kulturell reichlich Streptokokken.

25. VIII. Wunde mit leicht blutenden frischen Granulationen vollständig austapeziert. Im Abstrich vereinzelte Kokken.

30. VIII. Seit dem 26. VIII. Abstriche mikroskopisch und kulturell steril, darum heute Sekundärnaht.

I. IX. "Wundkontrolle. Etwas seröse Absonderung aus dem Drain.

3. IX. Völlig fieberfreier Verlauf. Sekretion aus dem unteren Wundwinkel gering. Entfernung der Klammern. Zwischen oberem und mittlerem Drittel der Nahtlinie klafft die äußere Wunde etwas, während sie nach der Tiefe $\mathrm{zu}$ verschlossen ist. Gehörgang trocken.

9. IX. Nahtlinie bis auf den unteren Wundwinkel verheilt, Gehörgang trocken geblieben, Trommelfell blaß. Stets fieberfrei. Wohlbefinden. Aus dem unteren Wundwinkel entleert sich immer noch etwas Sekret, das jetzt schleimig-fadenziehend ist, aber keine Bakterien enthält. Heftpflasterverband.

I7. IX. Der untere Wundwinkel wird wieder wegen der unverändert bestehenden Sekretion etwas weiter geöffnet $(I / 2 \mathrm{~cm})$ und mit Jodoformgaze tamponiert.

20. IX. Wunde am unteren Wundwinkel hat sich verkleinert, Absonderung gering, immer schleimig-fadenziehend. Bakterienfrei.

27. IX. Keine wesentliche Änderung.

30. IX. In ambulante Behandlung entlassen.

Epikrise: Bei der Beurteilung dieses Falles muß man folgendes zunächst berücksichtigen. Es handelt sich um eine sehr schwächliche, in ihrem Ernährungszustande stark reduzierte Frau in hohem Alter, bei welcher der Eingriff am Warzenfortsatz an sich schon etwas bedenklich war. Die hochgradige Arteriosklerose und die Tatsache, daß die Antrotomiewunde der anderen Seite, welche mit Jodoformgazetamponade 82 Tage behandelt worden war, noch immer aus einer Fistel Eiter absonderte, lieBen die Aussichten auf eine glatte Heilung von vornherein gering erscheinen. Wenn trotzdem nach gelungener Sterilisierung der Wunde die Sekundärnaht ausgeführt werden konnte und - allerdings erst nach Wochen - zur definitiven Heilung führte, so kann man dies meines Erachtens doch noch als einen Erfolg buchen. Man muß dabei bedenken, daß die subkutanen Heilungsvorgänge, welche nach dem Verschluß auch bei gesunden Individuen noch einige Zeit in Anspruch nehmen, bei derartig schwächlichen und alten Personen ganz wesentlich verlangsamt sind, ja sogar nicht selten völlig ausbleiben. Der Befund auf der anderen, im März d. Js. operierten Seite ist gerade in diesem Falle ein Beispiel dafür.

$$
\text { Fall I5. }
$$

H., Samuel. Aufgenommen IO. IX. I920.

Subakute Mittelohreiterung seit Mitte August. Jetzt hinter der Ohrmuschel großer subperiostaler AbszeB, welcher sich fast bis zum Scheitel und nach vorn bis zum Jochbogen erstreckt.

II. IX. Antrotomie. Entleerung des außergewöhnlich großen Abszesses durch Stichinzision, dann übliche Freilegung des Knochens. Periost und 
Weichteile zum Teil in eine zerfetzte, schmierige Masse verwandelt. Am hin: teren Rande des Warzenfortsatzes ein mit Granulationen angefüllter Durchbruch. Von hier ausgehend trifft man gleich auf den Sinus und einen a usgedehnten perisinuösen AbszeB. Knochen in der Umgebung eingeschmolzen, nach dem Antrum zu nur wenig verändert, letzteres mit Granulationen erfüllt. Nach gründlicher Resektion alles Krankhaften, wobei die Sinuswand in großer Ausdehnung freigelegt werden muß, aber nur geringfügige fibrinöse Auflagerungen zeigt, soweit möglich Entfernung aller nekrotischen oder zur Nekrose eventuell neigenden Weichteilpartien mit scharfem Löffel und Schere. Einlegen von drei Drains zur Carrelbehandlung.

14. IX. Verbandwechsel. Tampons etwas trocken infolge ungenügenden Eingießens der Dakinschen Lösung. Diejenigen Stellen, welche von der Lösung erreicht waren, sehen tadellos frisch aus und granulieren, die übrigen sind trocken und reaktionslos. In den Buchten des Abszesses kein Eiter. Am unteren Wundwinkel einzelne kleine nekrotische Fetzen. Abstrich: Unzählige Bakterien. (Streptokokken und Staphylokokken).

16. IX. Patient ist seit der Operation fieberfrei und fühlt sich vollkommen wohl. Wunde sieht heute gleichmäßig gut aus, aus dem Antrum keine Absonderung, Gehörgang trocken. Im Abstrich mikroskopisch heute nur vereinzelte Streptokokken:

20. IX. Der größte Teil der Wunde zeigt schöne frische Granulationen. An den Wandungen des subperiostalen Abszesses sowie am unteren Wundwinkel stoßen sich noch kleine nekrotische Partien ab. Abstrich heute mikroskopisch frei von Bakterien.

24. IX. Trotz des guten Aussehens der Wunde und trotzdem auch der Abstrich vom 22. IX. negativ war, kann mit Rücksicht auf die Nekrosen, welche am unteren Wundwinkel noch Sekretion unterhalten, der Sekundärverschluß nicht ausgeführt werden.

27. IX. Bei Druck auf die Umgebung des unteren Wundwinkels kommt aus der Tiefe etwas Eiter, welcher mikroskopisch Staphylokokken enthält. (Später kulturell gleicher Befund.) Bei der Revision findet sich noch ein kleiner Teil der Warzenfortsatzspitze erweicht und muß mit Zange und scharfem Löffel entfernt werden.

5. X. Wunde jetzt völlig einwandfrei, Antrum durch Verwachsung der Granulationen in der Tiefe des Wundtrichters abgeschlossen. Abstrich mikroskopisch und kulturell steril.

9. X. Sekundärnaht, nachdem das Wundsekret vier Tage hintereinander bakterienfrei gelbieben ist. $\mathrm{Da}$ sich die Wundränder schon sehr stark nach innen umgeschlagen haben und besonders der hintere ziemlich weit retrahiert ist, macht die Vereinigung derselben Schwierigkeiten, und gelingt nur nach ausgedehnter Ablösung und Präparation, außerdem nur oberflächlich.

I I. X. Kontrolle der Naht, die bisher gehalten hat. Keine Nahteiterung. Nur ganz geringfügige Absonderung eines gelblich-serösen Wundsekrets aus dem Drain.

13. X. Entfernung der Klammern. Im oberen Drittel sind die Wundränder etwas auseinander gewichen, es besteht hier ein Spalt von ca. $2 \mathrm{~cm}$ Länge, der jedoch durch kleine Hautbrücken in mehrere Lücken geteilt ist.

I8. $\mathrm{X}$. Wundlücke wesentlich verkleinert, kaum Absonderung.

23. X. Die restierende Wundlücke hat sich noch vollkommen geschlossen. Die jetzt vorliegende Narbe ist nicht ganz glatt, sondern im oberen Drittel 
leicht eingezogen. Kosmetische Entstellung jedoch nur sehr geringfügig. Beschwerdefrei und geheilt nach Hause entlassen.

Heilungsdauer 42 Tage.

Epikrise: In diesem Falle rechnete ich von Anfang an, besonders wegen des sehr großen subperiostalen Abszesses und der starken Weichteilveränderungen mit einem langsameren Verlauf der Wundsterilisierung, die jedoch nachher hauptsächlich dadurch verzögert wurde, daß sich im Bereich der Warzenfortsatzspitze post operationem noch Einschmelzungsprozesse vollzogen, welche einen weiteren Eingriff nötig machten. Nach Eliminierung dieses Herdes erfolgte dieselbe in relativ kurzer Zeit. Bemerkenswert ist aber vor allem, daß hier auch die granulationsanregende Wirkung der Dakinlösung ganz besonders schön in Erscheinung trat. Beim ersten Verbandwechsel, wobei ich die Feststellung machte, daß die Berieselung mit der Lösung durch die drei Rohre nicht gleichmäßig erfolgt sein konnte, war es direkt auffallend, welchen Unterschied die von nassen Tampons bedeckten Stellen der Wunde gegenüber den weniger angefeuchteten bzw. trockenen Partien darboten. An den ersteren bereits tadellose frische Granulationen mit deutlicher Abgrenzung nekrotischer Teilchen gegen gesunde, an den letzteren noch keine Reaktion. Zwei Tage später hatte sich, nach richtiger Handhabung der Eingießungen der Unterschied ziemlich ausgeglichen, außerdem ließ sich ein rapider Sturz der Bakterienzahl nachweisen. Das nicht ganz vollständige Gelingen der Sekundärnaht ist darauf zurückzuführen, daß dieselbe erst 28 Tage nach der Antrotomie ausgeführt werden konnte. Vielleicht wäre hier ein kleiner Entspannungsschnitt zweckmäßiger gewesen.

\section{Fall I6.}

L., August, $35 \mathrm{~J}$. Aufgenommen Io. IX. I920.

Akute Mittelohreiterung rechts und Mastoiditis. Zunächst konservative Behandlung, dann wegen Zunahme der mastoidealen Symptome am

2I. IX. Antrotomie rechts. Zellen des ganzen Warzenfortsatzes bis weit in die Gegend der oberen Pyramidenkante und einschließlich der Spitze mit Granulationen und serös-eitrigem Sekret angefüllt, ebenso das Antrum. Sinus und Dura sind nirgends erreicht und werden auch nicht freigelegt. Nach gründlicher Resektion alles Krankhaften sofortige Einleitung der Carrelschen Behandlung.

25. IX. Wunde sehr frisch, an keiner Stelle eitriges Sekret. Abstrich ergibt mikroskopisch noch vereinzelte Kokken. Der bei der Operation entnommene Abstrich hatte kulturell Streptokokken ergeben, welche von Proteus überwuchert waren.

27. IX. Wunde zeigt auch heute gutes Aussehen, nur sind die Tampons etwas trocken (mangelhafte Durchspülung). Gehörgang trocken. Abstrich mikroskopisch bakterienfrei. Gutes Allgemeinbefinden, Verlauf völlig fieberfrei.

28. IX. Sekundärnaht in üblicher Weise.

30. IX. Kontrolle der Wunde. Naht trocken. Aus dem unteren Wundwinkel nur ganz minimale, rein seröse Sekretion. 
2. X. Entfernung der Klammern. Wunde primär verheilt, aus dem Drain im unteren Wundwinkel keine Absonderung mehr. Drain fortgelassen.

5. X. Über Nacht ist ohne Störung des Allgemeinbefindens, aber unter leichter Temperatursteigerung auf 37,6 eine mäßige Weichteilschwellung in Gegend des oberen Wundwinkels aufgetreten. Rötung fehlt, doch ist etwas Ödem vorhanden. Patient gibt auf Befragen an, seit gestern einen heftigen Schnupfen zu haben. Mit Rücksicht auf eine mögliche Sekretverhaltung wird vom oberen Wundwinkel aus in Richtung auf das Antrum sondiert, wobei sich auch Eiter mit Schleimbeimengung findet. Der Eiter wird mittels Paukenröhrchenspülung vollständig entleert und sowohl am obe ren wie am unteren Wundwinkel ein feines Drain eingeführt. Im Ausstrich des entleerten Eiters fanden sich Streptokokken! Dakinverband.

6. X. Schwellung völlig zurückgegangen, Sekretion mehr dünnflüssig, serös. Schleimeiterabsonderung aus dem Gehörgang.

7. X. Absonderung noch geringer als gestern. Durchspülung wie gestern, Borsäurebehandlung.

20. X. Während die Absonderung aus dem Gehörgang seit dem II.X. wieder aufgehört hat, mußte die Drainage und tägliche Durchspülung der Wundhöhle hinter dem Ohr bisher noch fortgesetzt werden. Die Sekretion ist all; mählich geringer geworden, eine Verhaltung nicht wieder aufgetreten. Bis auf die beiden Drainöfnungen von je $2 \mathrm{~mm}$ Durchmesser ist die Wunde fest und glatt vernarbt.

23. X. Sekretion hat aufgehört, Drains werden fortgelassen.

25. X. Wunde verheilt.

30. X. Patient wird heute geheilt nach Hause entlassen.

Heilungsdauer 39 Tage.

Epikrise: Die in diesem Falle nach bereits erfogter glatter Wundverheilung aufgetretene Komplikation hat große Ähnlichkeit mit den Erscheinungen, wie sie nicht allzu selten bei der im AnschluB an die Primärnaht entstandenen "Sekretstauung" beobachtet wurden. Daß es sich jedoch nicht nur um eine einfache Stauung von Wundsekret gehandelt hat, die wohl nur zu einer einfachen Vorwölbung der Weichteile geführt haben würde (vgl. Fall 6), sondern um einen echten entzündlichen Prozeß, geht daraus hervor, daß eine wenn auch nur leichte Temperatursteigerung vorhanden war, die Weichteile ödematös geschwollen waren und sich im Sekret wieder Bakterien fanden. Es wäre aber meines Erachtens verfehlt, wenn man für diese Komplikation die Behandlung verantwortlich machen und annehmen wollte, daß sie als Folge einer ungenügenden Sterilisierung der Wunde anzusehen sei. Dazu liegt nach dem anfänglich einwandfreien Verlauf und dem mikroskopisch wie kulturell negativem Wundsekretbefund keine Veranlassung vor. Viel näher liegt es, und diese Annahme besteht glaube ich zu vollem Recht, daß eine Neuinfektion der Wunde auf tubarem Wege erfolgt ist und die entzündlichen Symptome ausgelöst hat. Dafür spricht unbedingt das Einsetzen derselben nach einem heftigen akuten Schnupfen und das gleichzeitige Auftreten einer neuen Schleimeiterung in der Paukenhöhle. Wir haben dementsprechend Verhältnisse vor uns, wie 
sie auch bei der offenen Tamponadebehandlung gelegentlich aufzutreten und, falls schon eine Vernarbung dabei erfolgt war, das sogenannte Narbenrezidiv zu verursachen pflegen. Die täglichen Durchspülungen von einer nur $2 \mathrm{~mm}$ großen Gegenöffnung brachten auch diese Neuinfektion schnell wieder zum Schwinden, so daß insbesondere das kosmetische Resultat in keiner Weise eine Beeinträchtigung erfuhr.

\section{Fall 17.}

S., Otto, Io J. Aufgenommen 28. IX. 20.

Akute Mittelohreiterung links seit I7 Tagen mit Entwicklung eines großen subperiostalen Abszesses hinter dem Ohr.

30. IX. Antrotomie. Entleerung des subperiostalen Abszesses. Zellen des Warzenfortsatzes sämtlich mit Eiter und Granulationen angefüllt. Große Spitzenzelle. Sulcus sigmoideus intakt, Dura jedoch an linsengroßer Stelle von dem Prozeß erreicht und hier etwas pachymeningitisch verändert. Antrum wird breit eröffnet. Nach sorgfältiger Entfernung alles Krankhaften übliche Dakintamponade.

3. X. Erster Verbandwechsel, Tampons sind stark von Sekret durchtränkt, doch sieht nach Herausnahme derselben die Wunde gut aus. Absonderung aus dem Gehörgang reichlich. Im Sekret Bakterien in großer Zahl.

10. X. Ungestörter Wundverlauf, Wundtrichter überall mit frisch aussehenden Granulationen ausgefüllt. Antrum in der Tiefe bereits abgeschlossen. Im Wundsekret nur noch vereinzelte Bakterien. Absonderung aus dem Gehörgang noch vorhanden. Wohlbefinden, fieberfrei.

I5. X. Wunde zeigt tadelloses Aussehen, Sekretion aus dem Gehörgang hat aufgehört. Seit zwei Tagen ist das Wundsekret sowohl mikroskopisch wie kulturell steril. Deshalb heute Sekundärnaht.

I8. X. Nahtlinie und Umgebung vollkommen reizlos, keine Stichkanaleiterung. Absonderung aus dem Gehörgang nicht vorhanden, aus dem unteren Wundwinkel sehr gering.

19. X. Entfernung der Nähte, Wunde primär verheilt. Absonderung aus dem unteren Wundwinkel gelblich serös, Menge mäßig, Sekret steril.

25. X. Drain fortgelassen. Heftpflasterverband. Mittelohr trocken.

27. X. Verband fortgelassen. Wunde völlig vernarbt. Tadellose glatte, lineare Narbe ohne Einziehung.

3I. X. Geheilt nach Hause entlassen.

Heilungsdauer 27 Tage.

Epikrise: Ein näheres Eingehen auf den Verlauf dieses Falles. erübrigt sich, da besondere Beobachtungen dabei nicht gemacht wurden.

\section{Fall I8.}

H., Hertha, 4 J. Aufgenommen 30. IX. Ig20.

Seit drei Wochen akute Mittelohreiterung links mit profuser Sekretion. Seit einigen Tagen Schwellung hinter dem Ohr. Sehr blasses, schwächliches Kind.

I. X. Antrotomie. Weichteile und Periost stark infiltriert. Zellen des ganzen Warzenfortsatzes mit blaß aussehenden, fast weißlichen Granulationen und dünnflüssigem eitrigen Sekret erfüllt. Spitze morsch, muß zum größten Teil reseziert werden. Dura oder Sinus werden nicht freigelegt. Übliche Wundversorgung zur Carrelbehandlung. 
5. X. Wunde noch vollkommen reaktionslos, sondert profus ab. Dakinlösung ausgesetzt, Jodoformgaze. Im Sekret vereinzelte Streptokokken.

8. X. Das Kind sieht außerordentlich blaß aus, befindet sich aber subjektiv wohl. Wundverhältnisse unverändert. Höhensonne.

I I. X. Schwache Granulationsbildung sichtbar. Sekretion noch sehr stark, durch das Trommelfell geringer.

I8. 10. Unter allmählicher Besserung des Allgemeinbefindens zeigt auch die Wunde frischeres Aussehen. Zur Beschleunigung der Granulationsvorgänge und mit Rücksicht darauf, daß sich im Wundsekret wieder sehr zahlreiche Streptokokken finden, Übergang zur Carrelbehandlung.

22. $\mathrm{X}$. Unter dem Einfluß der Dakinlösung haben sich die Wundverhältnisse in den letzten vier Tagen ganz außerordentlich gebessert. Seit gestern sind auch im Wundsekret keine Bakterien mehr nachweisbar, deshalb heute Sekundärnaht.

26. X. Wunde primär verheilt. Entfernung der Klammern. Absonderung aus dem unteren Wundwinkel kaum vorhanden. Mittelohr trocken geblieben. gelassen.

30 X. Nahtlinie fest verheilt. Keine Absonderung. Drain wird fort-

1. XI. Das Kind wird nach Hause entlassen. Heilungsdauer 30 Tage.

Epikrise: Hier glaubte ich zunächst, nachdem fünf Tage lang die Einwirkung der Dakinlösung erfolglos gewesen war, an einen Versager. Die Wundsekretion war so außerordentlich stark, daß die Verbandstoffe kaum genügten, das von einem zum anderen Tag produzierte Sekret restlos aufzusaugen. Daran änderte sich jedoch nichts, als ich zur Jodoformgazetamponade überging. Erst mit einer deutlich erkennbaren Besserung im Allgemeinzustand des sehr anämischen und schwächlichen Kindes durch reichliche Ernährung, Kräftigungsmittel und Höhensonnenbestrahlungen trat ein Umschwung im Verhalten der Wunde ein. Jetzt wurden mit Rückkehr zur Dakinlösung auch die Granulationen bedeutend schnell besser und die Wunde, welche nach I3tägiger Jodoformgazebehandlung mehr Bakterien (Streptokokken) enthielt, als vor derselben, sterilisierte sich in drei Tagen, so daß die Wunde geschlossen werden konnte. Die Heilung erfolgte dann schnell ohne weitere Störung.

Fall I9.

O., Elfriede, I2 J. Aufgenommen 20. IX. I920.

Rechtsseitige Ohreiterung im Anschluß an Scharlach. Leichte hämorrhagische Nephritis. Rechtes Ohr: Starke Schmerzen. Seröse Sekretion. Rötung und Vorwölbung des Trommelfells. Warzenfortsatz druckschmerzhaft. Parazentese, Eisblase.

Verlauf: Bis 23. hohes Fieber, dann Temperaturabfall unter Besserung des Allgemeinbefindens. Ohrbeschwerden auch nach nochmaliger Parazentese am 24. IX. unverändert. Dann gingen unter konservativer Behandlung die Mittelohrerscheinungen allmählich zurück, dafür kam es aber am Warzenfortsatz zur Infiltration der Weichteile und schließlich zur Ausbildung eines subperiostalen Abszesses. Deshalb am

7. X. Antrotomie. Weichteile zum Teil nekrotisch und blutig imbibiert. Persistierende Sutura mastoideo-squamosa, aus welcher Eiter und Granu- 
lationen hervorquellen. Großer, mit Granulationen erfüllter Hohlraum im Knochen, letzterer in großer Ausdehnung erweicht. Sinus freiliegend und bis über das obere und untere Knie hinaus mit schwammigen Granulationen bedeckt. Obere Pyramidenkante muß zum Teil reseziert werden. Dura der mittleren Schädelgrube zeigt fibröse Auflagerungen. Da klinische Erscheinungen seitens des Sinus fehlen, wird derselbe nicht eröffnet. Nach gründlicher Ausräumung Jodoformgazetamponade.

IO. $\mathrm{X}$. Wunde sieht gut aus, kein Eiter, keine Nekrosen. Carrelbeh andlung.

12. X. Im Abstrich keine Bakterien zu finden. Wunde zeigt frisches Aussehen. Sinusgranulationen fest.

I8. X. Nachdem die Abstriche stets bakterienfrei geblieben sind, Sekundärverschluß in zwei Etagen. Drain in den unteren Wundwinkel.

22. X. Entfernung der Klammern. Außer dem unteren Wundwinkel, welcher die Drainageöffnung enthält, ist der obere noch etwas offen.

23. X. Oberer Wundwinkel verklebt. Unten nur Spur serös-blutiges Sekret. Drain fortgelassen.

25. X. Wunde in ganzer Ausdehnung ohne Zeichen einer Sekretretention verheilt. Trommelfell blaß. (Bild.)

26. X. Entlassen. Heilungsdauer I9 Tage.

Fall 20.

B., Willi, I3 J. Aufgenommen 7. X. 1920.

Akute Mittelohreiterung seit acht Wochen. Seit acht Tagen Mastoiditis. Konservative Behandlung ohne Erfolg. Nach anfänglicher Besserung Senkung der hinteren oberen Gehörgangswand, der subperiostale AbszeB vergrößerte sich, deshalb am

15. X. Antrotomie. Entleerung des Abszesses. Weichteile stark infiltriert und hochgradig verdickt. Linsengroßer Durchbruch in der Fossa mast. Zellen mit Granulationen und serös-eitriger Flüssigkeit erfüllt, nach der Spitze zu freier Eiter. Sulkuswand an bohnengroßer Stelle zerstört, hier Sinuswand verdickt. Bei Aufdeckung des Antrums zeigt sich, daß der Einschmelzungsprozeß sich auch auf die perilabyrinthären Zellen erstreckt. Die weichen Massen werden hier vorsichtig mit dem scharfen Löffelchen entfernt. Nach gründ. licher Resektion alles Krankhaften Säuberung und Jodoformgazetamponade.

I9. X. Temperatur seit der Operation zwischen 37 und $38^{\circ}$, bei relativ gutem Befinden. Verbandswechsel: Wunde trocken. Im Abstrich reichliche Bakterien. Übergang zur Carrelbehandlung. Durch das Trommelfell noch Absonderung.

21. X. Gehörgang trocken. Wunde sieht sehr frisch aus.

25. IO. Nachdem die Bakterienzahl bei täglicher Kontrolle im Wundsekret ständig abgenommen hat, gestern und heute keine Keime mehr nach. weisbar waren, da jetzt auch die Temperatur normal ist und die Wunde sehr frisch aussieht und üppig granuliert. Sekundärverschluß, der sehr leicht gelingt.

27. X. Wundkontrolle, besonders auch deshalb, weil gestern Abend Temperatur auf 38,2 erhöht war. Stauungserscheinungen nicht vorhanden. Absonderung aus dem Drain im Gegenteil sehr gering. Naht völlig trocken, Weichteile reizlos.

29. X. Wunde verheilt. Entfernung der Klammern. Spur-Sekretion aus dem Drain. Temperatur seit dem 27. X. abends wieder normal.

3I. X. Keine Sekretion mehr. Drain fortgelassen. 
I. XI. Wunde mit vollkommen linearer, kaum sichtbarer Narbe verheilt. Verband fällt fort. Trommelfell blaß (vgl. Abb. 3).

6. XI. Gesund nach Hause entlassen. Flüstersprache $5 \mathrm{~m}$.

Heilungsdauer i6 Tage.

Epikrise zu Fall I9 und 20: Den Verlauf in diesen beiden Fällen darf man wohl als besonders günstig bezeichnen, vor allem im Fall I9, wo die ausgedehnten Sinusveränderungen sowohl gegen die Primärnaht wie die Sekundärnaht - sofern nicht die Sterilität der Wunde eine Garantie für die Gefahrlosigkeit abgegeben hätte - ; eine strikte Kontraindikation abgegeben hätten. Auch nach der Entlassung traten nicht die geringsten Störungen auf, wovon ich mich durch verschiedentliche Kontrolluntersuchungen überzeugen konnte.

Fall 21 .

G., Joachim, 6 J. Aufgenommen 19. X. I920.

Seit drei Wochen akute Mittelohreiterung mit profuser Sekretion bds. Hochgradig blasser und schwächlicher Junge. Dauernd erhöhte Temperatur um $38^{0}$ herum. Beide Warzenfortsätze druckempfindlich. Bis II. XI. konservative Behandlung, dann wegen Fortbestehens der profusen Absonderung, erhöhter Temperaturen und Zunahme der Druckempfindlichkeit der beiden Warzenfortsätze doppelseitige Antrotomie. Beiderseits finden sich sämtliche Zellen des gut entwickelten Warzenfortsatzes mit Eiter angefüllt, im Antrum ebenfalls Eiter und Granulationen. Nach gründlicher Ausräumung Jodoformgazeta mponade, Okklusivverband.

13. XI. Temperatur gestern noch bis auf 38,3 gestiegen. Rechts wird heute der Verband gewechselt und Carrelbehandlung eingeleitet. Im Wundsekret mäßig reichlich Bakterien.

15. XI. Temperatur auf die Norm gesunken. Wohlbefinden. Im Sekret der rechten Wunde nur noch ganz vereinzelt Bakterien, im Sekret der linken Wunde, die bisher mit Jodoformgazetamponade behandelt war, noch reich.. lich Streptokokken. Einleitung der Carrelbehandlung auch links.

I6. XI. Tamponwechsel bds. Im Sekret des rechten Warzenfortsatzes keine Bakterien mehr, links noch mehrfach Streptokokken nachweisbar.

Rechter Gehörgang trocken, links noch mäßige Absonderung. Beide Wunden sehen frisch aus.

I8. XI. Beide Wunden granulieren gut, heute weder rechts noch links Bakterien nachwe is bar.

20. XI. Sekundärnaht bds., welche fast ohne Mobilisierung der Weichteile in einer viertel Stunde ausgeführt werden kann.

22. XI. Kontrolle der Wunden, da gestern Abend Temperatur auf $38,3^{\circ}$ gestiegen. Nahtlinien trocken, nicht die geringste Entzündung oder Infiltration der Weichteile, nur aus dem linken unteren Wundwinkel etwas stärkere Absonderung. Durchspülung mit Dakinlösung, Drainwechsel.

24. XI. Temperatur seit gestern früh wieder normal. Wohlbefinden. Nahtlinie bds. völlig reizlos, fest verklebt. Entfernung der Klammern.

27. XI. Drains fortgelassen, da keine Sekretion mehr vorhanden. Das Kind hat sich seit dem Eingriff sehr wesentlich erholt, Temperatur normal geblieben.

I. XII. Kind wird mit festvernarbten Wunden nach Hause entlassen. Flüstersprache bds. mehr als $6 \mathrm{~m}$.

Heilungsdauer 20 Tage. 
Epikrise: Von besonderem Interesse ist in diesem Fall nur die Feststellung, daB die rechtsseitige Antrotomiewunde, welche zuerst mit der Dakinlösung behandelt wurde, früher bakterienfrei war, als die linksseitige, bei welcher ich zum Studium gerade dieses Punktes die Jodoformgazetamponade noch' einige Tage länger fortsetzte. Die Jodoformgaze hatte überhaupt keinen merkbaren Einfluß auf den Bakteriengehalt der Wunde, eine Beobachtung, welche mit den Untersuchungsergebnissen Keyssers übereinstimmt und die ich auch bei den früheren Fällen schon mehrfach konstatieren konnte. Leider war dies der einzige Fall, der doppelseitig operiert werden mußte; so daß es noch nicht erlaubt ist, aus dieser einen deutlichen Unterschied zugunsten der Carrelbehandlung ergebenden Beobachtung bindende Schlüsse zu ziehen.

Fall 22.

Z., Ernst, to J. Aufgenommen 20. XII. I920.

Der sehr blaß und elend aussehende Knabe wird mit ausgesprochener linksseitiger Mastoiditis im Anschluß an eine jetzt drei Wochen währende heftige Mittelohreiterung eingeliefert und sofort antrotomiert:

Großer subperiostaler Abszeß. Knochendurchbruch unterhalb der Fossa mast., Zellen völlig eingeschmolzen, doch hat der Prozeß Sinus und Dura nicht erreicht. Nach Entfernung alles Krankhaften und breiter Eröffnung des Antrums Sauberung des subperiostalen Abszesses von Nekrosen, sofortige Einleitung der Carrelbehandlung.

23. XII. Erster Verbandwechel. Wunde sieht sehr gut aus, geringfügige Sekretion noch aus dem Gehörgang. In der Wunde das ubliche glasige Sekret. Im Abstrich mäßig reichliche Bakterien.

Allgemeinbefinden gut, Temperatur nach einmaligem Anstieg post operationem auf 37,8 normal.

25. XII. Wunde sieht sehr gut aus, Bakterien noch in einzelnen Gesichtsfeldern vorhanden.

27. XII. Wunde zeigt überall frische Granulationen, Gehörgang trocken. Abstrich heute bakterienfrei.

29. XII. Auch gestriger Abstich bakterienfrei, deshalb heute Sekundärverschluß.

2. I. I92I. Nahtlinie primär verheilt, ganz geringfügige Absonderung aus dem Drain.

5. I. Drain fortgelassen.

9. I. Wunde völlig verheilt, keine Sekretretention.

II. I. Geringfügige Sekretretention am unteren Wundwinkel, der deshalb mit der Pinzette etwas eröffnet wird. Dabei zeigt sich, daB hier einer der zur Sekundärnaht benutzten Katgutfäden abgestoßen wird.

15. I. Wunde wieder verschlossen, keine Sekretverhaltung mehr.

Heilungsdauer 20 Tage.

Fall 23.

H., Regina, I3 J. Aufgenommen 20. XII. I920.

Seit fünf. Wochen linksseitige akute Mittelohreiterung, zurzeit Senkung der hinteren oberen Gehörgangswand, hinter dem Ohr Infiltration der Weichteile und deutlicher subperiostaler AbszeB. Deshalb am 2I. XII. Antrotomie: 
Entleerung des subperiostalen Abszesses. Linsengroßer Knochendurchbruch in der Fossa mast. Zellen mit Granulationen und Eiter angefüllt, große Terminalzelle. Sinus und Dura nicht erreicht und nicht freigelegt. Nach Säuberung der subperiostalen Abszeßhöhle sofortige Einteitung der Carrelbehandlung.

24. XII. Fieberloser Verlauf. Wunde sieht frisch aus, ganz geringfügige Absonderung eines glasigen, schwach-eitrigen Sekrets. Spur-Sekretion auch aus dem Gehörgang. Im Abstrich finden sich in mäßiger Menge Bakterien.

26. XII. Wunde sehr frisch, fast überall bereits granulierend. Gehörgang trocken. Wundsekret rein glasig, Abstrich bakterienfrei.

28. XII. SekundärverschluB.

30. XII. - Nahtlinie völlig trocken und reizlos, per primam verklebt, inklusive des unteren Wundwinkels, aus welchem das Drain herausgerutscht war.

2. I. I92I. Wunde völlig per priman verheilt. Keine Sekretverhaltung, Gehörgang trocken.

Heilungsdauer I2 Tage.

\section{Fa11 24.}

Sch., Robert, 36 J. Aufgenommen 20. XII. I920.

Patient leidet an vorgeschrittener Lungentuberkulose. Anfang Oktober ist schmerzlos nach vorausgegangener Hämoptoë rechtsseitige Ohreiterung aufgetreten. Fötide eitrige Absonderung, Senkung der hinteren oberen Gehörgangswand, heftige Kopfschmerzen. Warzenfortsatz stark druckempfindlich. Deshalb am 2I. XII. Antrotomie:

Knochen zeigt graues Aussehen, ist sehr brüchig. Warzenfortsatz ist in eine große, mit schlaffen, blassen Granulationen ausgefüllte Höhle verwandelt, die gelben übelriechenden Eiter enthält. Dura und Sinus sind nicht erreicht und werden auch nicht freigelegt. Nach gründlicher Ausräumung alles makroskopisch Krankhaften sofortige Einleitung der Dakinbehandlung.

24. XII. Fieberfreier Verlauf. Kopfschmerzen geschwunden. Aus dem Gehörgang nur ganz geringfügige Absonderung, ebenso aus der Wundhöhle. Im Abstrich Bakterien, wenn auch in geringer Menge (Tuberkelbazillen nicht nachweisbar). Wunde zeigt bereits etwas Reaktion in Form von Granulationsbildung.

28. XII. Sekundärverschluß, da am 26. und 27. XII. Wundsekret bakterienfrei war. Im Gehörgang noch geringfügige dünnflüssige Absonderung, die auf eine leichte diffuse Otitis externa zu beziehen ist.

30. XII. Nahtlinie reaktionslos verklebt, Drain wird fortgelassen, da keine Sekretion aus der Wunde besteht.

I. I. Ig2 I. Entfernung der Klammern. Wunde in ganzer Ausdehung primär verheilt ohne Sekretverhaltung. In der Tiefe des Gehörganges nur eine Spur dünnflüssigen, nicht fötiden Sekretes.

2. I. Verband fällt fort.

6. I. Unter Borsäurebehandlung ist auch der Gehörgang trocken geworden.

Heilungsdauer II Tage:

Epikrise: Ein näheres Eingehen auf die Fälle 22 und 23 erübrigt sich, sie nahmen den erwarteten komplikationslosen Verlauf und kamen schnell zur idealen Heilung. Dagegen bedarf Fall 24 noch einer kurzen Besprechung. Es hat sich hier nach der Anamnese, der schmerzlosen. Entstehung der Trommelfellperforation und nach dem Operationsbefunde (fötider Eiter) wohl mit großer Wahrscheinlichkeit um einen 
tuberkulösen Prozeß gehandelt, obwohl Tb-Bazillen im Sekret selbst nicht nachgeweisen werden konnten. (Eine mikroskopische Untersuchung der Granulationen ist leider unterblieben.) Aus diesem Grunde hatte ich bei Vornahme des Sekundärverschlusses wenig Hoffnung auf eine glatte Heilung und war durch das schnelle Eintreten derselben ohne jede störende Sekretion in hohem Maße überrascht. Der Verlauf dieses Falles stellt uns vor die Frage, ob die Carrelbehandlung auf den Heilungsverlauf tuberkulöser Affektionen des Warzenfortsatzes besonders günstig einwirkt und ob die Dakinlösung vielleicht auch eine spezielle Wirkung auf den Tb-Bazillus auszuiuben imstande ist. Dahingehende klinische und experimentelle Untersuchungen fehlen noch, so daß eine Beantwortung dieser Frage auf Grund dieser einen vielleicht zufällig günstigen Beobachtung noch nicht möglich ist. Immerhin scheint mir dieselbe eine gewisse Beachtung zu verdienen.

\section{Zusammenfassende SchluBbetrachtung.}

Wenn man die im vorstehenden aufgeführten und auch schon größtenteils kritisch gewürdigten Einzelergebnisse gemeinsam von dem Gesichtspunkt aus betrachtet, ob das erstrebte Ziel, d. h. die Sterilisierung der Antrotomiewunde auch wirklich erreicht wurde, so wird man diese Frage wohl ohne gröbere Einschränkung in bejahendem Sinne beantworten dürfen. In sämtlichen Fällen, welche der Carrelschen Behandlung unterzogen wurden, ist es gelungen, die bei und nach der Operation st ets vorhandenen und nachgewiesenen Infektionserreger nach einer gewissen, allerdings ziemlich wechselnden Zeit zum Schwinden zu bringen, so daß sie mikroskopischim Wundsekret nicht mehr gefunden werden konnten. Die Dauer der Sterilisation betrug im günstigsten Falle zwei, im ungünstigsten 24, durchschnittlich 7,7 Tage. Hierzu ist jedoch $\mathrm{zu}$ bemerken, daß ich aus einer gewissen Vorsicht heraus dabei weiter gegangen bin, als Carrel es fordert, indem er eine Wunde schon als klinisch steril ansieht, wenn die Bakterienzahl soweit vermindert ist, daß sich höchstens in jedem zehnten Gesichtsfeld ein Keim findet, während ich die Behandlung solange fortgesetzt habe, bis Bakterien überhaupt nicht mehr nachgewiesen werden konnten. Aus dem gleichen Grunde habe ich auch die praktischen Konsequenzen hieraus erst gezogen, nachdem der Bakterienbefund wiederholt negativ geblieben war. Diese Vorsicht schien mir deshalb am Platze zu sein, weil möglicherweise das nur von wenigen Stellen der Wunde, hauptsächlich Antrumgegend und unterem Wundwinkel entnommene Sekret bakterienfrei sein konnte, während sich in den übrigen Teilen der Wunde noch Keime befanden. Ich habe deshalb, nachdem einmal der Befund negativ gewesen war, bei der nächsten Sekretabnahme vor allem auch die Buchten zwischen Haut und Knochen abgesucht, und erst, wenn 
sich auch hier keine Bakterien mehr fanden, den Sekundärverschluß ausgeführt.

Hier könnte nun der Einwand erhoben werden, daß das Fehlen der Bakterien im mikroskopischen Präparat noch nicht die absolute Sterilität einer Wunde garantiere. Es muB auch ohne weiteres zugegeben werden, und wird von Carrel und Dehelly bereits ausgesprochen, daB die mikroskopische Untersuchung eine relativ grobe Prüfung auf den Infektionszustand einer Wunde darstellt und wahrscheinlich mit dem Kulturergebnis nicht immer übereinstimmt. Um hierüber Klarheit zu gewinnen, habe ich in einer größeren Anzahl meiner Fälle bei jeder Sekretentnahme auch das Kulturverfahren einleiten lassen. Ich sagte mir, daß die Methode einen noch größeren Wert besitzen und ein noch größeres Sicherheitsgefühl geben würde, wenn der negative Bakterienbefund im mikroskopischen Präparat durch die Kultur bestätigt würde. Das Resultat ist in den Epikrisen bereits mitgeteilt worden, die Nebeneinanderstellung läßt erkennen, daß in sechs von den acht untersuchten Fällen das Kulturergebnis ebenfalls negativ war, in zwei Fällen dagegen nicht. Einen ganz überraschenden Befund ergab die Untersuchung im Fall I3. Hier war bei positivem und noch dazu reichlichem Bakterienbefund im Präparat die Kultur steril, später war es gerade umgekehrt. Ich muß sagen, daß dieses Ergebnis mir zunächst ein gewisses Unbehagen verursachte, welches erst schwand, als die Fälle einen durchaus einwandfreien Verlauf nahmen. Obwohl ich deshalb glaube, daß dieser Punkt vielleicht nur theoretische Bedeutung hat, zumal auch Carrel bei seinem außerordentlichen umfangreichen Material unangenehme klinische Folgen nicht beobachtet hat, und Keyßer feststellen konnte, daß selbst das Wundsekret aseptischer Operationswunden sich in der größten Mehrzahl der Fälle bakterienhaltig erweist, ohne daB Störungen des Wundverlaufs eintreten, scheint mir doch eine weitere Nachprüfung desselben von Interesse zu sein, und ich werde dieselben in späteren Fällen weiter verfolgen. Ein definitives Urteil muß ich mir einstweilen für die Zukunft vorbehalten.

Was den weiteren Verlauf der Fälle nach Sterilisierung der Wunde anlangt, so konnte einmal die Sekundärnaht nicht zur Ausführung gelangen, weil bei dem betreffenden Patienten (Fall 5) ein HirnabszeB und anschließend eine Meningitis manifest wurden, welche den Exitus herbeiführten. Wir haben hier einen Fall vor uns, wie er in der Einleitung bereits angedeutet wurde. Die intrakranielle Komplikation bestand ohne Zweifel schon zurzeit der einfachen Aufmeißelung, machte damals aber noch keine Symptome. Die übrigen 24 Fälle konnten dagegen sämtlich vernäht werden, und zwar 22 mal mit vollem, 2 mal mit teilweisem Erfolg, indem hier die Wundränder im Bereich des 
oberen Drittels nach Entfernung der Klammern infolge der zu starken Spannung auseinanderwichen. Aber auch in diesen beiden Fällen kam es nachträglich noch zu einem vollständigen Verschluß ohne Hinterlassung einer Fistel. Zum weitaus größten Teil waren die resultierenden Narben geradezu ideal zu nennen, unterschieden sich in nichts von solchen, wie man sie bei einem primären Verschluß hätte erwarten können. Dies Ergebnis und die Tatsache, daß alle Wunden überhaupt vernäht werden konnten, gewinnt eine ganz besondere Bedeutung dadurch, daß nicht etwa nur günstig liegende, unkomplizierte Fälle dafür ausgewählt wurden, sondern sämtliche in I8 Monaten an unserer Klinik antrotomierten Fälle, soweit nicht primär intradurale Eingriffe erforderlich waren, der Behandlung unterworfen wurden. Ich habe mich, nachdem ich bei den ersten Wunden nicht die geringsten Schädigungen beobachtete, durch keine noch so ausgedehnten pathologischen Veränderungen am Sinus und der Dura beider Schädelgruben davon abhalten lassen und glaube unumwunden sagen zu dürfen, daß sich dieses Vorgehen gelohnt hat. Wenn man objektiv urteilt, wird man zugeben müssen, daß ein großer Teil der behandelten Fälle schon wegen des häufig vorhandenen, teilweise überaus großen subperiostalen Abszesses und der begleitenden entzündlichen Weichteilinfiltration (I4 mal) für die Primärnaht durchaus ungeeignet gewesen wären, ganz zu schweigen von den Fällen mit schweren Duraveränderungen (fünfmal). Für die Carrelsche Behandlung waren dagegen gerade diese Fälle außerordentlich dankbar. Die durchschnittliche Heilungsdauer in den 24 Fällen betrug nur 20,76 Tage.

Bezüglich der klinischen Erscheiungen, welche durch die Behandlung der Antrotomiewunden mit der Dakinlösung zur Beobachtung kamen, muß man trennen zwischen den allgemeinen, den Gesamtzustand beeinflussenden, und den rein lokalen, nur die Wunde und ihre nähere Umgebung betreffenden Wirkungen. Über die erstere ist nur wenig zu sagen. Die Behandlung wurde durchweg, d. h. in allen Fällen gut vertragen, abgesehen von dem einen Falle, bei welchem es infolge Zuführung kalter Dakinlösung mittels des beschriebenen Apparates wie bei der kalorischen Prüfung zu Nystagmus und Schwindel kam, traten niemals Labyrinthsymptome auf, die Eingießung der auf Körpertemperatur erwärmten Lösung wurde meist sogar recht angenehm empfunden. Im übrigen war eine Beeinflussung des Allgemeinzustandes nur insofern zu konstatieren, als der letztere im Abhängigkeitsverhältnis zur Körpertemperatur stand. Immerhin scheint mir die Tatsache, daß Fieber, sofern es überhaupt bestand, jedesmal prompt herunterging, nicht auf einen Zufall zu beruhen, wenn ich in dieser Beziehung aus meinen 25 Fällen auch noch keine allgemein gültigen Schlüsse ziehen möchte. Ich hatte durchaus den Eindruck, daß das schnelle Absinken der Tem- 
peratur in einzelnen Fällen mit der schneller als gewöhnlich eintretenden Virulenzverminderung der in der. Wunde befindlichen Keime und der Vernichtung ihrer Toxine in ursächlichem Zusammenhang stand, doch läßt sich damit noch nicht viel beweisen, weil häufig die Eliminierung des Krankheitsherdes allein den gleichen Effekt haben kann. Hierfür müssen erst weitere Erfahrungen abgewartet werden. Eine Allgemeintoxikation, wie sie Keyßer einmal beobachtet haben will, hat sich niemals feststellen lassen.

Von wesentlich größerer Bedeutung sind die lokalen Erscheinungen an der Wunde und ihrer Umgebung. Hier ist zunächst hervorzuheben, $\mathrm{da} \beta$ ich irgendwelche Erscheinungen an der Wunde, die man als $\mathrm{Ge}$ websschädigung hätte ansehen müssen, im Gegensatz zu anderen Autoren nicht ein einziges Mal habe konstatieren können. Ich mọchte es dạhingestellt sein lassen, ob dafür die sorgsame Bereitung der Lösung und ihre stetige Kontrolle oder die besonderen Verhältnisse der Antrotomiewunde maßgebend gewesen sind, Tatsache ist, daß ich bei meinen Fällen nur durchaus günstige Wirkungen beobachtet habe. In die Augen springend war vor allem der Einfluß der Dakinlösung auf die Granulationsbildung. Diese war stets - ausgenommen in Fall I8, in welchem die zunächst mangelhafte allgemeine Regenerationsfähigkeit auch durch die lokale Einwirkung des Antiseptikums nicht behoben werden konnte - eine überraschend schöne. Nicht nur, daß die Granulationen durch ihr frisches Aussehen und ihre blutstrotzende Fülle, ihre Sauberkeit und gleichmäßige Entwickelung imponierten, es war auch unverkennbar, daß sie sich zum Teil wesentlich früher bildeten, als man es sonst bei der Antrotomiewunde findet. Ich verweise hier als charakteristisch nochmals auf den Fall ${ }_{5}$, in welchem diese Wirkung durch einen Fehler in der Berieselung besonders schön zur Geltung kam. Im gleichen Falle war auch ein deutlicher Effekt auf nekrotische Stellen der großen subperiostalen Abszeßhöhle zu beobachten. Die makroskopische Abgrenzung dieser Partien und Gewebsteilchen während der Operation war ganz unmöglich, unter der Wirkung der Dakinlösung ging sie in der Folgezeit zweifellos schneller vor sich wie gewöhnlich. Im allgemeinen kamen Nekrosen nur selten zur Beobachtung, weil, wie schon erwähnt, die Wunden von vornherein durch Entfernen aller bekanntermaßen zur Nekrose neigenden Gewebsfetzen möglichst sauber und glatt gestaltet wurden.

Neben dem Hinweis auf die granulationsanregende Wirkung scheint mir mit Rücksicht auf meine früheren Ausführungen besonders die Beantwortung der Frage wichtig, wie sich die Sekretionsverhältnisse der Wunde unter dem Einfluß des Carrelschen Verfahrens gestalteten. War meine dort geäußerte Ansicht, daß die Sekretion einer Wunde in einem direkten Abhängigkeitsverhältnis zu ihrem Infektionszustande 
steht, richtig, so mußte das auch in ihrem Verhalten bei zunehmender Sterilisierung zum Ausdruck kommen, Das war in der Tat der Fall. Je mehr sich die Wunde dem Stadium der Keimfreiheit näherte, um so geringfügiger war ihre Absonderung, um schließlich ganz minimal zu werden. Außerdem änderte sie in ganz charakteristischer Weise ihre Beschaffenheit. Während in der ersten Zeit bis zum ersten, mitunter auch zweiten Verbandwechsel noch deutlicher Eiter zwischen den Tampons zu erkennen war, zeigte das spätere Sekret das typische, von Carrel bereits gekennzeichnete Aussehen von einer gewissen glasigen Transparenz, war fadenziehend und vollkommen geruchlos. Auftreten von Fötor, dessen Vorhandensein nach Carrel stets auf ungenügende Berieselung der Wunde schließen läßt, habe ich niemals feststellen können. Nach Ausführung des Sekundärverschlusses trat noch wieder einige Tage eine Zunahme der Sekretion auf, über deren Ursache ich bereits das Nötige gesagt habe, dieselbe ging jedoch schnell wieder auf das physiologische Maß zurück und verschwand nach weiterer kurzer Zeit restlos.

In engem Zusammenhang mit dem Fortschreiten des Sterilisationsprozesses in der Wunde stand deutlich auch der Ablauf der Entzündungserscheinungen in der Paukenhöhle. Es war vielfach auffallend, wie schnell die Absonderung aus dem Mittelohr zum Stillstand kam und wie schnell vor allem auch das Trommelfell wieder abblaßte. Schon beim ersten, spätestens aber beim zweiten Verbandwechsel war in den meisten Fällen der Gehörgang trocken, nur zweimal bestand zurzeit des Sekundärverschlusses noch eine geringfügige Sekretion. Wie aber die schnelle Abheilung der Schleimhautentzündung in der Pauke einerseits als Auswirkung des Sterilisationsprozesses anzusehen ist, so möchte ich sie andererseits aber auch für eine Vorbedingung halten für das Gelingen der Wundsterilisation, da ich weit eher eine Reinfektion der Wunde von der Pauke her für möglich halte, als umgekehrt. Die beiden Fälle, bei denen es infolge einer Neuinfektion auf dem Wege über die Tube wieder zur Paukeneiterung gekommen war, bekamen beide auch Erscheinungen seitens der Wundhöhle, während es sonst in allen Fällen von Sekundärverschluß niemals auch nur zur geringsten Absonderung durch das Trommelfell mehr kam.

Am deutlichsten traten jedoch die eigentlichen Wirkungen der Wundsterilisation erst in Erscheinung nach Vornahme der Sekundärnaht. Unter den sämtlichen 24 Fällen, bei welchen sie zur Ausführung gekommen ist, befindet sich tatsächlich kein einziger, bei dem im Anschlu $B$ an diesen Eingriff auch nur die leisesten Entzündungserscheinungen im Bereich der Naht selbst wie der umgebenden Weichteile zur Beobachtung gekommen sind. Bemerkenswert ist vor allem auch das Ausbleiben jeder Stichkanaleiterung, die bei sonstigen 
Operationen im Bereich infizierter Wunden zu den gewöhnlichen Erscheinungen gehört, weil ja der Faden durch infiziertes Gebiet geführt werden muß. Ich glaube, daß hierzu die feuchten Verbände mit Dakinlösung auch noch nach der Sekundärnaht in erheblichem Maße beigetragen haben und möchte deshalb diese Maßnahme für einen wesentlichen Bestandteil der weiteren Behandlung halten. Niemals wurden ferner Fiebererscheinungen oder Störungen des Allgemeinbefindens beobachtet, welche man mit dem sekundären Verschluß in einen ursächlichen Zusammenhang hätte bringen können. Dies alles scheint mir noch mehr als die Tatsache, daß das nach Verschluß der Wunde abgesonderte Sekret fast immer rein serös und vor allen Dingen keimfrei war, dafür zu sprechen, daß die Wunde nach dem Carrelschen Verfahren auch wirklich im klinischen Sinne aseptisch geworden war.

Einer etwas ausführlicheren Besprechung bedürfen noch die Erfahrungen, welche ich bei meinen Versuchen bezüglich der Dakinlösung, wie der Technik der Wundbehandlung sammeln konnte. In den einleitenden Bemerkungen zu meinen Versuchen hatte ich schon erwähnt, daß ich die Lösung zunächst nach der von Dobbertin gegebenen Vorschrift zubereitet hatte, welche im großen und ganzen mit der Originalvorschrift Dakins übereinstimmt. Später, als mir die Titriermethode bekannt wurde, stellte ich jedoch fest, was auch Carrel auf Veranlassung Daufresnes bewogen hatte, von dieser Methode Abstand zu nehmen, daß nämlich der Hypochloridgehalt diese Lösungen nicht konstant war, sondern in relativ weiten Grenzen schwankte. Ich fand Differenzen von 0,32 bis $0,46 \%$. Da ich zu gleicher Zeit von der Firma Braun in Melsungen ein Angebot von konzentrierter Natriumhypochloridlösung in Ampullen erhielt, durch deren Verdünnung nach besonderer Anweisung eine allen Anforderungen entsprechende Dakinlösung herzustellen sei, beschloß ich, zunächst Versuche damit anzustellen, weil ich glaubte, daß dadurch eventuell eine Vereinfachung der Technik bedingt sein könnte. Den Ampullen ist eine Empfehlung Dobbertins beigegeben, nur eine $0,25 \%$ ige Lösung zur Wundbehandlung zu gebrauchen, um sicher Gewebsschädigungen zu vermeiden. Von dieser Anweisung habe ich keinen Gebrauch gemacht, weil ich nicht nur die granulationsanregende Wirkung ausnutzenwollte, sondern entsprechend den Vorschriften Carrels auf eine vollkommene Sterilisierung der Wunde hinzielte. Ich habe deshalb nur die Hälfte der zur Verdünnung angegebenen Wassermenge benutzt, wobei eine $0,5 \%$ ige Hypochloridlösung resultieren mußte. Die Nachprüfung mittels des Titrierverfahrens ergab jedoch auch hierbei nicht den nach Carrel unbedingt notwendigen Prozentgehalt, einmal nur $0,3 \mathrm{I} \%$, so daß ich davon wieder abgekommen bin, zumal ich auch mehrfach alkalische Reaktion fand. Jetzt bereite ich mir die Dakinlösung nur noch nach 
dem Rezept von Daufresnes, welches sich mir bezüglich der Erzielung eines konstanten und richtigen Hypochloridgehaltes bei weitem am besten bewährt hat. Ich konnte mich allerdings nicht von der ábsoluten Haltbarkeit dieser Lösung: überzeugen, sondern habe häufig ein ziemlich schnelles Sinken des Hypochloridgehaltes auch hierbei konstatiert. Nach meinen Erfahrungen ist es notwendig, spätestens alle acht Tage die Lösung zu bereiten und nur in so großen Mengen, als sie in der Zwischenzeit gebraucht werden. Kontrolle ist etwa alle 4-5 Tage erforderlich. Das ist keine zeitraubende Arbeit. Wenn man sich erst einmal die wenigen für die Titrierung nötigen Reagentien beschafft hat, ist es eine Arbeit von nur wenigen Minuten, bis man den Hypochloridgehalt der fertiggestellten Dakinlösung ermittelt hat. Die Methode unterscheidet sich von der Titriermethode des Chlorkalkes lediglich durch die Multiplikation der gebrauchten Kubikzentimeter Natriumthiosulfatlösung mit einer anderen Zahl, wie auf Seite rgo genauer angegeben ist. $\mathrm{Da}$ eine Titrierung auch des Chlorkalkes in jedem Falle notwendig ist, möchte ich nochmals besonders betonen. Obwohl von den Apotheken Chlorkalk unter 25\% Chlorgehalt nicht abgegeben werden soll, fand ich solchen von $21,2 \%$ oder gar $19,7 \%$. Die nach Daufresne hergestellte Dakinlösung reagierte niemals alkalisch, sie blieb auch nach der Filtrierung stets vollkommen klar.

Von der in der Einleitung zum speziellen Teil angegebenen Technik bin ich im weiteren Verlauf meiner Versuche nur wenig abgegangen, da sich die getroffenen Maßnahmen als durchaus genügend erwiesen. Der Einfachheit und Bequemlichkeit halber habe ich mir jedoch eine größere Anzahl Gummiröhrchen von verschiedenem Kaliber $(2-6 \mathrm{~mm})$, welche an dem einen Ende zugeschmolzen und verschieden weit $\left(I^{1} / 2-3 \mathrm{~cm}\right)$ mit feinen Löchern versehen waren, herstellen lassen, sie standen stets ausgekocht zur Verfügung. Eingelegt wurden in die Wunden jedesmal so viele Röhrchen, daß eine ausgiebige Berieselung garantiert war. Eine bestimmte Norm dafür aufzustellen, ist überflüssig. Die sterilen Gazestreifen wurden trocken um die Röhrchen herumtamponiert, da sie sich in diesem Zustande besser in die Wundbuichten hineinbringen lassen, als wenn sie angefeuchtet sind. Die Anfeuchtung erfolgte nach beendeter Tamponade durch einfaches Aufgießen der Lösung (Abbildung 4). Als zweckmäßigstes Instrument für die Eingießungen hat sich mir eine etwa $100-200 \mathrm{~cm}$ fassende Glasundine erwiesen, deren Spitze so dünn ausgezogen sein muß, daß sie gut in die engsten Röhrchen eingeführt werden kann. In diesen Glasundinen läßt sich auch die Dakinlösung sehr bequem durch Hineinstellen in warmes Wasser erwärmen, durch die für die Luftzufuhr bestimmte Öffnung kann man die Temperatur mittels eines Thermometers dabei leicht kontrollieren. Es ist nötig, jedesmal nur so viel Lösung 
anzuwärmen, als für eine einmalige Eingießung gebraucht wird, weil sie sich beim Erwärmen schnell zersetzt und an Hypochloridgehalt verliert. Bei einmaliger Erwärmung ist dieser Verlust so gering, daß er eine praktische Bedeutung nicht besitzt.

Was den Zeitpunkt anbetrifft, an welchem die Carrelbehandlung der Antrotomiewunde am vorteilhaftesten einsetzt, so möchte ich mich nach meinen Erfahrungen dahin aussprechen, daß der günstigste Augenblick zweifellos der unmittelbar post operationem ist. Man wird dann am schnellsten die Sterilisation erreichen, am frühzeitigsten die Wunde sekundär schließen und demgemäß die schnellste und auch kosmetisch beste Heilung erzielen können. Kann man sich aus dem einen oder anderen Grunde, der ja immer mal vorliegen mag, dazu nicht entschließen, schadet es aber auch nicht, wenn man noch zwei oder drei Tage wartet. Die grọ̈ßte von seiten der Infektion drohende Gefahr ist ja bei der Antrotomiewundé durch die Operation beseitigt worden, in dieser Beziehung besteht doch ein gewisser Unterschied gegenüber den Kriegswunden, bei denen die sich erst auf einem günstigen Boden entwickelnde Infektion so frühzeitig als möglich bekämpft werden mußte. Aus dieser Überlegung heraus habe ich mit Rücksicht auf den Schlaf der Patienten auch späterhin von einer zweistündlichen Berieselung der Wunden während der Nacht Abstand genommen, habe dieselben von to Uhr abends bis 6 oder 7 Uhr morgens nur 2--3 mal ausführen lassen, nachdem ich beobachtet hatte, daß dies zur völligen Feuchthaltung der Tampons genügte. Einen merklichen Nachteil habe ich davon nicht gesehen. Die Fälle I und 8 beweisen, daß aber auch die Behandlung noch zu jeder anderen späteren Zeit einsetzen kann und auch dann noch günstige Wirkungen zeitigt. Daß Sinusund Duraveränderungen selbst von weitester Ausdehnung nach meiner Ansicht keine Kontraindikationen für die Methode darstellen, sondern im Gegenteil gerade die besten Aussichten bieten, sei hier nochmal der Vollständigkeit halber erwähnt.

Bezüglich der Sekundärnaht bin ich bei meiner anfangs gewählten Methode geblieben. Vielfach war bei frühzeitigem Verschluß eine Mobilisierung kaum notwendig, durch die tiefen Katgutnähte ließ sich das Periost meist vollkommen über die Höhle herüberziehen. Die Vereinigung der tieferen Weichteile dient gleichzeitig zur Entspannung der oberflächlichen Hautnaht. Das Drain im unteren Wundwinkel wird stets mit einem Faden versehen, welcher um die Ohrmuschel gelegt wird. Durch diese Maßnahme wird ein Hineingleiten des Drains in die Wundhöhle, wie ich es einmal erlebt habe, vermieden. Es wird fortgelassen, sobald man darauf rechnen kann, daß das noch gebildete Sekret von der Wunde anstandslos resorbiert werden kann.

Es bleibt jetzt nur noch ein Punkt zu erwähnen, den ich wegen 
seiner Bedeutung an den Schluß gestellt habe und von dem meiner Meinung nach das Gelingen der Wundsterilisierung in entscheidendem Maße abhängig ist, das ist die peinlich genaue Durchführung der Wundberieselung alle zwei Stunden (mit der oben bereits angegebenen Einschränkung während der Nacht) und stets in genügender Menge. Will man in dieser Beziehung sicher gehen, so ist eine dauernde Kontrolle des mit der Durchführung dieser Maßnahmen betrauten Personals durch den behandelnden Arzt notwendig, zum mindesten so lange, bis das Personal völlig eingearbeitet ist. Als sehr zweckmäßig hat es sich mir erwiesen, die Kranken selbst dafür zu interessieren und sie anzuweisen, sich immer rechtzeitig bei der Schwester zu melden. Wenn man ihnen sagt, daß sie bei strikter Durchführung der Behandlung unter Umständen um Wochen früher nach Hause könnten, dann kann man ziemlich sicher sein, daß sie der Anweisung rechtzeitig nachkommen. Ich habe jedenfalls, seitdem ich in dieser Weise vorgehe, eine ungenügende Durchfeuchtung der Tampons niemals mehr erlebt.

Nach den Ergebnissen, welche ich an den mitgeteilten 25 Fällen erzielen konnte, glaube ich es nunmehr wagen zu dürfen, die Carrelsche Wundbehandlung bei Antrotomiewunden der Nachprüfung warm zu empfehlen. Ich bin mir vollkommen darüber klar, daB schon mit Rücksicht auf die relativ geringe Anzahl der Fälle die von mir gegebenen Leitsätze lediglich eine Grundlage abgeben können für weitere Versuche, daß es noch einer großen Reihe von Beobachtungen bedarf, bis sich klare und allgemein gültige Richtlinien geben lassen, welche den Wert der Methode natürlich noch erhöhen würden. Insbesondere scheint mir noch die Frage beantwortet werden zu müssen, ob es wirklich zweckmäßig ist, alle Fälle ohne Ausnahme dieser Behandlung zu unterwerfen, trotzdem gerade hierdurch die Methode allen anderen überlegen sein würde. Ich bin überzeugt, daß șich mit zunehmender Erfahrung, wenn das bei erstmaligen Versuchen nie ganz zu vermeidende Hin- und Hertasten fortfällt, eine präzise Indikationsstellung bald ergeben wird. Man wird aber auch bei dieser Wundbehandlungsmethode nie vergessen duirfen, daß es einen absoluten Schematismus bei der Behandlung einer Wunde nicht gibt und nicht geben darf. Für die alte Nachbehandlungsform der Antrotomiewunde hatte schon Schwartze sich dahin ausgesprochen, daß die Operation als solche erst als der Anfang unserer Therapie anzusehen sei, und daß wir in der weiteren Behandlung der Wunde den schwierigeren Teil unserer Aufgabe zu lösen hätten. Nur Sachkenntnis und strenge Konsequenz können zum Ziele führen. Dieser Satz hat noch heute volle Geltung. Das beweist schon die Tatsache, daß ältere erfahrene Operateure auch mit der Dauertamponade erheblich bessere und schnellere Resultate $\mathrm{zu}$ erzielen pflegen, als jüngere, welche mehr zu schematisieren geneigt sind und den vielfach sonst 
noch inbetracht kommenden Faktoren, die durch den Allgemeinzustand und die Reaktionsfähigkeit des erkrankten Individuums bedingt sind, nicht die genügende Beachtung schenken. Bei keiner Operation ist es wohl so notwendig, die Nachbehandlung streng nach dem Einzelfall $\mathrm{zu}$ individualisieren, wie gerade bei den Eingriffen am Warzenfortsatz, sie ist gewissermaßen Gefühlssache und dementsprechend erst durch langjährige Erfahrung gründlich zu erlernen. Dasselbe gilt natürlich auch für jede andere Behandlungsform, die Carrelmethode macht davon keine Ausnahme.

Ihr Hauptwert besteht meines Erachtens darin, daß sie uns einen objektiv verwertbaren Anhaltspunkt gibt über den Infektionszustand der Wunde und uns nach erreichter Sterilisation derselben die praktischen Konsequenzen - das ist den Verschluß der Wunde - zu ziehen gestattet, ohne da $B$ wir von den ehemals vorhandenen Infektionserregern noch Gefahren zu befürchten brauchen. Sollten sich die von mir gewonnenen Ergebnisse in größerem Maßstabe bestätigen, so scheint es mir nicht ausgeschlossen, daß ein beträchtlicher Teil der Otologen, welche sich jetzt noch allen auf eine Abkürzung des Heilverfahrens hinzielenden Vorschlägen gegenüber wegen des nie ganz fehlenden Risikos ablehnend verhalten, ihren Widerstand zum Nutzen ihrer Patientenaufgeben wird.

Nachtrag bei der Korrektur: Schon während des Krieges hatten Dakin und seine Mitarbeiter außer der Natriumhypochloridlösung organische Verbindungen des Chlors, sog. Chloramine zur Wundsterilisation verwandt, und zwar vor allem das p-Toluolsulfonchloramid - Natrium, das durch Zufügen von Natriumhypochlorid zu Toluolsulfoamin erhalten wird. Die Ergebnisse damit waren z. T. die gleichen, z. T. noch besser wie mit der gewöhnlichen Dakinlösung. Neuerdings ist dieses Präparat von der chemischen Fabrik von Heyden in Pulverform hergestellt und in den Handel gebracht worden. Dobbertin und Dold (Münch. med. W. I92I, H. I4) haben dies ChloraminHeyden eingehend nachgeprüft und gefunden, daß die mit ihm bereiteten Lösungen der Dakinlösung gegenüber erhebliche Vorteile bieten, vor allem dadurch, daß ihre bakterizide Kraft doppelt so groß ist als die des Hypochlorids, da $B$ die Lösungen sowohl in kaltemwie warmem $Z$ ustandewesentlichbeständiger sind, stets neutral reagieren und auf die Gewebe keinerlei schädigende Wirkung haben. Ich erblicke in dem Mittel einen großen Fortschritt, weil die mit der Herstellung der Dakinlösung verbundenen Schwierigkeiten gänzlich fortfallen und damit die ganze Carrelsche Wundbehandlung wesentlich vereinfacht wird. Ich habe sofort mit entsprechenden Versuchen unter Beibehaltung der bisherigen Technik begonnen. 


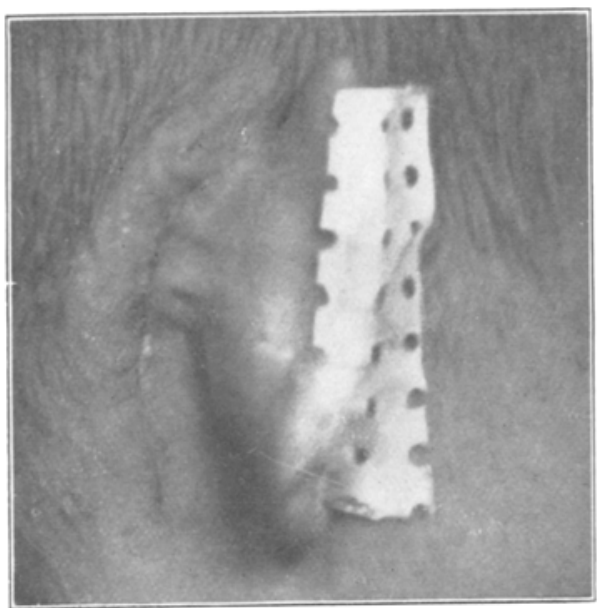

Abb. T. Fall 4. Narbe 25 Tage nach der Antrotomie.

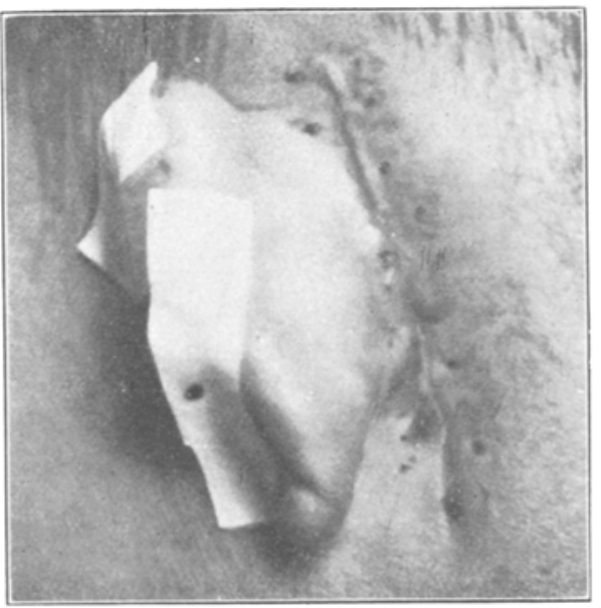

Abb 3. Fall 20. Narbe r6 Tage nach der Antrotomie.

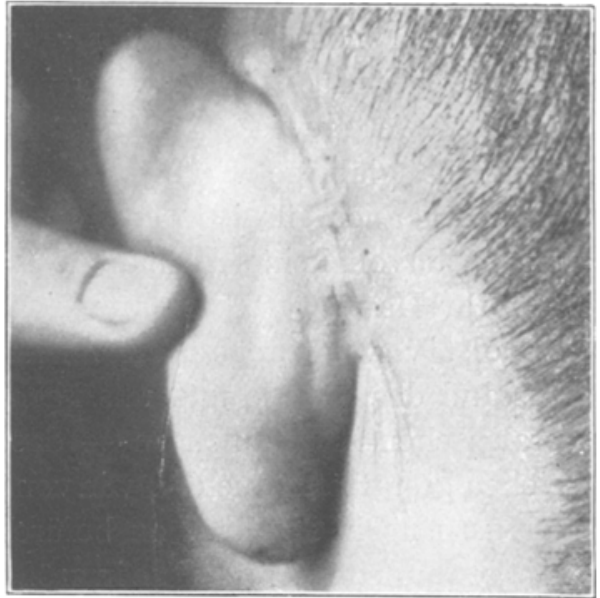

Abb. 2. Fall I $\mathbf{x}$ Narbe I Tage nach der Antrotomic.

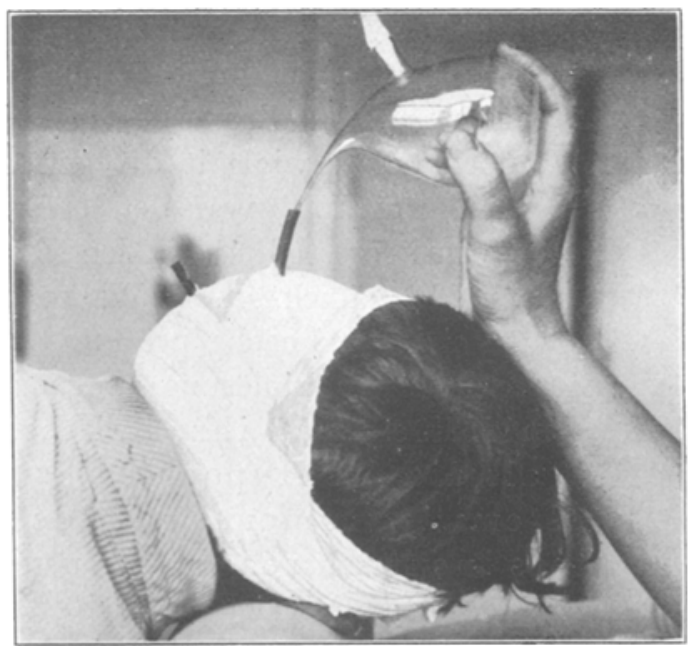

Abb. 4. Lagerung des Patienten beim Eingießen der Dakiniösung mittels Glasundine (2 Drainageröhrchen). 


\section{Literatur.}

I. Arnold: Repetitorium der Chemie, 14. Aufl. IgI3,

2. Baracz, R. von: Desinfektion der Hände mit besonderer Berücksichtigung der Kricgschirurgie. Zbl. f. Chir. I9I $7, \mathrm{Nr}, 2 \mathrm{I}$.

3. Bárány: Demonstr. in der Österr. Otol. Ges, Ref.: Cbl. f. Ohrenheilk., Bd, 8, S. 563.

4. Berggren: Ref.: Cbl. f. Ohrenheilk., Bd. I6, S. II5:

5. Bier: B. k1. W. I9r7, Nr. 30. - Korrespondenzen: D. m. W. I9I6, Nr. 46.

6. Blackwell: Ref: Z. f. Ohrenheilk., Bd. 64 , S. 387 .

7. Blake: Über primäre Heilung bei Warzenfortsatzoperationen, Arch. $f$. Ohrenheilk., Bd. $74, \mathrm{~S}, 15$.

8. Blegvad: Cbl. f. Ohrenheilk., Bd. Io, S. 2to.

9. Blumenthal: Über primären Schluß der Wunde nach Eröfnung des Warzenfortsatzes. D. In. W. I912, 3.

Io. Bondy: Zur Operation und Nachbehandlung der akuten Mastoiditis. Verh. der D. otol. Ges. I9II, S. 332 .

1 I. Bruns, P. von: Zur Wundbehandlung im Kriege. Beitr. zur klin. Chir., Bd. 98, H. I.

12. Bumiller s. u. Frensberg.

13. Busch: Kriegschirurgische Erfahrungen, insbes. über die Anwendung der Dakinlösung und über die Häufigkeit des Auftretens von Gasphlegmone. Arch. f. klin. Chir., Bd. rog, H. r.

14. Carrel, A. und Dehelly, G.: Le Trätement des Plaies infectées. Collection (Horizon) de Précis de Médecine et de Chirurgie de Guerre. II te Edition. Masson et Cie., Paris 1917 .

45. Chiari: Zur Wundbehandiung im Kriege. D. Z. f. Chir, Nr. 57 .

x. Dehelly: s. u. Carrel.

r7. Dobbertin: Das Chloren schwerinfizierter Wunden mit Dakinlösung. Feldärztl: Beil. der M. m. W. I9I6; H. 45. - Das Chloren schwerinfizierter Wunden.' Zweite Mitteilung. Feldärztl. Beil. der M: m. W. I9I7, H. I4. - Uber Haltbarkeit dèr Dakinlösung. M. m. W. 19I7, Nr. 47.

I8. Dunker: Feldärztl. Beil. der M. m. W. I9I7, Nr. 25.

19. Erdmann, H.: Lehrbuch der anorganischen Chemie 5. Aufl. Igro.

20. Fleischmann: Klinische Versuche mit der vollkommen primären Naht nach Antrotomien unter Benutzung der Morgenrothschen Chininderivate. Arch. f. Ohren-, Nasen- u. Kehlkopfheilk., Bd. 105, H. 3/4.

21. Frensberg und Bumiller: Zur Behandlung schwerinfizierter Wunden mit CarrelDakin-Lösung. Feldärztl. Beil. der M. m. W: 1917 , Nr. 32.

22. Frey: Diskussion zu Bondy (Nr. Io).

23. Gramén: Carrels Wundbehandlung. Hygiea Bd. 97, H. I7.

24. Hauser: Zur Wundbehandlung mit Dakinscher Lösung. D. m. W. rgr7, Nr. 36.

25. Heine: Operationen am Ohr, 3. Aufl.

26. Held: Ref.: Cbl. f. Ohrenheilk.; Bd. II, S. 363 .

27. Hirschberg: Zur Wundbehandlung mit Dakinscher Lösung. Physiologiśche Antisepsis: D. m. W. 1916, Nr. 5 r.

28. Hirschmann und Landau: Untersuchungen über die Dakinsche Lösung usw. Bruns Beitr. z. klin. Chir., Bd. II6.

29. Holmgren: Ref.: Z. t. Ohrenheilk., Bd. 66 , S. I48. 
30. Hufschmid und Preuße: Primäre Wundexzision von Schußverletzungen und Wundbehaudlung mit Dakinscher Lösung. D. m. W. I9I7, Nr. 8.

31. Imhofer: Cbl. f. Ohrenheilk., Bd. 16.

32. KeyBer: Chemische Antiseptik und Desinfektion in der Behandlung infizierter Wunden usw. Bruns Beitr. 2. klin. Chir., Bd. пा6.

33. Klapp: D. m. W. I9I7, Nr. 44. - M. m. W. I918, Nr. I9. - Ref.: Zbl. f. Chir. 1918, Nr. 12.

34. Kubo: Ref.: Cbl. f. Ohrenheilk., Bd. 9, S. $55^{8}$.

35. Kümmel: Diskussion zu Bondy (Nr. ro).

36. Lange: Über die Heilungsvorgänge nach Antrumoperationen, Beitr. zur Anat., Physiol., Pathol. u. Ther. des Ohres, der Nase u. des Kehlkopfes, Bd. 4, S. I.

37. Lange und Manasse: Handbuch der pathol. Anatomie des menschl. Ohres.

38. Lule: Desinfektion der Kriegsverletzungen durch die Carrel-Methode. Ref.: D. m. W. I917.

39. Matsui: Ref.: Cbl. f. Ohrenheilk., Bd. 9, S. 363 .

40. Mertens: Wundbehandlung mit Carrel-Dakin-Lösung. D. m. W. I917, Nr. 25.

41. Morgenroth: Jahreskurse f. ärztl. Fortbildung. igr7. Januarheft. - Ref.: Cbl. f. Chir. I9r8, Nr. I2.

42. Morgenroth und Bumke. D. m. W. Nr. 27.

43. Müller: Eine neue Behandlungsmethode schwerinfizierter Wunden ohne Wattegebrauch. Beitr. z. klin. Chir., Bd. I05, H. I.

44. Mygind: Monatsschr. f. Ohrenheilk. 1914. - Cbl. f. Ohrenheilk., Bd. 7, S. 505. Bd. 10, S. 71, Bd. I3, S. 108.

45. Otto: Zur Wundbehandlung mit Carre1-Dakinscher Lösung. D. m. W. IgI7. Nr. 6.

46. Passow: Über den Verschluß der Antrotomiewunde nach Antrumoperationen. Passow-Schäfer. Beitr., Bd. I.

47. Piffl: Über die Aufmeißelung des Warzenfortsatzes bei Komplikationen akuter Mittelohrentzündungen mit Bericht über 75 operierte Fälle. Arch. f. Ohrenheilk., Bd. 5I, S. 129. Diskussion zu Bondy (Nr. I0).

48. Politzer: Verfahren zum frühzeitigen Schluß der Wundhöhle nach operativer Eröffnung des Warzenfortsatzes. W. m. W. 1903, Nr. 30 .

49. Preysing: Diskussion zu Bondy (Nr. Io).

50. Proell: Behandlung von chronischen Eiterungen mit Dakinscher Lösung. Beitr. z. klin. Chir, Bd. ro6, H. 5.

5I. Reck: Ref.: Cbl. f. Ohrenheilk., Bd. 8, S. 478; Bd. I4, S. ro8.

52. Reinking: Über die Ausbreitung des Schleimhautepithels auf die Wundflächen nach Operationen am Mittelohr. Ztschr. f. Ohrenheilk., Bd. 54, S. 31 I.

Derselbe: Über die primäre Naht der retroaurikulären Wunde nach Operationen am akut erkrankten Warzenfortsatz. Ztschr. f. Ohrenheilk., Bd. 77, H. 2/3. D. m. W. I916, Nr. 39.

53. Richter: Die Dakinsche Lösung, ihre bakterizide Wirkung und praktische Verwendbarkeit in der Veterinärmedizin. Inaug.-Dissert. Hannover 1918.

54. Ritter: Über die Wirkung der Dakin-Lösung auf die Wundgewebe. D. Z. f. Chir., Bd. I59, H. I-6.

55. Rychlik: Gaswundinfektion. M. m. W. I9r7, Nr. zo.

56. Siegel: Erfahrungen mit der Da ki nschen Lösung in der Veterinärchirurgie. B. m. W. I91 7, Nr. 40 .

57. Schöne: Über antiseptische Wundbehandlung und die Einwirkung einiger Antiseptika auf die Gewebe. Arch. f. klin. Chir., Bd. Ir3, H. r/2.

58. Schwartze: Handbuch der Ohrenheilk., Bd. II. Operationslehre. 
59. Stephan: Wundbehandlung mit Carrel-Dakinscher Lösung und offene Wundbehandlung. D. m. W. I9I7, Nr. $3^{\circ}$.

6o. Tüffier: Technik der Carrel-Methode. Ref.: D. m. W., Presse med. I9I6, Nr. 72. 6r. Uffenorde: Die an der Göttinger Ohrenklinik üblichen Verfahren der Mastoidoperationen. Z, f. Ohrenheilk., Bd. 7I, S. I.

62. Voss: Plastisches Verfahren zum primären und sekundären Verschluß von Antrumoperationswunden. Verh. d. D. otol. Ges. I9I2, S. 225.

63. Walb: Beiträge zur praktischen Ohrenheilkunde. Z. f. Ohrenheilk., Bd. 68, S. 347.

64. Waldenström: Studienreise in Frankreich und England Herbst rgr6. (Ref.: D. m. W. $1917, \mathrm{Nr}, 2 \mathrm{I}$.

65. Winkelmann: Behandlung der Kriegswunden mittels Dakinscher Lösurg. Beitr. z. klin. Chir., Bd. Ior, H. 4 .

66. Wolff: Z. f. Ohrenheilk., Bd. 54. Über rezidivierende Mastoiditis.

67. Zarniko: Utber die offene Wundbehandlung in der Ohren- $u$. Nasenheilkunde. Z. f. Ohrenheilk., Bd. 75, S. I36.

68. Zeitschrift für Ohrenheilkunde, Bd. 56, S. $36 \mathrm{r}-363$ (Ref.); Bd. $58 ;$ Bd. 62, IV; Bd. $77, \mathrm{I}$.

69. Zeroni: Die ausbleibende Granulationsbildung des Warzenfortsatzes. Arch. f. Ohrenheilk., Bd. 73 .

70. ZuckerkandI: Antiseptika im Kriege. Feldärztl. Blätter der K. u. K. Armee. Nr. 22 und 23. 